\title{
Effects of a Worry Induction on Heart Rate, Emotion and Self- reported Arousal in Younger and Older Adults
}

Christine E. Gould

West Virginia University

Follow this and additional works at: https://researchrepository.wvu.edu/etd

\section{Recommended Citation}

Gould, Christine E., "Effects of a Worry Induction on Heart Rate, Emotion and Self-reported Arousal in Younger and Older Adults" (2011). Graduate Theses, Dissertations, and Problem Reports. 4722.

https://researchrepository.wvu.edu/etd/4722

This Dissertation is protected by copyright and/or related rights. It has been brought to you by the The Research Repository @ WVU with permission from the rights-holder(s). You are free to use this Dissertation in any way that is permitted by the copyright and related rights legislation that applies to your use. For other uses you must obtain permission from the rights-holder(s) directly, unless additional rights are indicated by a Creative Commons license in the record and/ or on the work itself. This Dissertation has been accepted for inclusion in WVU Graduate Theses, Dissertations, and Problem Reports collection by an authorized administrator of The Research Repository @ WVU.

For more information, please contact researchrepository@mail.wvu.edu. 
Effects of a Worry Induction on Heart Rate, Emotion and Self-reported Arousal in Younger and Older Adults

\author{
Christine E. Gould
}

Dissertation submitted to the Eberly College of Arts and Sciences at West Virginia University in partial fulfillment of the requirements for the degree of

Doctor of Philosophy

in

Psychology

\author{
Barry Edelstein, Ph.D., Chair \\ Michiko Iwasaki, Ph.D. \\ Elizabeth Kyonka, Ph.D. \\ Kevin Larkin, Ph.D. \\ Tracy Morris, Ph.D. \\ Department of Psychology
}

Morgantown, West Virginia

2011

Keywords: Older Adult, Worry, Anxiety 


\section{ABSTRACT \\ Effects of a Worry Induction on Heart Rate, Emotion and Self-reported Arousal in Younger and Older Adults}

\section{Christine E. Gould}

Anxiety disorders are the most frequently-diagnosed psychological disorder among older adults, with the exception of cognitive disorders. Generalized Anxiety Disorder (GAD) is one of the most prevalent anxiety disorders of older adults. However, the actual experience of worry, the hallmark symptom of GAD, is not well-understood among older adults. In the present study, older and younger adults participated in an experimental induction of worry or pleasant recall. After controlling for baseline age differences, older and younger adults did not differ in their ratings of worry intensity during the worry induction. An age difference in the experience of worry was found such that, younger adults reported greater anxiety following the worry induction compared to older adults. Younger adults experienced greater heart rates and reported greater arousal than older adults during both the worry and pleasant recall inductions. Thus, older adults may experience less anxiety and lower arousal during worry compared to younger adults. The implications of these findings for our understanding of worry among different age groups are discussed. Future examinations of the role of physiological arousal in older adult worry are needed. 


\section{Acknowledgement}

I would like to extend my sincere gratitude to a number of individuals who have helped and supported me throughout graduate school and throughout the course of my dissertation.

I thank Dr. Barry Edelstein, my dissertation committee chair and graduate advisor. His encouragement, advice, and guidance contributed to my development as a graduate student and my success in completing the project. In addition to the academic support, I appreciate his sense of humor which always brightens one's day and derails mundane conversations at the same time.

Additionally, I would like to express my appreciation to my dissertation committee: Dr.

Michiko Iwasaki, Dr. Elizabeth Kyonka, Dr. Kevin Larkin, and Dr. Tracy Morris. The committee provided valuable suggestions that helped me shape the project and improve the study design, method, results, and discussion.

Further, I owe a big thanks to my lab mates: Lindsay Gerolimatos and Caroline Ciliberti. I appreciate their support with the administrative aspects of the dissertation, which would have been difficult to manage from California without them! Without Lindsay's help with data collection and data entry, I wouldn't have been able to collect as large a sample as I had. I appreciate Melissa Shreve's assistance with data collection and data entry.

This project would not have been possible without one essential group - my research participants. I appreciate their willingness to contribute to my project and to further our understanding of older adult worry.

Finally, I would like to express my eternal gratitude to my wonderful parents, Joseph and Theresa Gould. This journey wouldn't have been possible without their encouragement and support. My fiancé, my brother, and friends provided the wit, social support, and camaraderie that made it possible to for me to complete my doctorate. To all, I express my sincere thanks. 


\section{TABLE OF CONTENTS}

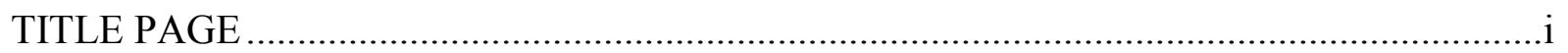

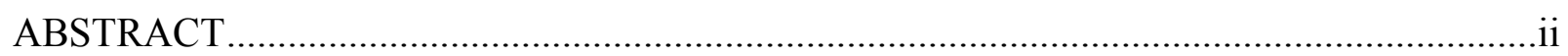

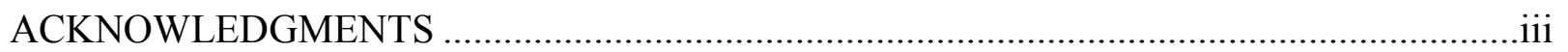

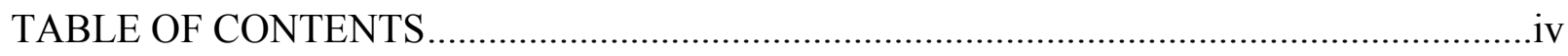

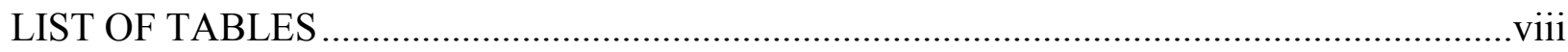

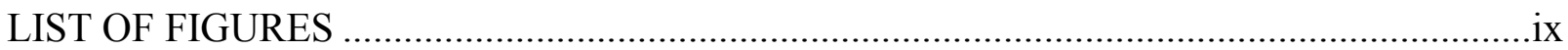

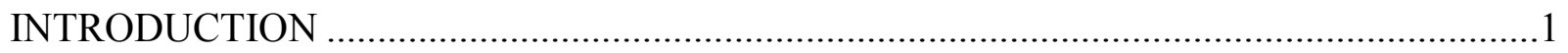

Experience of Anxiety in Younger and Older Adults ..............................................2

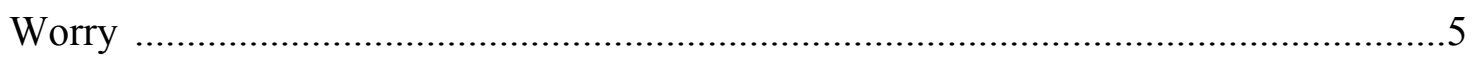

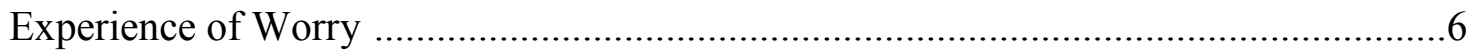

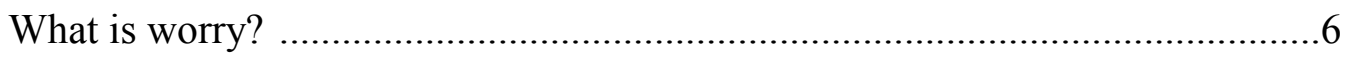

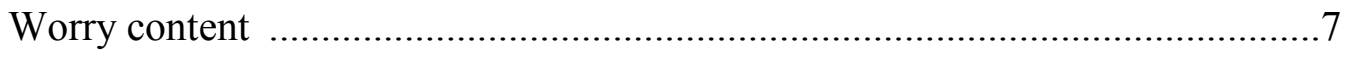

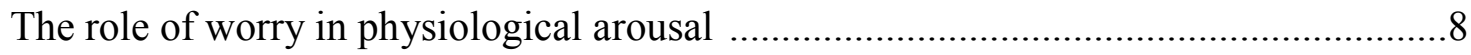

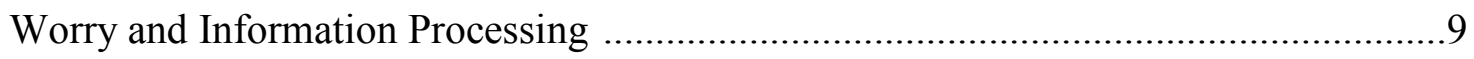

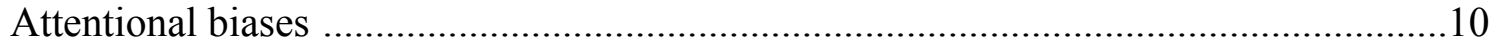

Explicit and implicit memory biases .......................................................

Impaired problem-solving and intrusions ................................................ 12

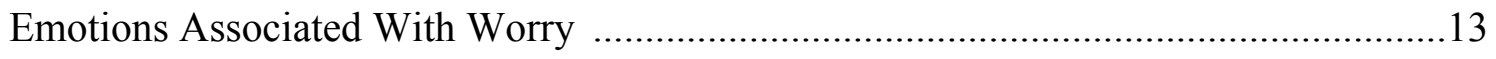

Worry and other thought processes .......................................................15

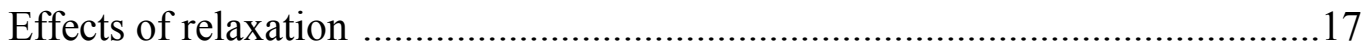

Theoretical Accounts of Worry and Emotional Responses ....................................18

Age-related differences in emotion regulation ...........................................20 
Life-span theories of emotion ................................................................22

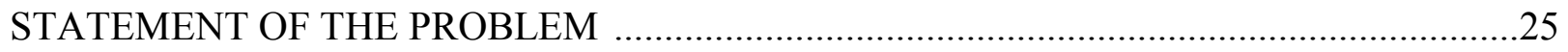

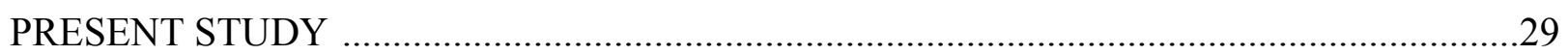

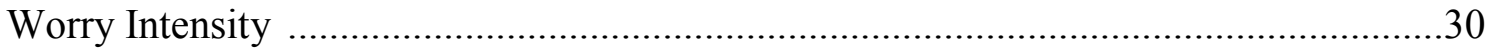

Self-Reported Arousal ................................................................................ 31

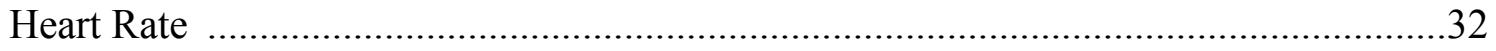

Emotions: Anxiety, Depression, Hostility, and Positive Affect ..................................32

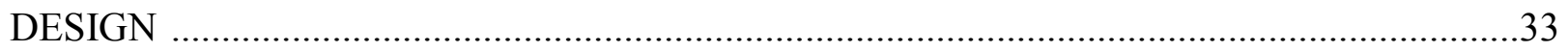

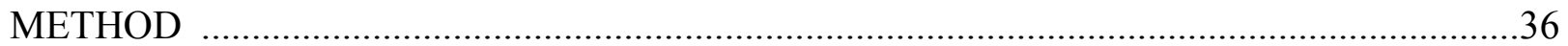

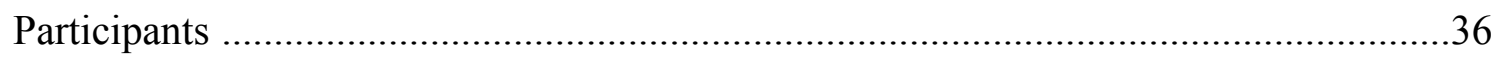

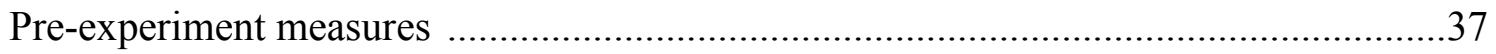

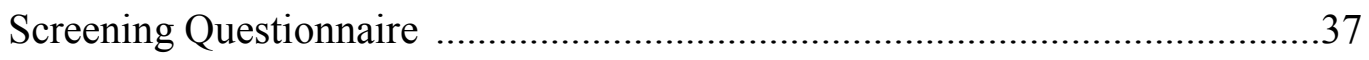

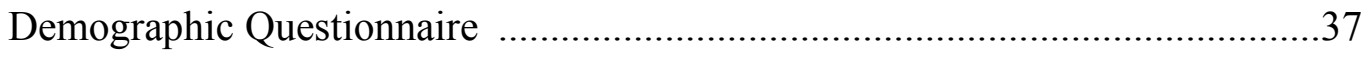

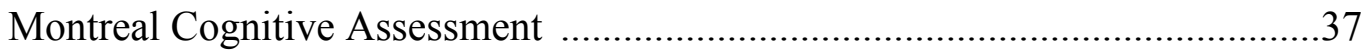

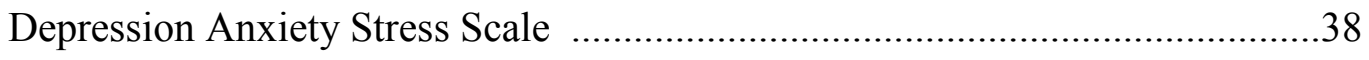

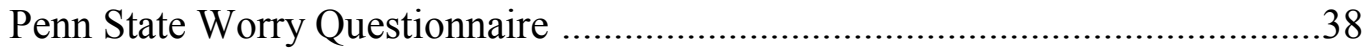

Dependent measures

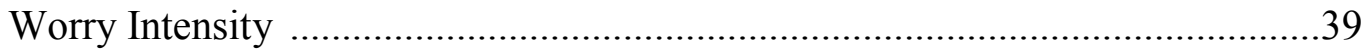

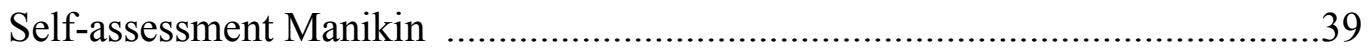

Multiple Affect Adjective Checklist-Revised ..............................................40

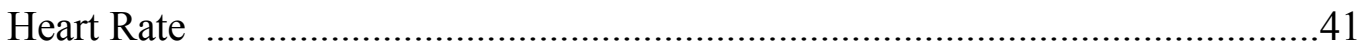

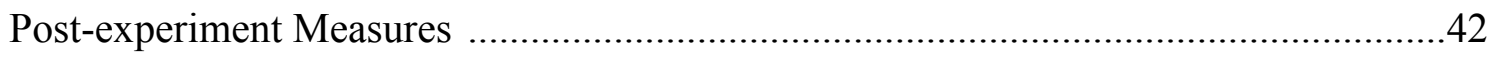

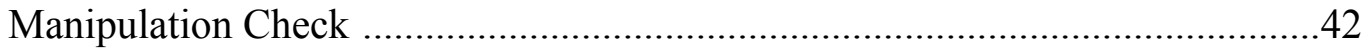




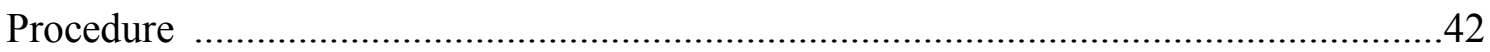

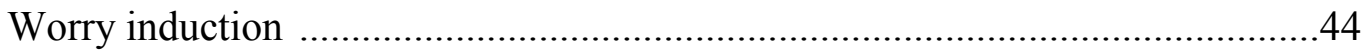

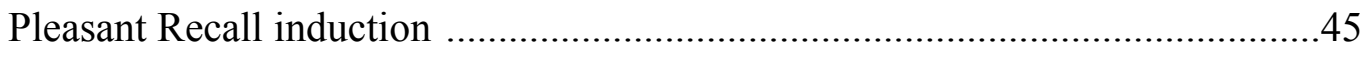

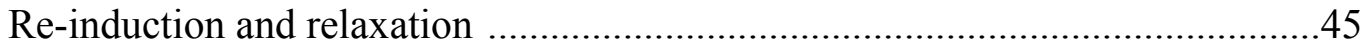

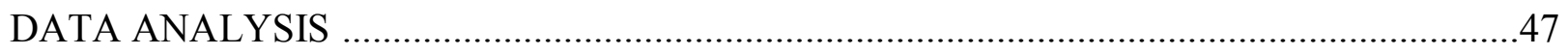

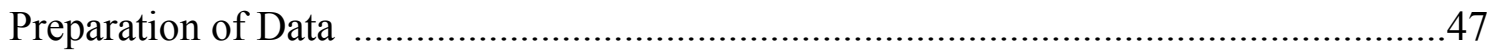

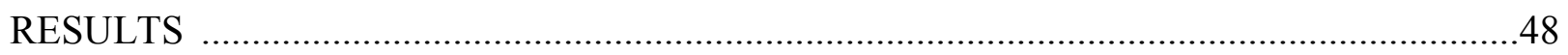

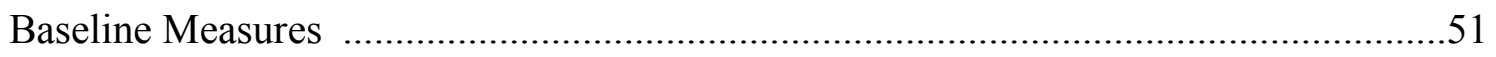

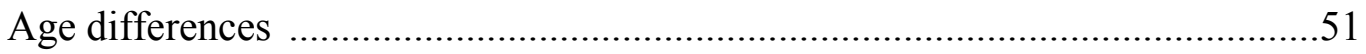

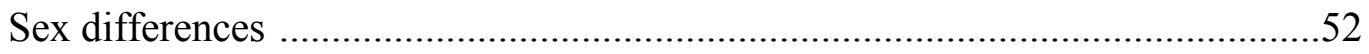

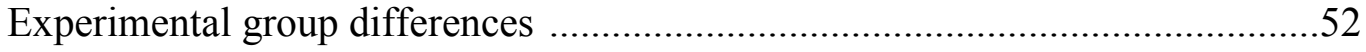

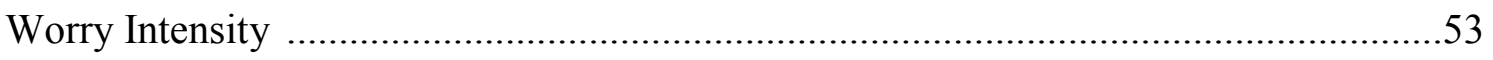

Effect of age and worry/pleasant recall induction ........................................54

Worry/pleasant recall induction and age group differences after relaxation ......55

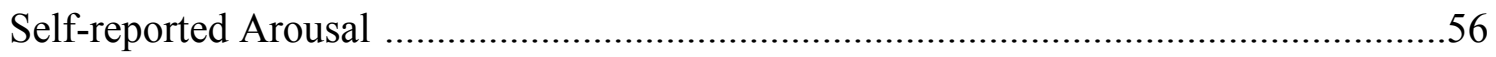

Effect of age and worry/pleasant recall induction ......................................57

Worry/pleasant recall induction and age group differences after relaxation ......58

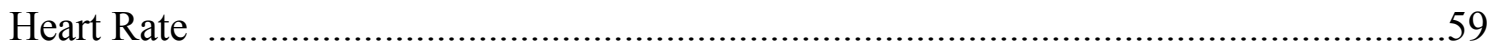

Anxiety, Depression, Hostility, and Positive Affect ..............................................5

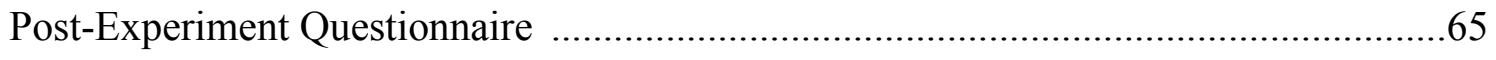

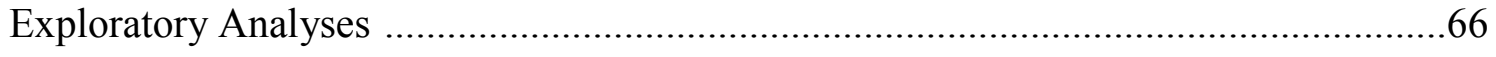

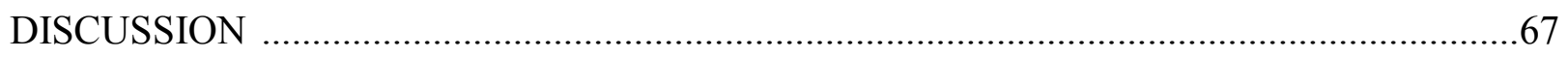

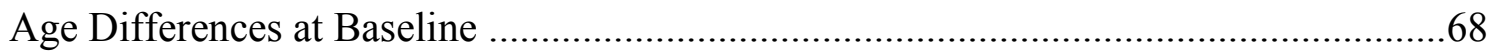




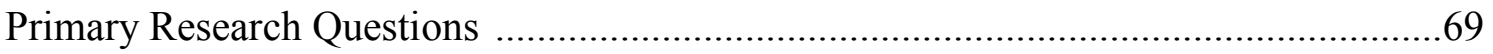

Effects on worry intensity ................................................................. 70

Effects on self-reported arousal …..................................................... 71

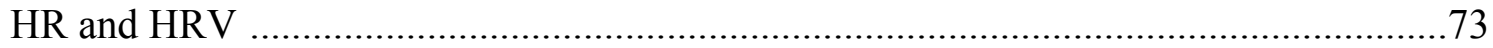

Self-reported Emotions: Anxiety, Depression, Hostility, and Positive Affect ...............76

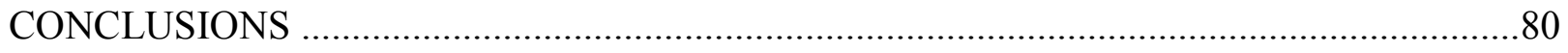

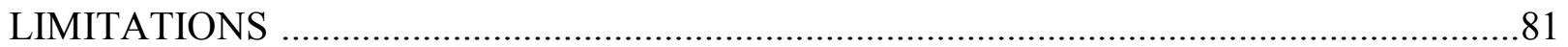

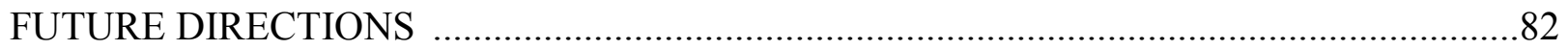

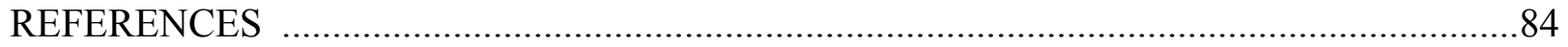

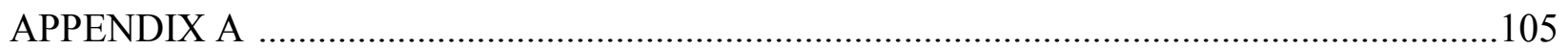

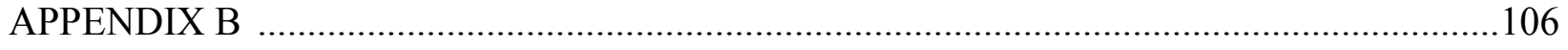

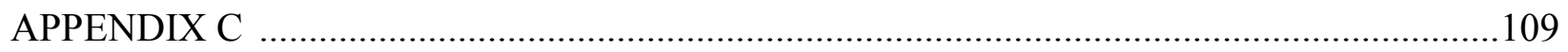

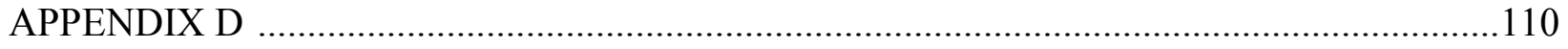

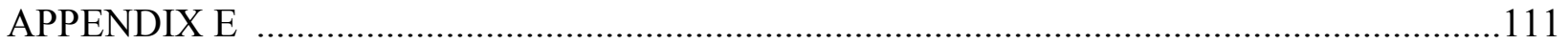




\section{LIST OF TABLES}

Table 1. Internal Consistency for Four MAACL-R Subscales .41

Table 2. Participant Characteristics .50

Table 3. Means and Standard Deviations for Questionnaires and Baseline Dependent Variables

Table 4. Adjusted Means and Standard Deviations for Induction and Relaxation Periods .61 


\section{LIST OF FIGURES}

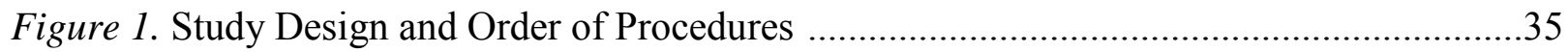

Figure 2. Mean Worry Intensity Rating for Pleasant Recall Group .....................................53

Figure 3. Mean Worry Intensity Rating for Worry Induction Group ....................................54

Figure 4. Mean Self-Assessment Maniken (SAM) Rating for Pleasant Recall Group .............56

Figure 5. Mean Self-Assessment Maniken (SAM) Rating for Worry Induction Group ...........57

Figure 6. Interactions of Condition and Age and Condition and Time on MAACL-R Anxiety 62

Figure 7. Interaction of Induction Condition and Time for Depression ................................63

Figure 8. Interaction of Induction Condition and Time on Hostility ...................................64

Figure 9. Interaction of Induction Condition and Time on Positive Affect ..............................65

Figure 10. Interaction of Age and Condition on HF Power (Ln-transformed) .......................67 
Effects of a Worry Induction on Emotion and Self-Reported Arousal in Younger and Older Adults

Anxiety disorders are the most common psychological disorder among older adults affecting $7 \%$ of this age group each year (Gum et al., 2009). In a recent review (Bryant, Jackson, \& Ames, 2007) of the late life anxiety disorders literature, a wide range of prevalence rates for anxiety disorders, ranging from about 1 to $15 \%$, was found. Gum and colleagues (2009) reported that phobic disorders were the most prevalent (4.6\%) anxiety disorder among adults aged 65 and older, followed by Social Phobia (3.2\%), and Generalized Anxiety Disorder (1.2\%). Previously, Beekman and colleagues (1998) found that Generalized Anxiety Disorder (GAD) was the most common anxiety disorder, affecting $7.3 \%$ of adults aged 55 and older. The onset of GAD is varied; it may be present since early adulthood or it may develop after middle age. In fact, late onset of GAD is found in over $40 \%$ of older adults diagnosed with GAD (Le Roux, Gatz, \& Wetherell, 2005; Lenze et al., 2005). The majority of literature on late life anxiety focuses on GAD, which has been demonstrated to impact quality of life (Wetherell et al., 2004) and is associated with increased functional impairment, chronic physical illness, poorer perceived health, and more days in bed (De Beurs et al., 1999).

Even though anxiety disorders are the most prevalent late-life psychological disorder, anxiety disorders that meet DSM-IV criteria are rare among older adults (American Psychiatric Association, 2000; Bryant et al., 2007). Nevertheless, anxiety symptoms are relatively common among older adults (Bryant et al). An individual's quality of life can be significantly impacted by subsyndromal symptoms of anxiety (Kogan \& Edelstein, 2004; Brown \& Barlow, 2009). For example, low rates of fears are associated with impairment in older adults' daily lives (Kogan \& Edelstein). Moreover, frequent worry and other symptoms of GAD that do not meet criteria for a 
disorder are associated with increased impairment, sleep problems, and fatigue (Wetherell, Le Roux, \& Gatz, 2003).

The present study aimed to examine older and younger adults' experience of worry using an experimental manipulation. In the present study, experience of worry is characterized by selfreports of worry intensity, arousal, and emotions, and objective measurement of heart rate and heart rate variability. Worry and several aspects of anxiety are reviewed and discussed in the introduction. When available, research findings on older adults' worry and anxiety are integrated in the review. The introduction begins with a brief overview of anxiety in younger and older adults. Age differences in worry, specific aspects of worry, and the impact of worrying on information processing and certain emotions are discussed. In order to provide a framework for understanding the maintaining factors of worrying among older and younger adults, theoretical accounts of worry and emotion responses are presented. After research findings and theoretical accounts of worry and life-span theories of emotion are reviewed, the gaps in the literature are highlighted as the introduction concludes.

\section{Experience of Anxiety in Younger and Older Adults}

Anxiety is generally experienced as cognitive and physiological arousal in anticipation of future events. Barlow (1991) describes anxiety as being "a loose cognitive-affective structure which is composed primarily of high negative affect, a sense of uncontrollability, and a shift in attention to primarily self-focus or a state of self-preoccupation" (p. 60). Little research has examined the experience and frequency of anxiety symptoms across the lifespan. In one of the few, yet important studies, Stanley, Beck and Zebb (1996) found that older adults scored lower than younger adults on self-report measures of anxiety, fear, and worry. Higher scores on anxiety measures for younger adults may suggest that anxiety symptoms are more prevalent among 
younger adults compared to older adults. Although younger adults worry more than older adults (e.g., Gould \& Edelstein, 2010; Hunt, Wisocki \& Yanko, 2003), it seems that there is an upturn in the prevalence of anxiety among the oldest-old (individuals aged 85 and older; Neikrug, 2003). In a study examining anxiety symptoms among older adults, Neikrug (2003) found that more anxiety symptoms were reported by the oldest-old in comparison to the young-old (aged 65 to 75$)$.

It is not clear whether older adults experience anxiety in the same way that younger adults experience anxiety. To date, two published studies (Fox \& Knight, 2005; Teachman \& Gordon, 2009) used experimental methods to examine anxiety in older adults. Fox and Knight (2005) induced anxiety by asking older adults participants to read an article about biological terrorism and to summarize the article during a videotaped speech. In one condition, the researchers informed participants that this speech would be watched, rated, and scored by a panel of judges; however, participants were not actually asked to present a speech to a panel of judges. The anxiety induction was effective for older participants, but not for the younger adults. This differential response to the manipulation was mentioned by the authors, but these data were not reported in the published paper. In sum, this study demonstrated that older adults found the threat of presenting a speech about bioterrorism to be anxiety-provoking, but it was an unsuccessful attempt to make comparisons across age groups.

In the second study, Teachman and Gordon (2009) examined the experience of anxiety among older and younger adults using multiple methods of measurement of responses to three anxiety-inducing tasks and one control task. Two tasks, candle blowing (Barlow \& Craske, 1994) and straw breathing (Taylor \& Rachman, 1994) simulate feelings of panic. Teachman and Gordon found that older and younger adults did not differ in subjective anxiety, perceived heart 
rate, bodily sensations, thoughts regarding a loss of control, or objectively-measured heart rate (HR) in response to the candle blowing and straw breathing tasks. The third anxiety-provoking task, an impromptu 2-min speech, resulted in greater anxiety, perceived HR change, fear of bodily sensations, and HR for younger adults compared to older adults. Interestingly, on a questionnaire administered after the experiment, older adults endorsed greater perceived threat from physical threats (e.g., candle blowing) compared to younger adults. Thus, the task of giving a speech resulted in different responses from older adults across the two studies (Fox \& Knight, 2005; Teachman \& Gordon). Perhaps the difference in the results is related to the content of the material in each speech task. Teachman and Gordon asked participants to speak about what participants liked about their hometown, whereas Fox and Knight had participants prepare a speech based on a document about bioterrorism.

In a third study, Lau (2000, unpublished manuscript) examined physiological responses of older and younger females to an anxiety-evoking stimulus, a film of a snake. Lau reported one major limitation to the study: $60 \%$ of participants who reported being snake-fearful on a questionnaire were not fearful of a snake on a movie screen. Despite this limitation, Lau found that older adults had slower skin conductance responses on a Stroop task and a slower recovery in skin conductance level compared to younger adults. This study provides preliminary evidence for age differences in skin conductance reactivity and recovery.

The aforementioned experimental studies have demonstrated that using physical threats are an effective in inducing anxiety among older adults. Furthermore, anxiety has been induced using both overt physical threats (Teachman \& Gordon, 2009) and anticipation of anxietyevoking stimuli (e.g., speech summarizing bioterrorism article, Fox \& Knight, 2005). Both Teachman and Gordon (2009) and Lau (2000) found that older adults had lower arousal as 
evidenced by HR and skin conductance in response to stress inducing tasks (e.g., speech, Stroop tasks). Lau (2000) found that older adults had slower recovery following the task. Furthermore, Teachman and Gordon did not find age differences on tasks in which physical stressors were used (candle blowing, straw breathing). The aforementioned studies demonstrate that it is feasible to induce anxiety in older adult samples. It seems that older adults experience greater anxiety if the threat is physical and older adults' physiological recovery is slower than younger adults' recovery. In the following sections, I address the gap between the few examples of experimental manipulations of anxiety among older adults and findings from research on the most frequently researched late life anxiety disorder. To begin this discussion, I consider the definition and characteristics of worry, the primary symptom of GAD.

\section{Worry}

Worry is a covert behavior closely related to anxiety that consists of verbal self-talk focused on future-oriented events (Borkovec, Alcaine, \& Behar, 2004). Worry is an important construct, and the study of which can offer a window into the experience, presentation, and control of anxiety. Moreover, the act of worrying can be disabling even when it occurs separately from its associated psychiatric diagnoses (e.g., GAD). Frequent worriers differ from individuals with GAD on quantitative measures of worry, but not on qualitative measures (e.g., Ruscio, 2002; Ruscio \& Borkovec, 2004). Furthermore, worry is not limited to the experience of GAD. Worry is often observed in other anxiety disorders (social anxiety, health anxiety, obsessivecompulsive disorder, post-traumatic stress disorder), insomnia, and mood disorders (as reviewed by Purdon \& Harrington, 2006). Most individuals with or without psychological disorders probably engage in worry at one time or another. Thus, worry is a clinical phenomenon worthy of study on its own. 
Several researchers (e.g., Borkovec et al., 2004; Barlow, Allen, \& Choate, 2004)

proposed that worrying may be a way in which one attempts to cope with his or her anxiety or to solve problems (Davey, 1994). Worry may be considered a maladaptive coping strategy as it is associated with prolonged stress responses (e.g., Brosschot, Van Dijk, \& Thayer, 2007; Pieper, Brosschot, Van der Leeden, \& Thayer, 2007). Brosschot, Gerin, and Thayer (2006) suggest that worrying may prolong the body's response to stressors by lengthening the attention towards an anxiety-evoking stimulus. In their perseverative cognition hypothesis, Brosschot and colleagues (2006) hypothesized that worry is related to cardiovascular disease and illness. This hypothesis is substantiated by Kubzansky and colleagues (1997)'s finding that a person's tendency to worry predicted the incidence of a second myocardial infarction.

As mentioned earlier, older adults worry less than younger adults. Age differences in worry have been observed in multiple studies using community-dwelling older adults compared to younger adult students or community members (e.g., Beck, Stanley \& Zebb, 1995; Crittendon \& Hopko, 2006; Gould \& Edelstein, 2010; Hunt et al., 2003). In one study, Basevitz and colleagues (2008) asked older adults to consider if their worrying has changed since they were younger. Forty-six percent of older adults reported that their worry decreased across their lifespan, $25 \%$ reported an increase in worry, and 25\% reported no change (Basevitz et al.). Despite the lower prevalence of worry in late life, worry lowers older adults' quality of life (Wetherell et al., 2003) and is a cardiovascular risk factor (Kubzansky et al., 1997).

\section{Experience of Worry}

What is worry? Borkovec, Robinison, Pruzinsky, and DePress (1983) provided the following, often-used, definition of worry: "worry is a chain of thoughts and images, negatively affect-laden and relatively uncontrollable; it represents an attempt to engage in mental problem- 
solving" (p. 10). In experimental studies, individuals were asked to rate the percentage of thoughts compared to images experienced while worrying. Results from this task demonstrate that individuals consistently report that worry is primarily composed of verbal thought rather than imagery (Borkovec \& Inz, 1990; Freeston, Dugas \& Ladouceur, 1996). When participants worry about a problem, the content of the worries was associated with a less-clearly defined problem compared to problems that participants did not worry about (Stöber, 1998). Worry is best characterized as verbal, negative, and abstract thoughts about anticipated present or future occurrences.

Worry content. Worry content varies among individuals and across the lifespan. Worries include thoughts about minor matters (e.g., car repairs, being on time), family, friends, interpersonal matters, financial concerns, and health concerns. Age differences have been found in the content of worries (see Hunt, Wisocki, \& Rogers, 2009, for a review). In general, older adults worry the least about social concerns compared to other concerns, whereas younger adults frequently report these concerns (Hunt et al.). Most studies have found that older adults worry more about their health than younger adults worry about their health (e.g., Diefenbach, Stanley, \& Beck, 2001; Person \& Borkovec, 1995; Wisocki, 1994), whereas other studies did not find differences in worries about health-related concerns (e.g., Gould \& Edelstein, 2010; Powers, Wisocki, \& Whitbourne, 1992). Some examinations also have found that the content of worries can differentiate individuals with and without GAD. Younger adults with GAD worry more about minor matters than non-anxious control participants (e.g., Craske, Rapee, Krackel, \& Barlow, 1989; Roemer, Molina \& Borkovec, 1997). Minor matters also differentiated older adults with GAD from non-anxious older adults in one study (Wetherell et al., 2003), but not in another examination of older adult worry content (Diefenbach et al.). 


\section{The Role of Worry in Physiological Arousal}

When considering the role of worry in physiological arousal, it is important to revisit the construct of anxiety. As discussed earlier, anxiety consists of cognitive and physiological arousal that occurs in anticipation of future events. One of the prominent theories of worry explores this relation further and explains how worry maintains anxiety over time. In Borkovec and colleagues' (2004) Cognitive Avoidance Theory of worry, worry is conceptualized as a cognitive avoidance strategy that is employed when a problem or threat is foreseen. By engaging in worry, one avoids physiological arousal associated with anxiety, and instead uses verbal-self talk, which is associated with lower rates of arousal. Engaging in worry may function as a problem-solving strategy, but it also suppresses anxiety that accompanies perceived future threats. Over time worrying is negatively reinforced as high levels of arousal are avoided.

Multiple research studies have examined physiological arousal during worry (e.g., Borkovec et al., 1983; Thayer, Friedman \& Borkovec, 1996; Vrana, Cuthbert, \& Lang, 1986). Vrana and colleagues (1986) found that HRs are lower when participants are worrying than when participants are picturing or imagining aversive imagery. However, HRs are higher when participants are worrying than when they are participating in a baseline or relaxation condition (Thayer et al.). Additionally, no group differences in HR are observed when individuals without GAD and individuals with GAD engage in worrying. When individuals worry prior to imagining an anxiety-evoking image (e.g., imagining oneself giving a speech), a suppression effect of HR is observed, with lower HR observed immediately prior to or during the imaginal period (Borkovec \& Hu, 1990; Borkovec, Lyonfields, Wiser \& Diehl, 1993; Peasley-Miklus, \& Vrana, 2000). It appears that worry may enable an individual to reduce physiological arousal if the anxiety- 
evoking stimulus is represented verbally (as in worry) as opposed to represented in one's imagination (Thayer et al.).

Moreover, Borkovec's Cognitive Avoidance Theory has been examined in studies that measured the effects of worrying prior to exposure to an anxiety-evoking stimulus on physiological arousal (e.g., Borkovec \& Hu, 1990; Hazlett-Stevens \& Borkovec, 2001). When the anxiety-evoking stimulus is a real stressor, such as a videotaped speech presentation (HazlettStevens \& Borkovec, 2001), response to negative pictures (Arch \& Craske, 2006), or a serial subtraction task (Taylor \& O'Brien, 1999), worrying does not lower HR prior to the presentation of the stimulus. Interestingly, Hazlett-Stevens and Borkovec (2001) found that worrying prior to giving a videotaped speech presentation was associated with the greatest subjective anxiety compared to the neutral and relaxation conditions. The authors found that worry did not reduce arousal in response to in vivo exposure to an anxiety-arousing stimulus. Thus, worrying is not a consistently effective avoidance strategy when the stimulus is real and not imagined.

\section{Worry and Information Processing}

As stated earlier, worrying begins after a potential threat is identified (Matthews \& Funke, 2006). Information-Processing accounts of worry (for a review, see MacLeod \& Rutherford, 2004 ) suggest that attentional biases increase the detection of threat because a greater proportion of attention is directed towards threatening stimuli compared to neutral stimuli. Additionally, researchers have examined biases for explicit and implicit memory (e.g., Friedman, Thayer, \& Borkovec, 2000) and impairment in problem-solving and decision-making as a consequence of worrying. A brief overview of the relation between worry and information processing is provided in this section. 
Attentional biases. Experimental tasks such as the Stroop task (Stroop, 1935) and dotprobe task have been used to demonstrate attentional biases. In one examination, Mogg and colleagues (1989) found that when the content of one's worries (e.g., social matters or physical harm) is matched to the content of words read during a Stroop task, participants' responding was slower compared to their responses to the unrelated stimuli. This suggests that individuals devote more attention to anxiety-provoking material. Fox and Knight found that low trait anxious older adult participants in an anxiety induction condition experienced more interference, that is, they were slower to respond to threat words than high trait anxious older adults. In contrast, the high trait anxious older adult individuals in the anxiety induction condition did not experience interference on the emotional Stroop task. Nevertheless, these findings contrast with aforementioned findings from younger adult samples in which slower performance on the Stroop task occurred when words matched younger adults' worries (Mogg et al., 1989). These conflicting findings are evidence that there are limitations to using these methods to examining attention biases.

Another experimental task, the dot-probe task has been used to examine implicit biases for attention to threat-related information among younger (MacLeod, Mathews, \& Tata, 1986; for a review, see Cisler \& Koster, 2010) and older adults (Fox \& Knight, 2005; Lee \& Knight, 2009). In the dot-probe task, participants view two words on a screen. Then, one of the words is replaced by a dot and participants are instructed to identify the location of the dot by pressing a key as quickly as possible. The response latency, that is, the time from the appearance of the dot to the participant's press of the key, for neutral and threat words is measured. When participants have a shorter latency to respond to threat stimuli compared to neutral stimuli, it is presumed that one has an implicit bias for threat related information, that is, one may detect threat information 
more quickly than neutral information. A bias toward responding more quickly to threat words (e.g., poison, cancer, incompetent; MacLeod \& McLaughlin, 1995) was found for younger GAD participants using a dot-probe test (e.g., MacLeod et al., 1986; MacLeod \& McLaughlin). Additionally, Fox and Knight (2005) found a bias toward threat words for both high trait anxious and low trait anxious older adult participants who read an article about bioterrorism in the anxiety condition. In another examination of attentional bias using the dot-probe task, Lee and Knight (2009) found that younger adults did not demonstrate attentional biases for threat. In contrast, older adults demonstrated varying levels of biases for threat contingent on the stimuli displayed (e.g., angry or sad faces, threat words) and on the level of baseline trait anxiety for each participant (Lee \& Knight). In sum, these findings demonstrate that the relation between anxiety and attention may be complex and dependent on one's anxiety levels and the duration of exposure to a stimulus.

Explicit and implicit memory biases. An explicit memory bias for threat information would be evidenced by greater recall of threat related information on a direct recall or recognition task after the presentation of threat and neutral stimuli. In a meta-analysis of memory biases in anxiety and anxiety disorders, Mitte (2008) concludes that high-anxious participants demonstrated a bias in the recall for threatening material, but do not differ in their recognition of threatening information. In contrast, Friedman and colleagues (2000) found that individuals with GAD recall more threat words than control participants.

An implicit memory bias is evidenced by differential responses in the presence of certain information, when the individual is not aware of the influence of the stored information on their responding (Mathews, Mogg, May, \& Eysenck, 1989). An implicit memory bias for threat related information is measured using tasks that do not directly measure memory. One such task 
is a word-stem completion in which participants are asked to complete the second-half of words after the stem is presented. Mitte (2008) concluded that no differences on this task emerged for high or low anxious individuals. Despite Mitte's conclusions regarding this task, there is some support for an implicit memory bias towards threat information in younger adult samples (e.g., MacLeod \& McLaughlin, 1995; Mathews et al.) and in an older adult with panic attacks and with chronic obstructive pulmonary disease. Research on implicit memory biases among individuals with anxiety have yielded conflicting findings.

Impaired problem-solving and intrusions. There are significant cognitive consequences of worrying, such as impaired problem-solving (Dugas, Letarte, Rhéaume, Freeston, \& Ladouceur, 1995) and decision making (Metzger, Miller, Cohen, Sofka, \& Borkovec, 1990). Metzger and colleagues reported the results of two studies using a sample of individuals who worried for more than $50 \%$ of the day (high worriers) and individuals who worried for less than $10 \%$ of the day (low worriers). In their first study they found that high worriers were slower to classify negative words than positive or neutral words. High worriers also took longer to classify ambiguous figures, which suggests that high worriers may have disrupted processing or attention to the task when categorizing figures. In their second study, Metzger et al. found that both high and low worriers displayed a reduced ability to classify the ambiguous figures after worrying for 15 minutes. This finding demonstrates that engaging in worry produces impairment in cognitive processing regardless of whether an individual worries frequently.

In sum, one investigation with anxious older adults (Fox \& Knight, 2005) demonstrated a cognitive bias toward threat, another study did not find evidence of an attention bias (Livermore et al., 2007), and a third study found that participants' baseline anxiety affected the extent to 
which a memory bias for threat information was found (Lee \& Knight, 2009). Thus, anxiety and worry may significantly impact cognition and information processing in late life (e.g., Beaudreau \& O’Hara, 2008; 2009). However, it is not clear whether declining cognition may impact anxiety symptoms as well.

\section{Emotions Associated with Worry}

In the following section, research on the effects of worrying on emotions will be reviewed. Worry is a behavior that is closely related to anxiety and mood disorders. As may be expected, individuals who worry frequently also experience negative affect. Borkovec and colleagues (1983, Study 3) conducted the first examination of the experience of worry among frequent worriers and non-worriers. At baseline, worriers were more anxious, hostile, and depressed. Participants were asked to recall how they felt while worrying in the past (Borkovec et al.). Participants endorsed experiencing anxious feelings most frequently followed by feeling tense, apprehensive, frustrated and nervous. Other affective states (e.g., depressed, anger, confusion) were endorsed less frequently. As expected, worriers report more negative emotion than non-worriers at baseline (e.g., Borkovec et al., Study 3; Ruscio \& Borkovec, 2004). Although it appears that frequent individuals, experience negative emotions, these correlational findings do not provide evidence examining the effects of worrying on emotions. To better understand the casual relation between worry and emotion, it is imperative to consider experimental designs in addition to correlation designs. Interestingly, after worry is experimentally induced, prior baseline differences among worriers and non-worriers disappear (e.g., Ruscio \& Borkovec).

In order to determine the effects of engaging in worry on emotions, researchers have used different methods to induce worry. Types of inductions include: (a) a modified Velten induction 
method using statements about worry (Velten, 1968; Andrews \& Borkovec, 1988; York, Borkovec, Vasey \& Stern, 1987), (b) instructions to worry in one's typical manner (e.g., Behar, Zuellig, \& Borkovec, 2005; McLaughlin, Borkovec, \& Sibrava, 2007a), and (c) instructions to worry about an upcoming speech (e.g., Hazlett-Stevens \& Borkovec, 2001). Andrews and Borkovec (1988) used the Velten induction method, a modified version of a mood induction in which participants read statements about worrying. Andrews and Borkovec used this method to induce worry and found that younger adults endorsed greater depressive affect, hostility, and anxiety (subjective and somatic), and less positive affect and sensation seeking on the Multiple Affect Adjective Checklist-Revised (Zuckerman \& Lubin, 1985) compared to neutral induction or to baseline assessments. A strength of the study was the use of other mood inductions as comparison conditions. The authors found that depression inductions yielded greater depression than worry, but less anxiety. The worry induction resulted in less anxiety than the somatic anxiety induction, but this difference was not reproduced by York et al. (1987).

Building upon earlier studies of mood inductions discussed above, researchers induced worry or comparison inductions, and then had participants view a film or emotionally-evocative pictures. The goal of these studies was to examine the effect of a previous state (e.g., worry) on participants' behavior and emotional experience during exposure to standardized stimuli. Two studies (Arch \& Craske, 2006; McLaughlin, Mennin, \& Farach, 2007b) examined the effects of different moods (including worrying) on responses to a brief film clip or the viewing of emotionally-evocative pictures (International Affective Picture System (IAPS), Bradley \& Lang, 1999). Arch and Craske (2006) assigned participants to one of three conditions, a worry, neutral, or mindfulness (breathing) condition prior viewing positive, negative, and neutral pictures selected from the IAPS stimuli. Arch and Craske examined the effects of the inductions on 
participants' emotional responses to the emotionally-evocative pictures and participants' willingness to view additional graphic pictures after the experiment concluded. Individuals in the worry condition reported greater variations in positive and negative affect in response to viewing the IAPS stimuli.

In the second study, McLaughlin, Mennin, and Farach (2007b) examined the effects of mood inductions prior to viewing film clips on participants' emotional responses and reported emotion regulation. The authors administered questionnaires to college students to identify individuals who met criteria for GAD. These identified students who met diagnostic criteria for GAD were considered an analog sample (rather than a clinical sample). The analog sample was divided into two groups based on their level of depressive symptoms (GAD with high dysphoria and GAD with low dysphoria). A control sample of college students was also recruited. Participants were randomly assigned to one of three inductions (worry, neutral, relaxation) prior to viewing a sad film clip. Following the film, the worry induction group reported the greatest negative affect, as was expected. No effect of neutral or relaxation inductions was found on depressed affect for all groups. In the relaxation group, individuals with GAD reported that their anxiety decreased after relaxation and was maintained after watching the sad film clip. Control participants in the relaxation induction reported a decrease in anxiety following relaxation, however, anxiety then increased after viewing the film. Thus, worrying negatively impacted individuals' experience of events, such that individuals experienced greater anxiety (McLaughlin et al., 2007b) and more variations in positive and negative affect (Arch \& Craske).

Worry and other thought processes. Recent studies have compared the effects of different thought processes on emotions. Behar et al. (2005) examined the effects of worry and trauma recall in a group of college students (Study 1), among college students with PTSD, 
students with PTSD and GAD, and students without PTSD or GAD (Study 2). Behar and colleagues found that depressed affect was greater following trauma recall compared to worry for both studies. This finding was expected as trauma recall would incorporate more images compared to the verbal nature of worrying. Furthermore, in Study 2, anxious affect was higher during worry compared to trauma recall regardless of whether students were met criteria for GAD, PTSD, or neither disorder. In Study 1 and 2, depressed and anxious affect were lowest during the relaxation condition as expected. Behar et al. (2005) found that the order of induction was important, such that when worry preceded trauma recall, it resulted in lower anxiety and depression. Thus, worrying may have been effective when it occurred prior to the imagined stimulus (trauma recall). This finding is similar to earlier discussed findings (e.g., Borkovec \& Hu, 1990; Borkovec et al., 1993; Peasley-Miklus \& Vrana, 2000).

McLaughlin et al. (2007a) examined the effects of two covert behaviors on emotion: worry and rumination. Rumination and worry are similar behaviors that both negatively affect emotion by increasing anxiety and/or depression (Nolen-Hoeksema, Wisco \& Lyubomirsky, 2008). In contrast, rumination functions to better understand the meanings of past or present events. Rumination is distinguishable from worry as it is focused on self-worth, meaning, and loss. McLaughlin et al. found that worry and rumination resulted in greater negative affect, lower positive affect, and increased depression and anxiety. The order of worrying and rumination differentially affected subsequent reports of emotions for an unselected group of college students (Study 1). In particular, when individuals ruminated first, anxiety increased from baseline to rumination and also increased after worrying. In contrast, when individuals worried prior to ruminating, anxiety decreased from worry to rumination inductions. In Study 2, college students were selected based on their scores on a battery of questionnaires to create three groups: (a) high 
rumination and worry, (b) high rumination, and (c) low worry and rumination. At baseline, the high rumination/worry group reported greater worry than the other two groups of students, while the low worry/rumination group reported less depression, worry, distress and anxiety. Despite baseline differences, no group differences were reported following the worry and rumination inductions. For depressive affect, an increase from baseline to worry and from worry to rumination was observed when participants worried prior to rumination. Conversely, when rumination preceded worry, depressive affect increased from baseline to rumination, but decreased during the worry induction. The first study's findings were replicated in Study 2. Thus, both worry and rumination resulted in greater negative affect, but the order of negative thinking predicts the level of anxiety or depressive affect experienced. These experimental findings demonstrate that worry generates depressive affect, but to a lesser extent than other covert behaviors such as rumination (Behar et al., 2005; Chelminski \& Zimmerman, 2003).

Worrying is followed by increased depressive affect, anxiety, and reductions in positive affect. Further, the order of covert behaviors affects one's emotions. Rumination generates greater depressive affect compared to worrying, while worrying after trauma recall increased negative affect. Greater depressive affect follows rumination more so than worry, but worrying after recall of a trauma generates substantial negative affect as well. Furthermore, these inductions serve to reduce or eliminate baseline group differences.

Effects of relaxation. Experimental studies of the effects of worrying have often included relaxation as a control condition or as a final condition to provide participants the opportunity to recover from the experimental manipulations. There is evidence for beneficial effects of relaxation on HR, and on subjective anxiety before an anxiety-evoking event and following a stressor (e.g., giving a speech). Hazlett-Stevens and Borkovec (2001) examined the 
effects of progressive muscle relaxation (PMR), worry, and a control condition on HR and heart rate variability (HRV) during a videotaped speech. Participants were assigned to one of the three aforementioned inductions. During the inductions, the relaxation group had slower HRs as evidenced by longer interbeat intervals (IBIs) compared to baseline, whereas worry did not differ in IBI compared to baseline. After the inductions were completed, all participants were provided with the speech topic followed first by a 1-min anticipation period and then by a 5-min videotaped speech presentation. The 5-min speech was broken up into 1-min segments alternating between one minute of the speech followed by a reinduction of the participant's assigned condition. The authors found that relaxation prior to speech presentations resulted in lower anxiety compared to worrying. The control group did not differ in anxiety ratings from either group. After the speeches, the worry group had greater reported anxiety following four of the five speech periods compared to the relaxation group. This study clearly highlights the physiological and subjective benefits of relaxation. Although there were some studies that did not demonstrate differences in HRV for relaxation and worry (Davis, Montgomery, \& Wilson, 2002), a substantial number of studies found positive effects for relaxation compared to worry (e.g., Peasley-Miklus \& Vrana, 2000; Ruscio \& Borkovec, 2004; Thayer et al., 1996).

Relaxation has been found to be effective in reducing anxiety in studies using older adults as well. Both progressive and imaginal relaxation exercises were found to reduce subjective anxiety among older adults (Scogin, Rickard, Keith, Wilson, \& McElreath, 1992). These aforementioned findings demonstrate that relaxation be beneficial prior to stressors, by reducing subjective anxiety for older adults.

\section{Theoretical Accounts of Worry and Emotional Responses}

There are two theories in particular that address the emotional experience of individuals 
with GAD: Cognitive Avoidance Theory (Borkovec et al., 2004) and Emotion Dysregulation Theory of GAD (Mennin, Heimberg, Turk \& Fresco, 2002). In their Cognitive Avoidance Theory of worry, Borkovec and colleagues (2004) proposed that worry may be a way of avoiding anxiety-provoking or emotional experiences. The Cognitive Avoidance Theory of worry emphasizes the avoidance of the physiological arousal associated with anxiety. By worrying, individuals detect possible threat earlier, which can lead into verbal thought aimed to decrease the likelihood of the threat (e.g., problem-solving). The sympathetic activation and somatic response associated with anxiety are suppressed by shifting attention to verbal self-talk opposed to attention to imagery. Over time, worry is maintained through negative reinforcement because worrying avoids exposure to anxiety that individuals experience in response to possible of future threats (e.g., bad things that could happen). Habituation to anxious arousal does not occur. The Emotion Dysregulation Theory of GAD (Mennin et al., 2002) extends the Cognitive Avoidance Theory from focusing on the avoidance of somatic anxiety and sympathetic arousal to the avoidance of negative emotions in general. Mennin and colleagues reviewed evidence of interpersonal difficulties experienced by individuals with GAD and suggest that worrying is related to emotion dysregulation. The theory posits that individuals with GAD experience emotions intensely, have a poor understanding of emotions, may learn to fear their emotional state that is poorly understood, and thus react negatively to their own emotional state. Then, worry is implemented as an emotion regulation strategy, which actually maintains and exacerbates the aforementioned emotional problems among people with GAD. This theory has garnered support from several recent studies, which examined the relation of worry to emotion regulation (Gould \& Edelstein, 2010; Mennin, Heimberg, Turk, \& Fresco, 2005; Novick-Kline, Turk, Mennin, Hoyt, \& Gallagher, 2005; Salters-Pedneault, Roemer, Tull, Rucker, \& Mennin, 
2006). Age-differences in worry may be better understood in light of age differences in emotion regulation and life-span theories of emotion and recent theoretical developments in the worry and GAD literature.

Age-related differences in emotion regulation. Emotion regulation refers to any behaviors that are aimed at controlling the experience or expression of emotions (for a review, see Gross \& Thompson, 2007). In general, research findings suggest that older adults report greater well-being, less negative affect, and greater positive affect (for a review, see Urry \& Gross, 2010). However, the question is whether age differences in emotion control yield the age differences in positive and negative affect.

In the earliest examination of age differences in control over emotions, Lawton, Kleban, Rajagopal, and Dean (1992) found that older adults reported carefully selecting situations to avoid excessive emotional stimulation. John and Gross (2004) suggested that older and younger adults use different strategies to regulate their emotions. John and Gross examined the use of two specific emotion regulation strategies, reappraisal and suppression of emotions, in collegeeducated older and younger women. Older women endorsed using positive reappraisal more frequently and using suppression of emotional experience less frequently compared to younger women (John \& Gross). Gross et al. (1997) found that older adults endorsed having greater control over anger compared to younger adults. In contrast to these findings, Gould and Edelstein (2010) failed to find age differences in emotion control over five emotions (happiness, sadness, anger, disgust, fear) or perceived control over anxiety; however, a significant age by gender interaction was observed. Younger females reported less control over the external signs of emotions and less perceived control over anxiety compared to younger men, whereas no gender differences were observed among older adults. Blanchard-Fields and colleagues found that when 
situations are highly emotional, older adults use more passive-dependent and avoidant strategies to avoid exacerbating an uncontrollable situation (Blanchard-Fields, 1997; Blanchard-Fields, Jahnke, \& Camp, 1995; Blanchard-Fields, Stein, \&Watson, 2004). In contrast, younger adults use more problem-focused strategies regardless of the emotional salience of the situation (Blanchard-Fields, 1997; Blanchard-Fields et al., 1995; Blanchard-Fields et al., 2004). These findings suggest that older and younger adults choose different types of emotion regulation strategies (Urry \& Gross, 2010) and may have different emotional goals in conflict situations. Additionally, there is some evidence that older adults may have greater control over their emotions, but this age difference may be due to gender differences. In general, one limitation of this research area is that many studies have used self-report questionnaires when examining emotion control or emotion regulation among older adults. Lang (1977) suggests that individuals may exhibit a desynchrony in self-report and physiological arousal, thus it is important to use multi-modal assessments.

A select few studies examined older adults' subjective and physiological responses to viewing films (e.g., Levenson, Carstensen, Friesen, \& Ekman, 1991; Tsai, Levenson, \& Carstensen, 2001). In general, older adults exhibited less autonomic reactivity than young adults in response to the films, but no differences in subjective or behavioral responses were detected. In another study, Kunzmann, Kupperbusch, and Levenson (2005) instructed older and younger adults to watch a film and regulate their emotional responses. In particular, participants were instructed to suppress or amplify their emotional response. The authors did not find age differences in emotional expression for suppression or amplification (Kunzmann et al.). However, observers found age differences when the suppression and amplification groups were compared. The observers found that younger adults exhibited better amplification of their 
emotional response, whereas older adults were better at suppressing their overt responses (Kunzmann et al.). Interestingly, older adults found the amplification task to be more stressful compared to young adults' perception of the task. To summarize, older adults employ passive emotion regulation strategies, such as avoidance of situations in which negative emotions occur, which could account for the lower prevalence of worry in late life. Passive emotion regulation strategies may be less cognitive demanding compared to other strategies. Additionally, individuals may select different emotion regulation strategies to use based on their available individual or environmental resources (Urry \& Gross, 2010).

Life-span Theories of Emotion. Life-span theorists (e.g., Carstensen, 1995; LabouvieVief \& Márquez, 2004; Schulz \& Heckhausen, 1998) suggest that regulation of emotion changes throughout adulthood; however, the mechanism of control varies among the theories. In her Dynamic Integration Theory (DIT; see Labouvie-Vief \& Márquez, 2004), Labouvie-Vief emphasizes the active, changing process of managing emotions across the lifespan via two interacting processes: affect optimization and affect complexity. Affect optimization aims to maximize positive affect and decrease negative affect. One who focuses on optimizing affect (a higher optimizer) would infrequently doubt or second-guess themselves (Labouvie-Vief, 2003). A high optimizer would examine his or her feelings in a more superficial way and ignore unpleasant information. Affect differentiation refers to the complexity of emotions, personal growth, objectivity, and individuation (Labouvie-Vief, Diehl, Jain, \& Zhang, 2007). One who engages in affect differentiation analyzes his or her emotions, and would be comfortable experiencing mixed emotional states (Labouvie-Vief, 2003).

In DIT affect optimization and affect complexity interact across the lifespan. From young adulthood through middle age, individuals experience increasingly complex emotions. Then, 
starting in middle age, emotion complexity begins to decrease through older adulthood (Labouvie-Vief, 2003). As individuals are experiencing declines in emotion complexity, older adults increase their reliance on affect optimization (Labouvie-Vief, 2003). Research studies have demonstrated that affect optimization increases across adulthood until becoming stable from age 60 to 70 years old, and then increasing again around age 80; Labouvie-Vief et al., 2007).

There are multiple consequences of older adults relying on affect optimization strategies. Older adults may view information from a positive light, are more susceptible to stereotypes, engage behaviors toward a restricted range of tasks or goals, and may also limit their environment. In particular, this theory is applicable to the apparent decrease in anxiety and worry in late life. An explanation that would be consistent with DIT suggests that older adults are more likely to avoid complex situations in which they may worry (as evidenced by decrease in affect complexity in late life) and to maintain low levels of negative affect and high levels of positive affect (Labouvie-Vief, 2008).

In her Socioemotional Selectivity Theory (SST), Carstensen (1995) suggests that younger adults have a more expansive time perspective, with their goals focused on gathering and obtaining information, which influences their type of social interaction. In contrast, as people age, their time-perspective shortens and becomes more focused on the present. As this occurs, emotional goals become more important than information seeking goals. Emotional goals achieved when one experiences positive emotions or meaningful social experiences (Carstensen, Fung, \& Charles, 2003). It appears that there is a trade-off in late life, such that older adults seek interactions with close friends and family more frequently than older adults seek interactions with acquaintances. Additionally, older adults have smaller social networks composed of close 
family and friends. Older adults select social situations to participate in based on the situation's potential for positive emotion and avoidance of negative emotion. This pattern has been replicated with other groups of people with shortened time perspectives (e.g., younger adults with terminal illnesses; Carstensen \& Fredrickson, 1998). Thus, the increased salience of emotional goals in late life leads to increased selection of situations and relationships that result in increased positive affect and decreased negative affect. Carstensen's theory focuses on the motivation to maintain positive affect, but implies that an older person would be motivated to avoid situations (e.g., situations that generate worry) in which negative affect would be generated. A younger adult would be less focused on the affect generated from a situation, but more focused on obtaining information.

Schulz and Heckhausen (1997) extended their Life-span Theory of Control (Heckhausen \& Schulz, 1995) to the control of emotions. Schulz and Heckhausen (1997) focus on the construct of control as a means to regulate development to enable a person to maximize his or her potential for survival. In their theory, emotions are viewed as mediators, serving to reinforce the evolutionary outcome of primary control. Changes to covert behavior can also occur (e.g., changes in thinking, disengagement from prior goals, worrying), which is termed secondary control and is less advantageous in evolutionary processes. The authors suggest that primary control is greatest in middle life, and decreases in late adulthood, exhibiting an inverted-Ushaped relation with age. In contrast, secondary control increases with age. Although the proposed mechanism of control may be different from Carstensen's theory, it appears that the outcome is the same. Both theories suggest that older adults downregulate the experience of negative emotions and increase positive emotional experiences. Schulz and Heckhausen argue 
that in old age, there are fewer novel positive experiences and increased losses, thus secondary control helps modulate emotions in late life.

\section{Statement of the Problem}

Worry may function to avoid autonomic arousal and anxiety (Borkovec et al., 2004;

Mennin et al., 2002). Although worry may be an attempt to avoid negative emotional experience in the present, excessive worrying (as in GAD) is not an effective long-term coping strategy. Worrying is associated with poor health outcomes (Kubzansky et al., 1997), depression, anxiety disorders, insomnia (see Purdon \& Harrington, 2006 for a review), and prolonged stress responses (e.g., Pieper et al., 2007). Among older adults, GAD is associated with lower quality of life (Wetherell et al., 2004), more severe depression (Lenze et al., 2001), and poorer social functioning (Lenze et al., 2001; Wetherell et al., 2004). Even sub-threshold GAD is associated with interference in one's life and with sleep disturbance (Wetherell et al., 2003).

Consistently, studies have demonstrated that older adults worry less than younger adults according to responses on self-report questionnaires (e.g., Hunt et al., 2003, Stanley, et al., 1996). Using an interview format, Basevitz and colleagues (2008) found $46 \%$ of older adults reported that their worry decreased over time. A substantial minority $(25 \%)$ of older adults reported that their worries increased over time (Basevitz et al., 2008). Furthermore, Le Roux et al. (2005) and Lenze et al. (2005) found that late-onset GAD occurs in over $40 \%$ of older adults with GAD. Worry is a problem for a significant portion of this age group. The increase in worry for some could be influenced by increased chronic health conditions that older adults and their family and friends experience.

Most of what we know about worry in late life has been gathered from non-experimental studies, thus no direct relation can be established between the experience of worry and responses 
on self-reports of worry intensity and emotion. The studies examining anxiety in late life have used samples of older adults recruited for clinical trials of GAD (e.g., Wetherell et al., 2003), large epidemiological samples (e.g., Beekman et al., 1998), community-based samples (e.g., Gould \& Edelstein, 2010; Hunt et al., 2003) and primary care samples (Stanley, Novy, Bourland, Beck \& Averill, 2001). To date, no studies have examined the effects of engaging in worry by using experimental manipulations with older adult participants.

What we know about the experimental effects of worrying is drawn from studies using mostly young adults. This verbal self-talk or worrying, decreases autonomic arousal to imagined anxiety-evoking stimuli (e.g., Borkovec \& Hu, 1990). Thus, worrying about the prospect of giving a speech in the future decreases autonomic arousal and avoids somatic anxiety in the short-term. However, worry does not decrease autonomic arousal to in vivo anxiety-evoking stimuli such as the act of giving a speech (e.g., Hazlett-Stevens \& Borkovec, 2001).

Additionally, younger adults experience frequent negative emotions, specifically depression and anxiety as a consequence of worrying (e.g., Andrews \& Borkovec, 1988; Behar et al., 2005; McLaughlin et al., 2007a). It is expected that worrying is associated with negative emotional experience among older adults as well. Worry may be a cognitive avoidance strategy that is effective in the short-term, but does not prevent the experience of negative emotions over time for young and older adults, even over a short duration (e.g., 5 to 10 minutes).

Findings from experimental manipulations of worry have demonstrated that worry is similarly experienced among younger adults that meet criteria for GAD and control participants (Ruscio \& Borkovec, 2004). Although worry has not been manipulated using experimental methods among older adults, experimental methods have been utilized to induce emotions in older adults (e.g., Fox, Knight, \& Zelinski, 1998; Knight, Maines, \& Robinson, 2002). 
Kunzmann and Grühn (2005) demonstrated that older adults reported more sadness following content-valid sad film clips, compared to younger adults. Fox and Knight (2005) found that their anxiety induction was effective for older adults but not for younger adults.

Most studies employed self-report measures to examine worry (e.g., Brenes, 2006; Hunt et al., 2003) and to examine emotion regulation (Gross et al., 1997; John \& Gross, 2004; Lawton et al., 1992). Self-report methods and the measures themselves have various limitations. To start, self-reports are usually based on retrospective accounts of behavior, which may be inaccurate. Additionally, older adults are more likely to recall positive information than negative or neutral information, which is referred to as the positivity effect (Mather \& Carstensen, 2005). Self-report measures are also influenced by social desirability. In particular, self-report data may not provide an accurate picture of symptoms for older adults who may minimize or deny symptoms as this is what is done among older cohorts (Blazer, 1996; Wong \& Baden, 2001). In addition to methodological problems with self-reports, the instruments themselves may be flawed. For example, the Emotion Regulation Questionnaire (Gross \& John, 2003) and the Carstensen Emotion Questionnaire (Carstensen, 2000) do not capture the use of passive emotion regulation strategies (e.g., avoidance), which have been reported in studies utilizing interviews (e.g., Blanchard-Fields et al., 2004).

The notion that worry is less prevalent among younger adults than older adults is wellsupported. An age difference in worry could be explained by three life-span theories of emotion. 1) Carstensen's Socioemotional Selectivity Theory would support the notion that older adults seek out social interactions to increase positive affect and decrease negative affect, thus resulting in fewer worrisome situations encountered. 2) Schultz and Heckhausen (1997) suggest that after mid-life, primary control over emotions and behavior decreases. At this point, emotion control 
can be achieved through secondary control processes, such as disengaging in unattainable goals (Wrosch, Schulz, \& Heckhausen, 2004). Schulz and Heckhausen's and Carstensen's theories may not account fully for age differences in worry. The theories are focused primarily on the valence of affect and the attainment of goals. 3)In Dynamic Integration Theory (DIT), LabouvieVief and colleagues suggest that it is important to consider the complexity of affect as well as the valence. Labouvie-Vief (2008) draws from the suggestion by earlier theorists (Helson, 1964; Lawton \& Nahemow, 1973) that an individual's tolerance for a stimulus may play a role in maintenance of homeostasis or emotion regulation. Emotion regulation may occur by decreasing environmental demands and seeking out less complex situations. This notion is supported by older adults' frequent use of passive emotion regulation strategies, such as avoidance (Blanchard-Fields et al., 1995; 2004). Consistent with Labouvie-Vief's predictions set forth in DIT, older adults may avoid arousing or complex situations which they would worry about. Labouvie-Vief and colleagues emphasize the dynamic nature of emotion regulation and the potential for individual differences. Considering developmental changes in emotion control across the life-span may help account for age differences in worry.

An experimental examination of worry in older and younger adults would contribute to two bodies of literature. First, the findings may provide support to some life-span theories of emotion. Learning more about how individuals experience emotions would improve the understanding of the aging process. Second, this knowledge about the experience of worry is essential for providers who are treating late-life anxiety. A substantial proportion of older adults meet criteria for anxiety disorders, experience problematic worry, or may have anxiety symptoms that are subthreshold, but still cause impairment. Moreover, older adults experience more chronic medical conditions than younger adults, and may have to make complex health 
care or financial decisions on a more frequent basis. As reviewed, anxiety and worry impacts information processing, attention, and decision making (e.g., Beaudreau \& O'Hara, 2009; Metzger et al., 1990; Ruscio \& Borkovec, 2004). Furthermore, worrying has a negative impact on health as it can lead to increased incidence of MIs (Kubzansky et al., 1997) and to poor immune responses (Segerstrom, Glover, Craske \& Fahey, 1999). In sum, worry may significantly impact health, emotional well-being, and the overall functioning of older adults. Obtaining a better understanding of the experience of worry will move the field a step closer to improving the identification of worry and anxiety in late life and in providing effective treatments.

\section{Present Study}

Questionnaire-based studies and retrospective accounts of worry are limited in what they can tell us about the experience of worry among older adults. Moreover, there are problems with self-report data. One's response is influenced by the phrasing of the question asked, the format of the answer (e.g., open-ended versus Likert-type scale response), and the context of the question (Schwartz, 1999). Furthermore, one may be motivated to present himself in a positive view and may edit his covert thoughts and responses when psychologists ask about emotions. Other methods of assessment, such as physiological assessments can capture variations in emotional experience that may be missed when using self-report measures only. Assessing physiological arousal using measures of HR may provide information about the extent to which physiological arousal accompanies worry in late life. In the present study, experimental manipulations of worry were used with older adults to examine causal relations among worry, arousal, and emotion. After the induction of worry, relaxation was used to allow participants to recover from any negative emotions experienced as a consequence of the worry period. Age-related differences in 
recovery following worry periods were expected to yield information regarding the control of worry and emotion in late life.

The present study had two general foci: (1) to compare the effects of a worry and pleasant recall induction on worry and (2) to examine age differences in the experience of worry. The second focus of the study was exploratory in nature because worry inductions have not been used with older adult samples. The present study's two foci are addressed using multiple assessments employing self-report and objective methods: self-reported worry intensity, self-reported arousal, HR, and self-reported emotions. Research questions are grouped by each assessment (dependent variable). To identify the effects of worry and pleasant recall inductions, the following questions were addressed:

\section{Worry Intensity}

(1) What are the effects of worry inductions or pleasant recall inductions on the intensity of reported worry? The goal of this question was to replicate the findings of Ruscio and Borkovec (2004) and extend their findings to older adults. Worry intensity was expected to be greater for the worry induction than the pleasant recall induction.

(2) To what extent does relaxation following a worry induction or pleasant recall induction affect worry intensity? This question has been addressed with previous research that examined attention following worry inductions with younger adult samples (e.g., Ruscio \& Borkovec, 2004). Worry intensity after relaxation was not expected to differ for the worry or pleasant recall inductions.

(3) Do older and younger adults differ in their intensity of worry in response to a worry induction? Younger adults were expected to report greater worry intensity 
at baseline, which would be consistent with life span theories of emotion (e.g., DIT, SST). However, after controlling for baseline differences, worry intensity was not expected to differ between age groups. Studies (e.g., Levensen et al., 1991) have demonstrated that older and younger adults do not differ in subjective experience of emotions.

(4) Do older and younger adults differ in their intensity of worry following relaxation? This question was exploratory; however, relaxation has been demonstrated to be effective for older adults (e.g., Scogin et al., 1992).

\section{Self-reported Arousal}

(5) What are the effects of a worry induction or pleasant recall induction on arousal (measured by arousal scale of Self Assessment Manikin (SAM)? The worrying induction was expected to result in greater arousal ratings than pleasant recall induction (e.g., Borkovec et al., 1983).

(6) To what extent does relaxation following a worry induction or pleasant recall induction affect arousal (measured by arousal scale of SAM)? The relaxation induction was expected to reduce arousal following the worry and pleasant recall inductions (e.g., Hazlett-Stevens \& Borkovec, 2001).

(7) Do older and younger adults differ in arousal (measured by arousal scale of SAM) following a worry or a pleasant recall induction? Older adults were expected to report less arousal than younger adults following these inductions (e.g., Levenson et al., 1991). 
(8) Do older and younger adults differ in arousal (measured by arousal scale of SAM) following relaxation? This question was exploratory; however, relaxation has been demonstrated to be effective for older adults (e.g., Scogin et al., 1992).

\section{Heart Rate}

(9) What are the effects of a worry induction and pleasant recall induction on HR? HR was expected to be greater during the worry induction than the pleasant recall induction.

(10) To what extent does relaxation following a worry or pleasant recall induction affect HR? In general, relaxation is associated with increased HR, but greater HRV compared to worrying (Thayer et al., 1996). No effects for the pleasant recall induction were expected.

(11) Do older and younger adults differ in HR during a worry or pleasant recall induction? Younger adults were expected to have higher HRs compared to older adults; however, no specific predictions were made regarding the effects of the two inductions on HR for older and younger adults.

(12) Do older and younger adults have different HRs following relaxation? Lau (2000) found that older adults were slower to recover from a fear induction using a measure of skin conductance. However, it is not clear in the present study whether there would be age differences in HR evident after relaxation.

\section{Emotions: Anxiety, Depression, Hostility, and Positive Affect}

(13) What are the effects of a worry induction or pleasant recall induction on selfreported emotions (measured by the Multiple Affect Adjective ChecklistRevised)? This research question has been addressed with younger adult samples 
(Andrews \& Borkovec, 1988; McLaughlin et al., 2007b, York et al., 1987), but not with older adult samples to date. For younger adults, worry resulted in increased anxiety, depression, hostility, and decreased positive affect. It is expected that the greater negative affect and decreased positive affect would be found for the worry induction than the pleasant recall induction.

(14) To what extent does relaxation following a worry induction or pleasant recall induction affect emotions (as measured by the MAACL-R)? Relaxation was expected to reduce the negative affect (anxiety, depression, hostility) and increase positive affect following the worry induction. No changes were expected for the pleasant recall induction.

(15) Do older and younger adults differ in their self-reported emotions experienced in response to a worry induction? One could infer from life-span theories of emotion that older adults would experience lower rates of negative emotions during the worry and pleasant recall inductions. Additionally, baseline differences were expected such that older adults would report less anxiety, depression, and hostility, but greater positive affect than younger adults.

(16) Is there an age difference in either the type or strength of emotions experienced during relaxation? Relaxation was expected to reduce negative affect experienced by both age groups. It was not clear whether relaxation would have a differential effect on emotions for older versus younger adults.

\section{Design}

The present study employed a mixed repeated measures quasi-experimental design, Between-subjects variables were age (older and younger) and condition (worry and pleasant 
recall). HR was measured continuously. Two self-report variables were measured at six time points; one questionnaire was administered at three time points. The study design and order of measures and inductions are displayed in Figure 1. 
Figure 1. Study Design and Order of Procedures
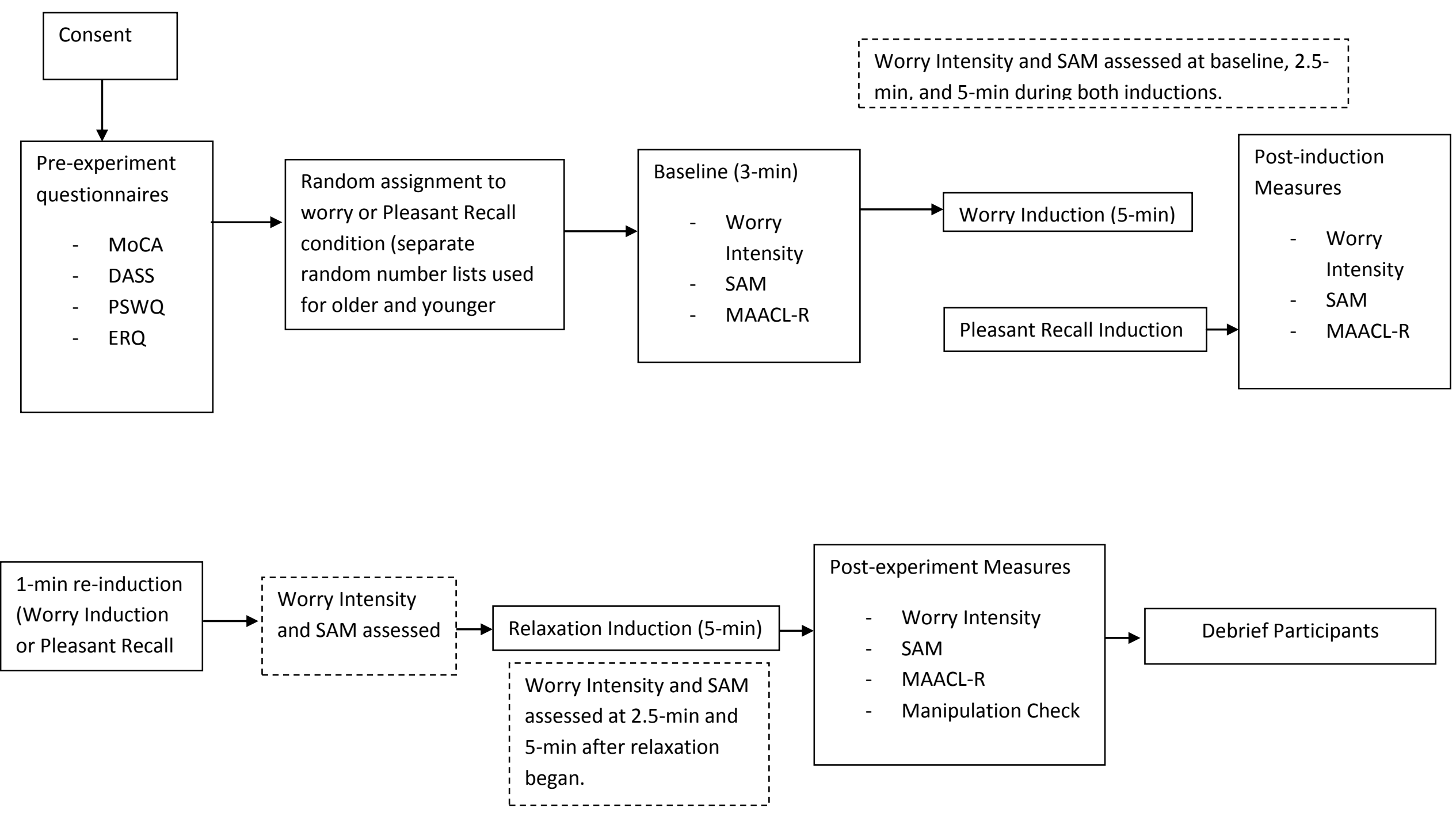


\section{Method}

\section{Participants}

Participants were screened for the study and were excluded if they did not meet inclusion and exclusion criteria. First, participants were excluded if they were not in one of two age groups: younger adults (aged 18 to 30 years) or older adults (aged 60 years or older). In addition to the specific age criteria, participants were excluded if they were current smokers, taking betablockers, anxiolytics, psychostimulants, or diet pills. Individuals who reported having pacemakers, arrhythmias, history of heart surgery, or heart attacks were not eligible to participate in the present study. Sixty older adults and 53 younger adults were consented to participate. The final exclusion criterion was performance on a cognitive screening instrument, the Montreal Cognitive Assessment (MoCA). Participants were excluded if they scored 22 or below on the MoCA. Two older participants scored below a 23 on the MoCA and were excluded and paid $\$ 5$. Additionally, data for two older adult participants were excluded because they had heart problems, which were not reported on the screening questionnaire, but were reported on the demographic and health questionnaire. The present study included 53 younger adults and 57 older adults.

Attempts were made to recruit equal numbers of male and female participants. Younger adult graduate or undergraduate students were recruited from psychology classes, emails to list servs, flyers, and word-of-mouth. Younger adult participants were compensated with 1.5 hours of extra credit for undergraduate psychology courses and $\$ 5$. Older adult participants were recruited using emails to list servs, news announcements posted on websites, television advertisements on the community bulletin, flyers posted in the community, researcher visits to senior centers, and word-of-mouth. Also, older adult participants from previous studies who 
expressed an interest in future studies were invited to participate in the present study. Older adults were provided $\$ 20$ in exchange for their participation in the present study.

\section{Pre-experiment measures}

Screening questionnaire. A screening questionnaire was read to participants over the telephone, completed by participants using an online data collection website (SONA), or completed in person (e.g., at senior centers). Inclusion and exclusion criteria were assessed. This questionnaire is displayed in Appendix A.

Demographic questionnaire. Each participant completed a demographic and health questionnaire. Information regarding ethnicity, race, marital status, years of education, income, past smoking status, alcohol use, exercise frequency, personal and family medical history, height and weight were assessed in this self-report questionnaire. The demographic questionnaire is presented in Appendix B.

Montreal Cognitive Assessment (MoCA; Nasreddine et al., 2005). The MoCA is a 30point clinician-administered cognitive screening instrument developed to detect mild cognitive impairment (MCI) or dementia in the early stages. Nasreddine et al. (2005) suggested that a cutoff of 26 be used to identify individuals with possible mild cognitive impairment and dementia However, Luis, Keegan, and Mullan (2009) found that a cutoff of 26 may be too high, as the specificity for detecting was MCI low (35\%) for his sample obtained from the Southeastern United States. Instead, Luis et al. suggested that a cut-off score of 23 yields excellent sensitivity (96\%) and specificity (95\%) when detecting individuals with MCI. Reliability of the MoCA was examined with a small sample of patients with Parkinson's Disease (Gill, Freshman, Blender, \& Ravina, 2008). Examination of test-retest reliability over an average of 4.4 month period yielded an intraclass coefficient of 0.79 for the two administrations. Examination of interrater reliability 
yielded an intraclass coefficient of 0.81 (Gill et al.). Convergent validity ranges between 0.62 and 0.87 for the MoCA and MMSE (Gill et al.; Nasreddine et al., 2005; Smith, Gildeh, \& Holmes, 2007). Additionally, convergent validity was established with a neuropsychology assessment battery (Spearman's $r=.72$; Gill et al.).

Depression Anxiety Stress Scale (DASS-21, Lovibond \& Lovibond, 1995). The DASS21 is a 21 -item measure with three subscales: depression, anxiety, and stress. Items are rated using a Likert-type scale ranging from 0 (Did not apply to me at all) to 4 (Applied to me very much, or most of the time). Gloster et al. (2008) found that the DASS-21 has good consistency $(\alpha=.87$ for DASS-D,$\alpha=.89$ for DASS-S,$\alpha=.69$ for DASS-A $)$ for older adult primary care patients. Convergent validity was established for all the subscales, as each subscale correlated more strongly with measures of the same construct than with the other DASS subscales (i.e., DASS-A and Beck Anxiety Inventory, $r=.74$; Gloster et al.). Test-retest (over a 2-week interval) for the three subscales ranged from $r=.71$ to .81 for the 42-item DASS (Brown, Chorpita, Korotitsch, \& Barlow, 1997). No test-retest reliability data for the DASS-21 have been published to date. In the present study, internal consistency was examined for three subscales: stress, anxiety, and depression. Good internal consistency was found for the younger adult sample ( $\alpha=.80$ for DASS-S, $\alpha=.62$ for DASS-A, $\alpha=.70$ for DASS-D). For older adults, internal consistency greatly varied from .40 for DASS-S and DASS-A to. 73 for DASS-D.

Penn State Worry Questionnaire (PSWQ; Meyer et al., 1990). The PSWQ is a 16-item questionnaire that assesses the excessiveness and uncontrollability of worry. Scores range from 16 to 80 with higher scores on this instrument indicative of greater worry. Participants are asked to rate each item using a Likert-type scale ranging from 1 (not at all typical) to 5 (very typical). The PSWQ has been validated for use with samples of younger (Meyer et al., 1990) and older 
adults (Beck et al., 1995; Stanley et al., 1996). Internal consistency was good in clinical, community, and college student samples ranging from .86 to .93 (Brown, Antony \& Barlow, 1992; Fresco, Frankel, Mennin, Turk, \& Heimberg, 2002; Molina \& Borkovec, 1994). Among college samples, test-retest reliability is adequate (ranging from $r=.74$ to .92 ,) over an interval of 2 to 10 weeks (Molina \& Borkovec, 1994; Meyer et al., 1990; Stöber, 1998). Stanley et al. (2001) found that test-retest reliability over an average test-retest interval of 69.5 days $(S D=$ 39.24, Range: 5 to 20 weeks) is poor among older adults with a diagnosis of GAD $(r=.54)$. Gould and Edelstein (2010) found the internal consistency for community dwelling older adults to be good $(\alpha=.86)$. In the present study, Cronbach's $\alpha=.95$ for younger adults and .84 for older adults.

\section{Dependent measures}

Worry intensity. The intensity of one's worry was assessed using a one-item measure with a 0 (not at all) to 100 (extremely) scale (Andor, Gerlach, \& Rist, 2008). The worry intensity item is displayed in Appendix C.

Self Assessment-Manikin (SAM; Bradley \& Lang, 1994). The Self Assessment Manikin (SAM) Test was created to be a picture-oriented instrument to assess three states: pleasure, arousal, and dominance that occur in response to a stimulus. The present study used the arousal item only. The arousal scale ranges from a "sleepy figure" to "an excited, wide-eyed figure" (Bradley \& Lang, 1994; p. 50). Backs, da Silva, and Han (2005) examined the psychometric properties of the SAM in older and younger adults. Internal consistency (coefficient alpha) for the arousal item among younger adults was .98. Among older adults, the internal consistency (coefficient alpha) for the arousal item was .98 (Backs et al., 2005). The arousal item and instructions for the SAM are displayed in Appendix C. 
Multiple Affect Adjective Checklist-Revised (MAACL-R; Zuckerman \& Lubin, 1985).

The state form of the MAACL-R asks participants to answer the question, "How do you feel today?" using a checklist of adjectives. The short form uses 66-items, which comprise the following subscales: anxiety, depression, hostility, positive affect, and sensation seeking. The authors expect internal consistency for the state version of the MAACL-R to be high for each subscale, but test-retest reliability is expected to be low when the instrument is used as a measure of change (Lubin \& Zuckerman, 1999). Internal consistency for the five scales of the state form of the MAACL-R ranges from .50 for sensation seeking in a sample obtained from the Air Force, to .95 for positive affect in a college student sample (Lubin et al., 1986). Test-retest reliability over a period of 1 to 5 days ranged from $r=.52$ (1-day) to .09 (5 days) in a sample of normal adults (Lubin \& Zuckerman, 1999). The state form of the MAACL-R has been used in studies with older adults (e.g., Beckingham, Coutu-Wakulczyk \& Lubin, 1993) and in studies with younger adults (Andrews \& Borkovec, 1988; McLaughlin et al., 2007b; York et al., 1987). For the present study, internal consistency (coefficient alpha) ${ }^{1}$ is reported in Table 1 for each MAACL-R subscale at each of the three administrations. Additionally, separate analyses were completed for younger and older adults. If participants did not endorse an item, it was determined to have no variance and was dropped from the analyses. The results suggest that there is great variation in the inter-item correlations across the three conditions: baseline, induction, and relaxation.

\footnotetext{
${ }^{1}$ Internal consistency for measures with dichotomous responses can be reported with Kuder-Richardson (KR-20) or with Cronbach's alpha. As both statistics yield the same results when the scale is dichotomous (Cortina, 1993), Cronbach's alpha is reported here.
} 
Table 1. Internal consistency for four MAACL-R subscales.

\begin{tabular}{|c|c|c|c|c|}
\hline & $\begin{array}{c}\text { Anxiety } \\
\text { (10 item scale) }\end{array}$ & $\begin{array}{c}\text { Depression } \\
\text { (12 item scale) }\end{array}$ & $\begin{array}{c}\text { Hostility } \\
\text { (15 item scale) }\end{array}$ & $\begin{array}{l}\text { Positive Affect } \\
\text { (21 item scale) }\end{array}$ \\
\hline \multicolumn{5}{|l|}{ Baseline } \\
\hline Younger & .68 & $.54(8)$ & $.81(9)$ & .85 \\
\hline Older & $.04(8)$ & .92 & $* * *$ & .92 \\
\hline Total & .64 & $.70(8)$ & $.81(9)$ & .90 \\
\hline \multicolumn{5}{|l|}{ Induction } \\
\hline Younger & .58 & $.28(8)$ & .68 (11) & .89 \\
\hline Older & .80 & .89 & .65 (12) & .96 \\
\hline Total & .67 & $.79(12)$ & $.65(12)$ & .93 \\
\hline \multicolumn{5}{|l|}{ Relaxation } \\
\hline Younger & $.42(6)$ & $.33(4)$ & $.56(5)$ & .89 \\
\hline Older & $.22(7)$ & $.06(7)$ & $.78(7)$ & .93 \\
\hline Total & $.24(8)$ & $.08(7)$ & $.74(9)$ & .92 \\
\hline
\end{tabular}

***14 of 15 items had no variance, so Cronbach's $\alpha$ was not calculated.

Note: Number of scale items included in each analysis are in parentheses, if differs from the items on the scale.

Heart rate. HR was measured via a Polar heart rate monitor model 810i (Lake Success, New York). A sensor strapped around participants' chests measure ECG signals and send the signals to a wireless transmitter to a nearby computer, monitored by the researcher. The Polar Precision Performance SQ analysis software was set at a moderate filtering level. As described by Wilson, Smith, and Holmes (2007), "the algorithm uses median and moving average-based filtering methods to substitute detected errors with corrected values" (p. 416). In the present study, the researcher previewed the corrections using the filtered Interbeat Interval (IBI) preview function before accepting changes. Across younger participants, a mean of $1.4 \%$ of data points (IBIs) were replaced. A mean of $0.9 \%$ of data points (IBIs) were replaced for older adults. From the filtered, recorded IBI data, average HR and HRV (High Frequency Power; HF Power) were calculated using Kubios HRV v2.0 (Niskanen et al., 2004). A fast Fourier transformation (FFT) 
was used by Kubios HRV 2.0 to compute High Frequency Power (HF Power), the heart rate variability measure of interest. HF power was selected as the component of a frequency measure of HRV because it is an estimate of vagal activity (American Heart Association, 1996).

\section{Post-experiment measures}

Manipulation check. A manipulation check was performed because independent variable manipulations focused on covert behaviors. Participants were asked to complete one item regarding the extent that they followed the instructions in the study (Arch \& Craske, 2006). The item used a Likert-type scale ranging from 1 (very untrue), to 7 (very true). Individuals in the worry condition were asked how similar this worrying had been to their everyday worrying (Andor et al., 2008). This item was rated with a Likert-type scale ranging from 1 (not at all similar) to 7 (very similar). See Appendix C for post-experiment measures.

\section{Procedure}

Screening took place over the telephone for the majority of older adults and for one younger adult. The majority of younger adults completed the screening questionnaire on SONA, an online data collection system. The remaining older adults and several younger adults were screened in person prior to the experiment session. Younger adult participants who were screened with SONA, were contacted through the SONA system, and either invited to participate, or informed that they were not eligible for the present study. Individuals who screened in person and were not eligible to participate in the present study were informed immediately. No compensation was provided to individuals who failed screening prior to the consent process. 
Prior to the start of the study, participants were consented. Following consent procedures, the researcher demonstrated the proper placement of the HR monitor and briefly explained how it works using the following instructions:

This is a heart rate monitor. It will send information about your heart rate to a computer in the other room using a wireless signal. It will not deliver any shocks or electricity; it will only monitor your heart rate. The heart rate transmitter belt will be worn throughout the entire study. You will wear the HR monitor and strap underneath your clothing, directly against your skin. I will demonstrate where to place it on myself, and then I will step out of the room so you can place it. [Researcher demonstrates placement of monitor]. After the participants placed the HR monitor, they completed four questionnaires: demographic questionnaire, the DASS, PSWQ, and ERQ. Then, the researcher administered a cognitive screening assessment, the Montreal Cognitive Assessment, in order to detect cognitive impairment. Individuals who scored below 23 (Luis, et al., 2009) were excluded from the present study and paid $\$ 5$.

After the screening and pre-experiment measures were completed, participants were randomly assigned to one of two conditions: worry induction or pleasant recall induction. Random assignment ensured that about half of the older and younger participants underwent the worry induction, while the other half of both groups underwent the pleasant recall induction. Random assignment was accomplished using a random number table.

To establish a baseline HR recording and subjective reports of mood, participants were instructed to sit quietly for three minutes with their eyes closed. The overhead lights in the laboratory were dimmed at this point. After the 3-min period, the researcher read a definition of worry to participants. The definition used for the current study has been used in recent research 
(McLaughlin et al., 2007a): "intrusive [distracting or bothersome] thoughts or images about potential future events or catastrophes [concerns] that produce negative feelings when they occur" (p. 27). Then, the researcher read instructions to participants for the completion of the worry intensity item and the SAM arousal rating. Participants were asked to complete the worry intensity item, SAM arousal item, and MAACL-R state questionnaire.

After the baseline measures were completed, the researcher read the induction instructions to explaining the 5-min induction procedure. The procedures for inducing worry and positive states been used in studies with younger adults (e.g., McLaughlin et al., 2007a; McLaughlin et al., 2007b).

Worry induction. Before the instructions were read to participants, participants were asked to write the three topics or concerns that they worry about the most on a sheet of paper provided by the experimenter. After the three worries were recorded, the researcher read the following instructions to participants in the worry induction condition:

"During this period, we would like you to create a worrisome state [or to worry as you usually do]. Please refer to your list of worrisome topics. When the experimenter asks you to begin, please close your eyes and worry about your most worrisome topic in the way you usually worry about it but as intensely as you can, until the experimenter asks you to stop and to open your eyes. If you normally worry about only one topic [or concern] at a time, please try to do the same during this period. However, if your thoughts change to another worry topic during this period feel free to allow these thoughts to continue. It is alright to change topics during this period if the changes occur naturally during the worry process" (McLaughlin et al., 2007b, p. 1740). 
At 2.5-min, the researcher interrupted the induction briefly to have participants complete the worry intensity item and the SAM arousal item. Intermittent ratings at intervals were used in several other investigations (McLaughlin et al. 2007a; Ruscio \& Borkovec, 2004; York et al., 1987) and did not appear to affect the induction. At the end of the 5-min induction, the researcher instructed participants to complete the worry intensity item, SAM arousal item, and the MAACL-R questionnaire.

Pleasant recall induction. The researcher provided participants with a sheet of paper with three lines and asked participants to write three pleasant activities or tasks completed last weekend on a sheet of paper (McLaughlin et al., 2007b). After this task was completed, the following instructions were read to participants:

"During this period, we would like you to take a few minutes to think about what you did this past weekend. When the experimenter asks you to begin, please close your eyes and think about what you did last weekend, until the experimenter asks you to stop and to open your eyes. It may help to start by thinking about the three things that you listed above. Please close your eyes and begin thinking" (McLaughlin et al., 2007b, p. 1740).

At 2.5-min, the researcher interrupted the induction briefly to have participants complete the worry intensity item and the SAM arousal item. Immediately following the pleasant recall induction, participants were asked to complete the worry intensity item, SAM arousal item, and the MAACL-R questionnaire.

Re-induction and relaxation. After participants completed the MAACL-R for a second time, a brief 1-min re-induction was conducted. A re-induction was included in case older adults took longer than to younger adults to complete measures such as the MAACL-R. The researcher 
read a briefer version of the worry or pleasant recall induction instructions for the re-induction. At the end of the 1-min period, participants were asked to rate their worry intensity and arousal. The relaxation immediately followed the completion of the re-induction ratings. The present study used focused breathing as a method of relaxation. In a recent examination of worry among younger adults, Arch and Craske (2006) used focused breathing to simulate the effects of firsttime practitioners of mindfulness. Relaxation has been used in clinical interventions for anxiety among older adults (as reviewed by Ayers, Sorrell, Thorp, \& Wetherell, 2007). The researcher read the instructions for the focused breathing (Davis, Eshelman, \& McKay, 2000) to participants. After the instructions were given, the researcher asked participants to continue practicing this focused breathing exercise for several minutes. The relaxation instructions were as follows:

Please sit in a comfortable position with your arms and legs uncrossed and your spine straight. Breathe in deeply. Let yourself pause before you exhale. Now, I would like you to count each time you exhale. For example, inhale. Then, as you exhale the first time count "one" to yourself. As you continue to inhale and exhale, count each exhalation: "Two... three... four." Continue counting your exhalations in sets of four. Notice your breathing gradually slowing, your body relaxing, and your mind calming as you practice this breathing meditation (Davis, Eshelman, \& McKay, 2000).

The researcher interrupted participants at 2.5-min to complete the worry item and the SAM arousal item. After the relaxation period ended, the post-experiment assessments were administered. These assessments include the worry intensity item, SAM arousal item, MAACL$\mathrm{R}$, and the manipulation-check items. Following the manipulation-check items, the researcher 
debriefed participants and inquired about any concern regarding the experiment or residual worry and/or anxiety.

\section{Data Analysis}

A power analysis was conducted using Sample Power 2 (Sample Power 2, SPSS, Inc, Chicago, IL), which suggested that a sample of 104 participants was needed to obtain a power level of .71 to detect a medium-sized effect for a 2 x 2 Factorial ANOVA. Additionally, Teachman and Gordon (2009) used a similar sized sample $(\mathrm{N}=98)$ to examine the effects of three anxiety inductions on older and younger adults found age differences on one of three anxiety inductions. All analyses were conducted with PASW Statistics 18 (SPSS Inc., an IBM Company, Chicago, IL).

\section{Preparation of Data}

The variable of age (older versus younger adults) was dummy-coded in the following analyses. Distributions of dependent variables were examined through scatter plots and histograms, and the calculation of skew and kurtosis. At baseline, all the variables except the positive affect subscale on the MAACL-R were positively skewed $(z<2.6)$. A positive skew was expected because the majority of the sample was not expected to report much worry, arousal, or other negative affect at baseline. By examining the data for the pleasant recall and worry groups separately, it was evident that the majority of variables (with the exception of positive affect) were significantly skewed for the pleasant recall group across conditions. As expected, the majority of participants reported little or no worry, arousal, or negative affect at baseline. For the worry group, significant skew was observed for a few variables during the induction (depression, hostility), and for all the measures during relaxation (except positive affect). Due to the skew, the assumption of normality was violated for the majority of variables at baseline, and for the control 
group throughout the induction and relaxation conditions. Normality was not achieved in the present sample due to the nature of the experimental design and the induced conditions. As the ANOVA and MANOVA are robust statistical methods (Howell, 2001), these data were not transformed.

The distributions for the independent and dependent variables were examined for outliers greater than three standard deviations from the mean (Tabachnick \& Fidell, 2007). One older participant was excluded from the statistical analyses because of extremely high baseline worry and depression ratings due to a recent stressor. Several multivariate outlier data points were identified. Multivariate analyses were conducted with and without these six participants (3 younger adult, 3 older adults). When the six multivariate outliers were excluded, a main effect of time was found. However this main effect was qualified by a significant interaction that was found in analyses with the outliers included and excluded. As excluding the six multivariate outliers did not affect any other findings, results are reported with these six participants included. By including these participants, we do not risk an artificial reduction in variability. In the exploratory analyses with HF Power as a dependent variable, four univariate outliers (two older adults, two younger adults) were excluded.

\section{Results}

All planned analyses are reported using alpha set at the .05 level. The mean age of younger adult participants was 21.4 years old $(S D=2.6$ years $)$. Younger adults were $58.4 \%$ female, $83.0 \%$ white, Non-Hispanic, and $98.1 \%$ were not married. The mean age of older adults was 69.2 years old $(S D=8.1$ years $)$. Older adults were $58.2 \%$ female, $96.4 \%$ white, NonHispanic, and 49.1\% were married. Demographic characteristics are presented in Table 2. Older and younger adults differed in marital status $\left(X^{2}(4)=83.8, p<.001\right)$, occupation $\left(X^{2}(5)=\right.$ $82.8, p<.001)$, and income $\left(X^{2}(3)=9.4, p=.03\right)$. Older adults also were more likely to report 
parental history of coronary heart disease $\left(X^{2}=15.8, p<.001\right)$, and myocardial infarction $\left(X^{2}=\right.$ $8.2, p=.004)$, and had more years of education $(F(1,107)=6.5, p=.01)$ and greater Body Mass Indices $(F(1,107)=12.4, p=.001)$. 
Table 2. Participant Characteristics

\begin{tabular}{|c|c|c|}
\hline & Younger Adults $(\mathrm{N}=53)$ & Older Adults $(\mathrm{N}=55)$ \\
\hline & $\mathrm{N}(\%)$ or $\mathrm{M}(\mathrm{SD})$ & $\mathrm{N}(\%)$ or $\mathrm{M}(\mathrm{SD})$ \\
\hline Age* & $21.4(2.6)$ years & $69.2(8.1)$ years \\
\hline Sex & $31(58.5 \%)$ Females & $32(58.2 \%)$ Females \\
\hline \multicolumn{3}{|l|}{ Race/Ethnicity } \\
\hline White, Non-Hispanic & $44(83.0 \%)$ & $53(96.4 \%)$ \\
\hline Black, Non-Hispanic & $4(75.4 \%)$ & $1(1.8 \%)$ \\
\hline Asian & $1(1.9 \%)$ & $1(1.8 \%)$ \\
\hline Hispanic & $2(3.8 \%)$ & 0 \\
\hline Biracial & $2(3.8 \%)$ & 0 \\
\hline \multicolumn{3}{|l|}{ Marital Status* } \\
\hline Single & $52(98.1 \%)$ & $6(10.9 \%)$ \\
\hline Married & 0 & $27(49.1 \%)$ \\
\hline Separated/Divorced & $1(1.9 \%)$ & $10(18.1 \%)$ \\
\hline Widowed & 0 & $12(21.8 \%)$ \\
\hline \multicolumn{3}{|l|}{ Occupation * } \\
\hline Working Full-time & $3(5.7 \%)$ & $8(14.5 \%)$ \\
\hline Working Part-time & $10(18.9 \%)$ & $7(12.7 \%)$ \\
\hline Homemaker & 0 & $1(1.8 \%)$ \\
\hline Retired/Disabled & 0 & $39(69.1 \%)$ \\
\hline Student & $40(75.5 \%)$ & 0 \\
\hline Years of Education* & $14.8(1.8)$ & $16.2(3.7)$ \\
\hline \multicolumn{3}{|l|}{ Family Income* } \\
\hline Less than $\$ 25,000$ & $7(13.2 \%)$ & $13(25.0 \%)$ \\
\hline$\$ 25,000$ to 50,000 & $13(24.5 \%)$ & $13(25.0 \%)$ \\
\hline$\$ 50,000$ to 74,999 & $8(15.1 \%)$ & $15(28.8 \%)$ \\
\hline$\$ 75,000$ or greater & $25(47.2 \%)$ & $11(21.2 \%)$ \\
\hline Body Mass Index* & $24.4(3.7)$ & $27.4(5.1)$ \\
\hline \multicolumn{3}{|l|}{ Weekly Physical Activity } \\
\hline Never & $4(7.5 \%)$ & $13(23.6 \%)$ \\
\hline $1-2$ times & $23(43.4 \%)$ & $14(25.5 \%)$ \\
\hline $3-6$ times & $22(41.5 \%)$ & $22(40.0 \%)$ \\
\hline 7 or more times & $4(7.5 \%)$ & $6(10.9 \%)$ \\
\hline \multicolumn{3}{|l|}{ Parental History of: } \\
\hline Hypertension & $23(43.4 \%)$ & $26(48.1 \%)$ \\
\hline Coronary Heart Disease* & 0 & $14(25.9 \%)$ \\
\hline Myocardial Infarction* & $3(5.7 \%)$ & $14(25.9 \%)$ \\
\hline
\end{tabular}

*Significantly different at $p<.05$

Means and standard deviations by age group for baseline measures are presented in Table

3. As found in previous research, age differences emerged for various measures completed

before the experiment began. ANOVAs were conducted to identify any potential age differences. 
Younger adults performed better on the MoCA, but had greater worry (PSWQ), anxiety, and stress (DASS) compared to older adults. In particular, the finding of greater worry, anxiety, and stress among younger adults is consistent with previous research.

Table 3. Means and Standard Deviations for Questionnaires and Baseline Dependent Variables

\begin{tabular}{|c|c|c|c|c|}
\hline \multirow[t]{2}{*}{ Variable } & \multicolumn{2}{|c|}{ Younger Adults $(\mathrm{N}=53)$} & \multicolumn{2}{|c|}{ Older Adults $(\mathrm{N}=55)$} \\
\hline & $\underline{\mathrm{M}}$ & $\underline{\mathrm{SD}}$ & $\underline{\mathrm{M}}$ & $\underline{\mathrm{SD}}$ \\
\hline MoCA* & 27.7 & 1.6 & 26.5 & 2.2 \\
\hline PSWQ* & 45.4 & 14.7 & 36.5 & 9.4 \\
\hline DASS Total* & 11.7 & 8.1 & 7.5 & 5.5 \\
\hline Stress* & 5.8 & 3.9 & 4.2 & 3.2 \\
\hline Anxiety* & 3.0 & 2.7 & 1.2 & 1.5 \\
\hline Depression & 2.9 & 2.7 & 1.9 & 2.3 \\
\hline Worry Intensity* & 27.5 & 26.4 & 15.7 & 21.2 \\
\hline SAM-Arousal & 3.1 & 1.7 & 2.5 & 1.8 \\
\hline MAACL-R (checked)* & 24.0 & 12.1 & 32.7 & 13.9 \\
\hline Anxiety* & 1.0 & 1.5 & .2 & .4 \\
\hline Depression & .3 & .7 & .1 & .3 \\
\hline Hostility* & .6 & 1.4 & .02 & 1 \\
\hline Positive Affect* & 8.6 & 5.8 & 13.1 & 5.8 \\
\hline Sensation Seeking & 4.4 & 1.8 & 4.8 & 1.7 \\
\hline Heart Rate $(\mathrm{bpm})^{*, 1}$ & 75.3 & 13.0 & 69.7 & 8.1 \\
\hline HF Power $\left(\mathrm{ms}^{2}\right)^{*, 2}$ & 1221.28 & 1137.90 & 288.83 & 521.20 \\
\hline $\begin{array}{l}\text { Log-transformed HF } \\
\text { Power }\left(\mathrm{ms}^{2}\right)^{*, 2}\end{array}$ & 2.86 & .51 & 2.09 & .57 \\
\hline
\end{tabular}

*Significantly different means at $p<.05$

${ }^{1}$ Based on a sample of $\mathrm{N}=53$ younger adults and $\mathrm{N}=52$ older adults.

${ }^{2}$ Based on a sample of $\mathrm{N}=46$ younger adults and $\mathrm{N}=47$ older adults.

\section{Baseline Measures}

Age differences. An examination of age group differences at baseline was conducted to determine whether there were preexisting differences that could affect the outcome of the study. Although there was a large range of worry intensity scores for both younger $(0-85)$ and older adults $(0-75)$, younger adults reported greater worry intensity $(M=27.5, M d=23.0, S D=26.4)$ than older adults $(M=15.7, M d=10.0, S D=21.2)$ at baseline. Younger adults reported greater 
anxiety, and hostility (MAACL-R) than older adults after the baseline period. In contrast, older adults reported greater positive affect (MAACL-R) than younger adults. Interestingly, older adults checked off more items on the MAACL-R, which suggests that they may have been more conscientious in responding or made finer discriminations when reporting experienced emotions. Age differences in objective measures were found as well. Younger adults had higher baseline HR than older adults and greater HRV, as measured by HF power. Thus, several age differences at baseline emerged.

Sex differences. As sex differences in anxiety have been reported in earlier studies (e.g., Gould \& Edelstein, 2010), ANOVAs were used to examine whether women and men differed in the variables at baseline. Women had higher rates of trait worry than men, as measured by the $\operatorname{PSWQ}(F(1,107)=5.2, p=.02)$, greater baseline worry intensity $(F(1,107)=4.8, p=.03)$, greater self-reported arousal $(F(1,107)=4.5, p=.04)$, greater anxiety, as measured by the MAACL-R $(F(1,107)=9.1, p=.003)$, and greater hostility, as measured by the MAACL-R $(F(1,107)=4.1, p=.05)$. Men had lower HRs than women, $(F(1,107)=5.6, p=.02)$. Due to multiple sex differences observed at baseline, sex was entered as a covariate for the following analyses.

Experimental group differences. Univariate ANOVAs were conducted on baseline MAACL-R, Worry Intensity, SAM ratings, HR, and HF Power to examine whether condition differences existed prior to the inductions. Significant differences in baseline ratings of arousal using the SAM emerged, $F(1,106)=24.57, p=.01$. Specifically, the pleasant recall group reported significantly higher arousal $(M=3.22, S D=2.00)$ than the worry group $(M=2.26, S D$ $=1.36$ ). Furthermore age differences at baseline were evident. Thus, random assignment did not yield equivalent condition groups for the dependent variable of arousal. Consequently, baseline 
measures of the dependent variable of interest were entered as covariates for each analysis. For example, baseline worry intensity was controlled for when analyzing change in worry intensity across time.

Older and younger adults identified three topics to think or worry about during the pleasant recall or worry induction. These topics are listed in Appendix E.

\section{Worry Intensity}

The mean worry intensity is graphed for each condition in Figures 2 and 3. Adjusted means are presented in Table 4.

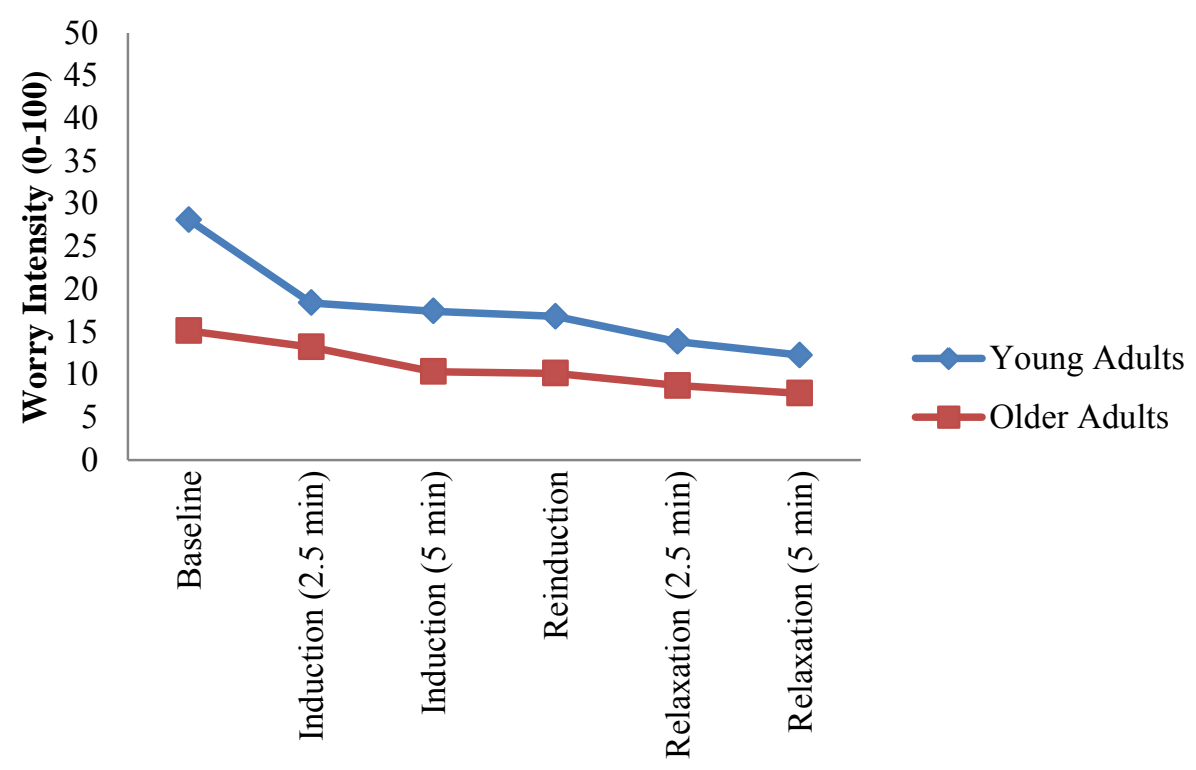

Figure 2. Mean Worry Intensity Rating for Pleasant Recall 


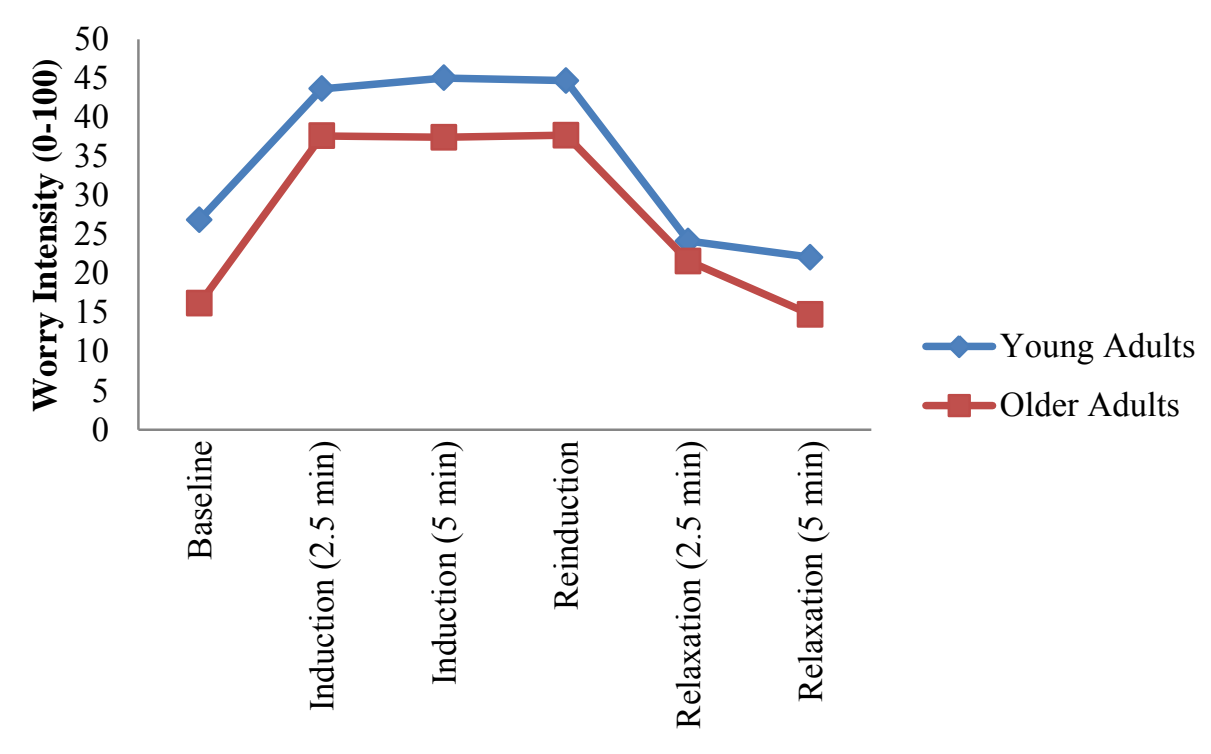

Figure 3. Mean Worry Intensity Rating for Worry Induction

Effect of age and worry/pleasant recall induction. To address the question of the effects of worry and pleasant recall inductions on worry intensity (research question 1) and the effects of age group on worry intensity (research question 3), a repeated measures analysis of covariance analysis (ANCOVA) was conducted with worry intensity as the dependent variable. Specifically a 2 (Age: Younger and Older Adults) x 2 (Induction: Worry and Pleasant Recall) x 2 (Time: Mid-induction/2.5-min, Post-induction/5-min) mixed-model ANCOVA was employed, with sex and baseline worry intensity entered as covariates. A main effect of condition emerged, $F(1,98)=85.93, p<.001$, partial $\eta^{2}=.47$. An inspection of the means demonstrated that the worry reported greater worry intensity than the pleasant recall, which was the focus of the first research question.. No significant effects of age or time emerged. Additionally, no interactions between variables were significant. These findings demonstrate that the worry induction was effective even after baseline ratings were controlled. The two experimental conditions resulted in a robust experimental manipulation, accounting for about $32 \%$ of the variance. To answer the 
third research question, the absence of a main effect or interaction including the variable of age suggests that older and younger adults do not differ in their worry intensity in response to a worry induction.

\section{Worry/pleasant recall induction and age group differences after relaxation. The} purpose of research question two was to examine the extent to which relaxation following a worry induction or pleasant recall induction affects worry intensity. The fourth research question addressed whether younger and older adults differed in worry intensity following relaxation. A mixed 2 (Age: Younger and Older Adults) x 2 (Induction: Worry and Pleasant Recall) x 3 (Time: Re-induction, Mid-Relaxation/2.5-min, Post-Relaxation/5-min) ANCOVA was conducted to answer research questions two and four. Sex and baseline worry intensity were entered as covariates. Mauchly's test indicated that the assumption of sphericity had been violated $\left(\chi^{2}(2)=\right.$ $35.44, p<.001)$; therefore degrees of freedom were corrected using Greenhouse-Geisser estimates of sphericity $(\varepsilon=.77)$. A significant main effect of time $(F(1.53,151.91)=14.69, p<$ .001 , partial $\left.\eta^{2}=.13\right)$, and condition $\left(F(1.53,151.91)=46.00, p<.001\right.$, partial $\left.\eta^{2}=.32\right)$ emerged. Additionally, a significant condition by time interaction emerged, $F(1.53,151.91)=$ 48.47, $p<.001$, partial $\eta^{2}=.33$.

Follow-up simple effects analyses demonstrated that for the pleasant recall condition, worry intensity was significantly reduced at the post-relaxation period compared to the reinduction period (See Figures 2 and 3). All MAACL-R means are present in Table 4. Additionally, worry intensity in the worry condition was greater than pleasant recall across all three time points. For the worry condition, worry intensity significantly decreased from the reinduction to mid-relaxation to post-relaxation. With regard to the second research question, worry intensity was greater for the worry condition than the pleasant recall condition across the 
three time points. For the worry induction group, worry intensity during relaxation decreased significantly from re-induction to mid-relaxation and from mid-relaxation to post-relaxation. In contrast, worry intensity decreased from re-induction to post-relaxation for the pleasant recall group. In sum, it appears that the relaxation induction was effective in reducing worry intensity for the pleasant recall condition and for the worry condition. Worry intensity decreased more for the worry induction than for the pleasant recall condition. With regard to answer research question four, no age difference in worry intensity was found for the worry or pleasant recall inductions.

\section{Self-Reported Arousal}

SAM self-reported arousal ratings for the pleasant recall group and worry induction group are demonstrated in Figures 4 and 5. Adjusted means are presented in Table 4.

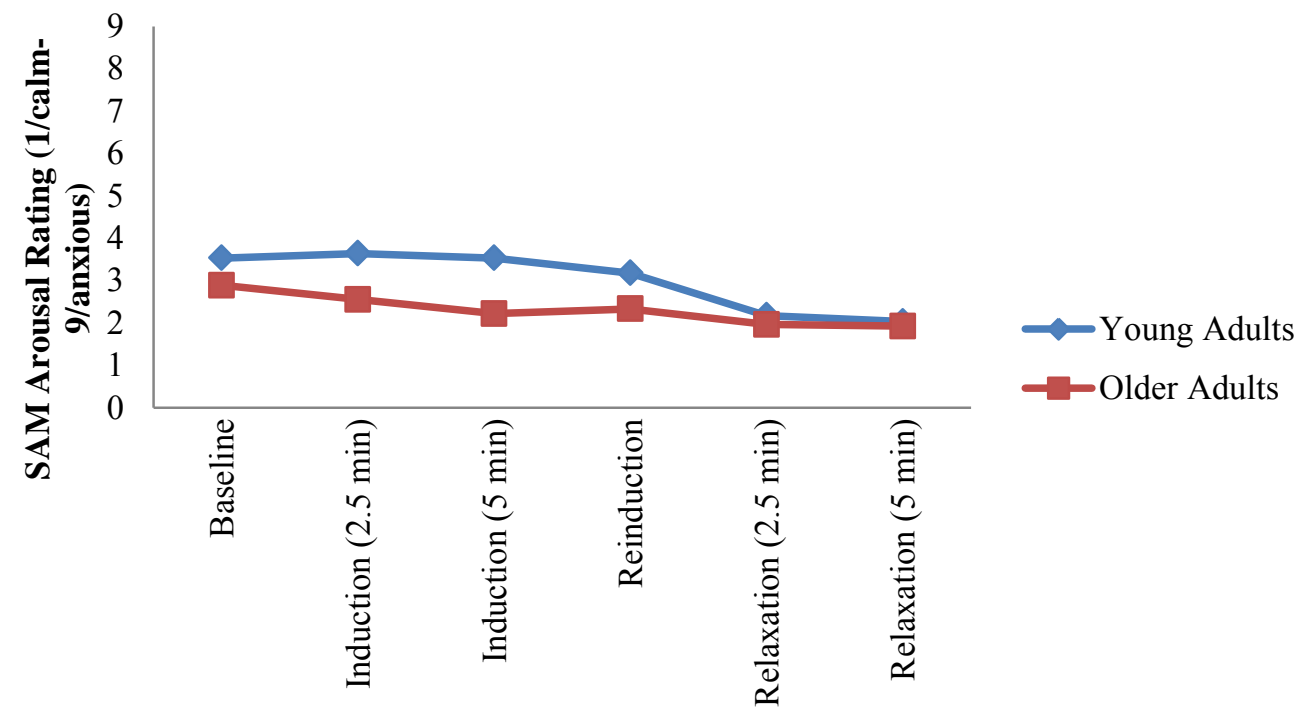

Figure 4. Mean Self-Assessment Maniken (SAM) Rating for Pleasant Recall 


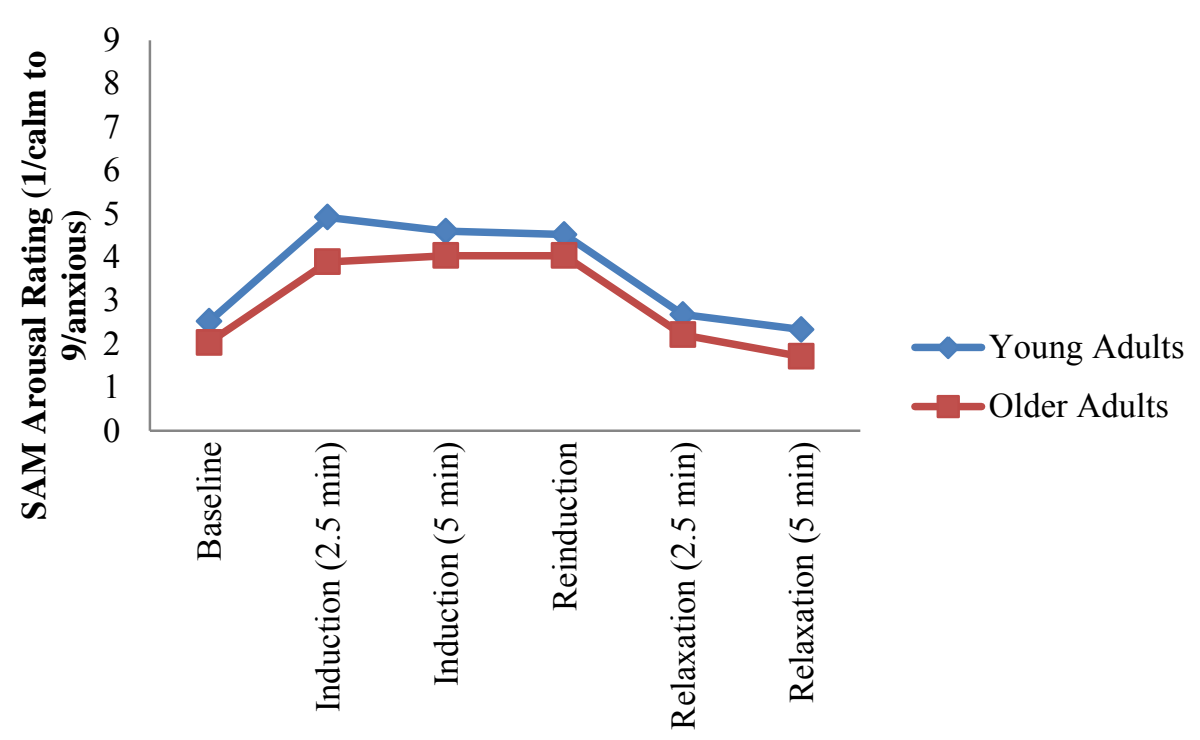

Figure 5. Mean Self-Assessment Maniken (SAM) Rating for Worry Induction

Effect of age and worry/pleasant recall induction. The fifth research question addressed whether the worry or pleasant recall inductions differed in their effects on selfreported arousal, as measured by the SAM arousal item. Research question seven addressed whether younger and older adults differed in self-reported arousal during the inductions. To answer research question five and seven, a repeated measures ANCOVA was conducted with the SAM arousal item as the dependent variable. Specifically a 2 (Age: Younger and Older Adults) $\mathrm{x}$ 2 (Induction: Worry and Pleasant Recall) x 2 (Time: Mid-Induction/2.5-min, Post-induction) mixed-model analysis of covariance (ANCOVA) was employed with sex and baseline selfreported arousal entered as covariates. A significant between-subjects main effect of condition was found, $F(1,102)=31.73, p<.001$, partial $\eta^{2}=.24$. With regard to research question five, individuals in the worry condition reported higher arousal ratings compared to individuals in the pleasant recall condition, as was hypothesized. A significant between-subjects main effect of age emerged, $F(1,102)=5.66, p=.02$, partial $\eta^{2}=.05$. Regardless of experimental condition and 
across time, younger adults reported higher arousal ratings compared to older adults. With regard to research question seven, younger adults reported greater arousal, as measured with the SAM, than older adults. No interaction of experimental condition and age was found.

\section{Worry/pleasant recall induction and age group differences after relaxation.}

Recovery during relaxation was measured using self-reported arousal. The extent to which relaxation affects self-reported arousal for the worry and pleasant recall induction conditions was addressed in research question six. Then, in the eighth research question, age differences in arousal after relaxation were examined. A mixed model repeated measures ANCOVA was conducted on self-reported arousal to address research questions six and eight. Specifically, a 2 (Age: Younger and Older Adults) x 2 (Induction: Worry and Pleasant Recall) x 3 (Time: Reinduction, Mid-Relaxation/2.5-min, Post-Relaxation/5-min) ANCOVA was conducted. Sex and baseline self-reported arousal were entered as covariates. Mauchly's test indicated that the assumption of sphericity had been violated $\left(\mathrm{X}^{2}(2)=44.86, p<.001\right)$; therefore degrees of freedom were corrected using Greenhouse-Geisser estimates of sphericity $(\varepsilon=.74)$. Two significant main effects were found for time $\left(F(1.47,148.37)=10.62, p<.001\right.$, partial $\left.\eta^{2}=.12\right)$, and condition $\left(F(1.47,148.37)=20.90, p<.001\right.$, partial $\left.\eta^{2}=.17\right)$. A significant interaction of condition and time emerged as well, $F(1.47,148.37)=18.63, p<.001$, partial $\left.\eta^{2}=.21\right)$. Simple effects analyses tested the effects of condition across time. Participants in the pleasant recall condition reported a significant decrease in arousal from re-induction to mid-relaxation. Additionally, post-relaxation arousal was significantly lower than re-induction arousal, but midand post-relaxation did not significantly differ. In contrast, significant reductions in arousal were reported by participants in the worry condition across the three time points. Significant differences for worry and pleasant recall were observed at re-induction and at mid-relaxation, but 
the two conditions did not differ at post-relaxation. With regard to research question six, arousal was greater for the worry group at re-induction and at mid-relaxation, but there were no differences observed after relaxation was completed. With regard to research question eight, no effects of age emerged.

\section{Heart Rate}

The ninth research question was addressed by examining the effects of a worry induction or pleasant recall induction on HR. Then, the extent to which older and younger adults differed in HR during a worry or pleasant recall induction was addressed in research question 11 . The focus of research questions 10 and 12 was to investigate the effects of relaxation on HR for the two conditions and for the two age groups. All four research questions (9-12) were examined using a 2 (Age: Younger and Older Adults) x 2 (Induction: Worry and Pleasant Recall) x 2 (Time: Induction, Relaxation) mixed model ANCOVA. Two covariates, sex and baseline HR, were entered as well. A significant main effect of age emerged, $F(1,98)=8.24, p=.005$, partial $\eta^{2}=.078$, such that younger adults had higher average HRs compared to older adults. Adjusted means are presented in Table 4. With regard to research question nine, no effect of induction on HR was found. With regard to questions 11 and 12, an age difference in average HR was found, such that older adults had lower HR than younger adults across time and across experimental conditions. No effects of experimental condition on HR were found with regard to research questions nine and 10. HRV data will be presented as exploratory analyses at the end of the results section.

\section{Anxiety, Depression, Hostility, and Positive Affect}

The thirteenth research question was addressed by examining the effects of worry or pleasant recall induction on four emotions (anxiety, depression, hostility, and positive affect). 
The extent to which older and younger adults experience different emotions during the worry or pleasant recall conditions was addressed in research question 14. After the two inductions, a relaxation period was conducted. The purpose of research questions 15 and 16 was to examine the effects of relaxation on emotions for each induction and for both age groups. To examine these four research questions, a repeated measures multivariate analysis of covariance (MANCOVA) was conducted. Four subscales of the MAACL-R (anxiety, depression, hostility, and positive affect) served as the dependent variables. Specifically, a 2 (Age: Younger and Older Adults) x 2 (Induction: Worry and Pleasant Recall) x 2 (Time: Induction and Relaxation) repeated MANCOVA was conducted on four subscales of the MAACL-R. Covariates were sex and participant's baseline ratings of emotions (MAACL-R anxiety, MAACL-R depression, MAACL-R hostility, and MAACL-R positive affect subscales). The assumption of equality of covariance matrices was violated, as Levene's Test was significant for all four dependent variables. As sample sizes are roughly equal, the Pillai-Bartlett trace is reported. Bray and Maxwell (1985) concluded that the Pillai-Bartlett trace is the most robust multivariate statistic when assumptions are violated. A significant main effect of condition emerged, (Pillai's Trace V $(4,96)=15.89, p<.001$, partial $\eta^{2}=.40$. However, two significant interactions found may help explain the main effect of condition. First, the interaction of condition by time was significant, Pillai-Bartlett V $(4,96)=14.49, p<.001$, partial $\eta^{2}=.38$. Second, the interaction of age by condition was significant, Pillai’s Trace V $(4,96)=3.44, p=.01$, partial $\eta^{2}=.13$. Adjusted means are presented in Table 4. 
Table 4. Adjusted Means and Standard Deviations for Induction and Relaxation Periods

\begin{tabular}{|c|c|c|c|c|c|c|c|c|}
\hline \multirow[t]{3}{*}{ Condition } & \multicolumn{4}{|c|}{ Pleasant Recall } & \multicolumn{4}{|c|}{ Worry } \\
\hline & \multicolumn{2}{|c|}{ Younger } & \multicolumn{2}{|c|}{ Older } & \multicolumn{2}{|c|}{ Younger } & \multicolumn{2}{|c|}{ Older } \\
\hline & Induction & Relaxation & Induction & Relaxation & Induction & Relaxation & Induction & Relaxation \\
\hline Worry Intensity & $13.70(2.88)$ & $12.49(2.99)$ & $18.27(2.83)$ & $15.41(2.94)$ & $40.20(2.93)$ & $41.72(3.04)$ & $40.36(2.88)$ & $40.36(2.99)$ \\
\hline SAM & $3.25(.32)$ & $3.17(.33)$ & $2.50(.33)$ & $2.22(.34)$ & $5.04(.31)$ & $4.72(.33)$ & $4.24(.32)$ & $4.30(.33)$ \\
\hline \multicolumn{9}{|l|}{ MAACL-R } \\
\hline Anxiety & $.25(.30)$ & $.10(.16)$ & $.39(.30)$ & $.26(.16)$ & $3.34(.31)$ & $.57(.17)$ & $2.20(.30)$ & $.35(.16)$ \\
\hline Depression & $.18(.27)$ & $.10(.08)$ & $.03(.28)$ & $.07(.08)$ & $1.05(.29)$ & $.19(.08)$ & $1.18(.27)$ & $.19(.08)$ \\
\hline Hostility & $.44(.30)$ & $.12(.13)$ & $-.001(.31)$ & $.02(.13)$ & $1.50(.31)$ & $.18(.13)$ & $1.50(.30)$ & $.27(.13)$ \\
\hline Positive Affect & $11.11(.98)$ & $10.06(.77)$ & $10.72(1.00)$ & $10.66(.79)$ & $5.54(1.03)$ & $8.54(.81)$ & $5.04(.99)$ & $9.47(.78)$ \\
\hline $\operatorname{HR}(N=104)$ & $72.90(.63)$ & $73.46(.77)$ & $72.02(.67)$ & $71.42(.82)$ & $73.53(.66)$ & $74.95(.81)$ & $71.50(.66)$ & $72.40(.80)$ \\
\hline $\begin{array}{l}\text { Ln-transformed } \\
\text { HRV }(N=75)\end{array}$ & $5.82(.17)$ & $6.24(.19)$ & $5.38(.18)$ & $5.26(.20)$ & $5.83(.19)$ & $6.02(.21)$ & $5.77(.19)$ & $5.88(.21)$ \\
\hline
\end{tabular}

Estimated marginal means and standard errors are displayed in each cell. 
Follow-up ANCOVAs were conducted to explore the significant age by condition interaction. First, a 2 (Age: Younger and Older Adults) x 2 (Induction: Worry and Pleasant Recall) $x 2$ (Time: Induction and Relaxation) ANCOVA was conducted on the anxiety subscale of the MAACL-R. Sex and baseline anxiety subscale scores were entered as covariates. A significant within-group effect of time demonstrated that anxiety decreased from the end of the induction to the end of the relaxation, $F(1,102)=11.54, p=.001$, partial $\eta^{2}=.10$. A significant main effect of condition $\left(F(1,102)=60.14, p<.001\right.$, partial $\left.\eta^{2}=.37\right)$ was found. These main effects are clarified by two two-way interactions. The interactions are displayed in Figure 6. First, a significant interaction of condition by time emerged, $F(1,102)=53.06, p<.001$, partial $\eta^{2}=.34$. A simple main effects analysis demonstrated that individuals in the worry induction reported greater anxiety compared to the pleasant recall induction. However, no group differences remained after the relaxation period. A second two-way interaction emerged between age and condition, $F(1,102)=5.89, p=.02$, partial $\eta^{2}=.06$. Simple main effects analyses demonstrated that younger adults reported greater anxiety than older adults in the worry condition, but no age differences in anxiety emerged during the pleasant recall condition. This demonstrates differential experiences of anxiety during worry for older and younger adults.
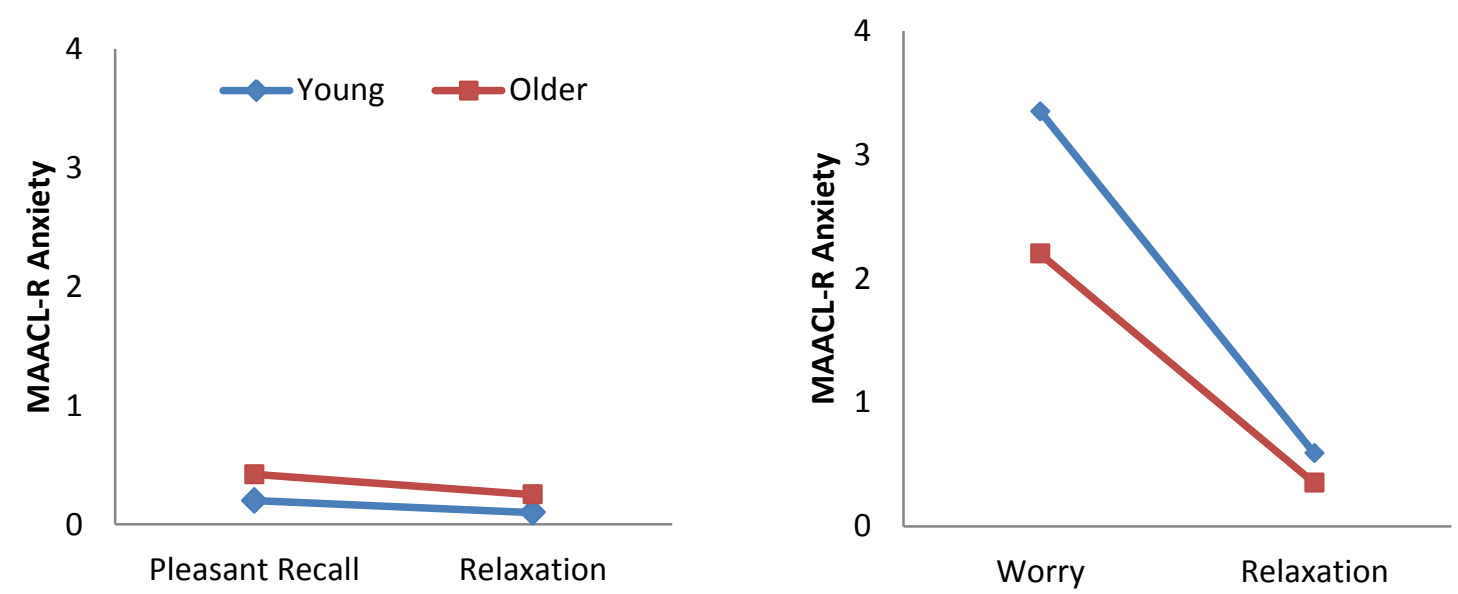

Figure 6. Interactions of condition and age and condition and time on MAACL-R anxiety. 
The second follow-up analysis to the MANCOVA was a mixed model repeated measures 2 (Age: Younger and Older Adults) x 2 (Induction: Worry and Pleasant Recall) x 2 (Time: PostInduction and Post- Relaxation) ANCOVA conducted on the MAACL-R depression subscale. Covariates were sex and baseline depression on the MAACL-R. A significant main effect of time, $F(1,102)=4.29, p=.04$, partial $\eta^{2}=.04$, and condition, $F(1,102)=14.88, p<.001$, partial $\eta^{2}=.13$, were found. A significant condition by time interaction emerged, $F(1,102)=$ 11.54, $p=.001$, partial $\eta^{2}=.10$. The interactions are displayed in Figure 7. Follow-up simple main effects analyses demonstrated that post-induction depression and post-relaxation depression did not differ for the pleasant recall induction group. However, after the worry induction, individuals reported significantly greater depression than individuals in the pleasant recall induction reported. Thus, depression was greater in the worry condition than the pleasant recall condition regardless of age.
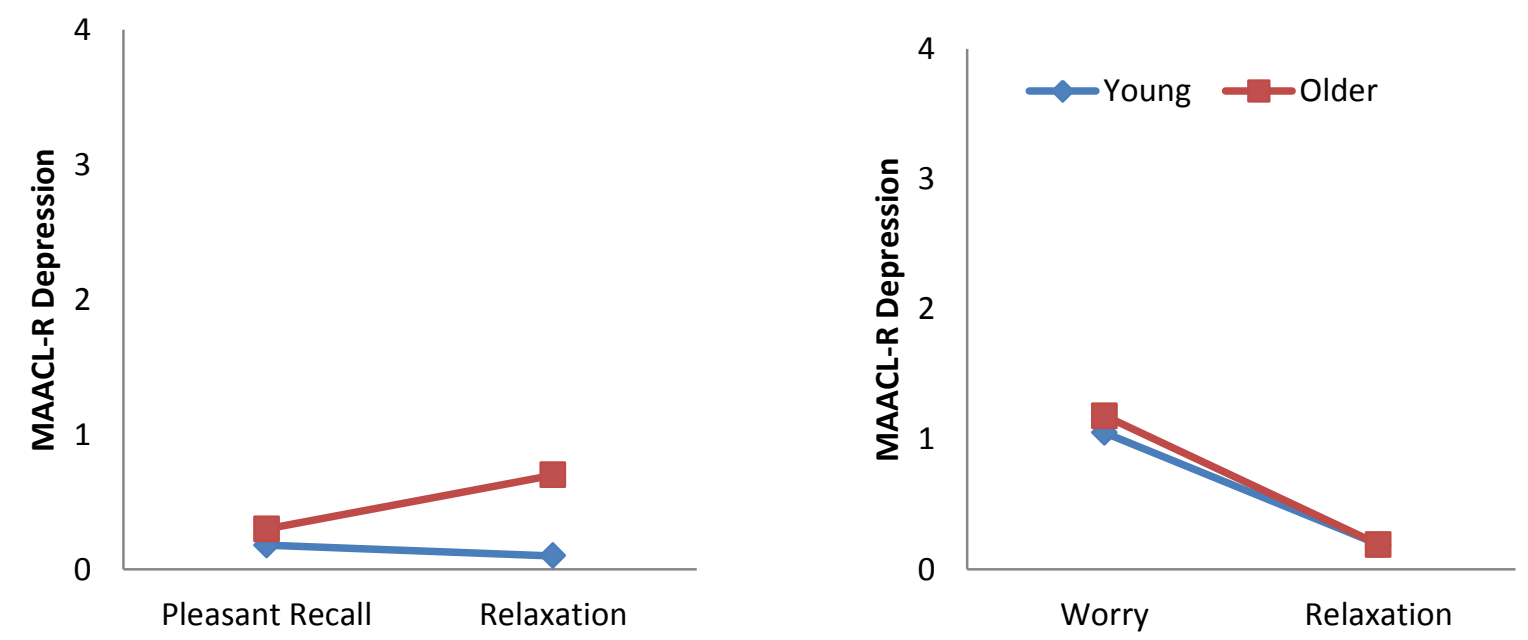

Figure 7. Interaction of induction condition and time for depression.

Third, a mixed model repeated measures 2 (Age: Younger and Older Adults) x 2 (Induction: Worry and Pleasant Recall) x 2 (Time: Post-Induction and Post- Relaxation) 
ANCOVA was conducted on the MAACL-R hostility subscale. Sex and baseline hostility scores were covariates. Again, a significant main effect of time, $F(1,102)=4.63, p=.03$, partial $\eta^{2}=$ .04 , and condition, $F(1,102)=15.95, p<.001$, partial $\eta^{2}=.14$, emerged. Furthermore, a significant condition by time interaction was found, $F(1,102)=12.59, \mathrm{p}<.001$, partial $\eta^{2}=.11$. This interaction is displayed in Figure 8. Simple main effects analyses demonstrated that participants experienced greater hostility post-induction, but this was reduced after relaxation. No difference in hostility ratings were found for the pleasant recall group. Hostility was greater following the worry induction than the pleasant recall induction regardless of age.
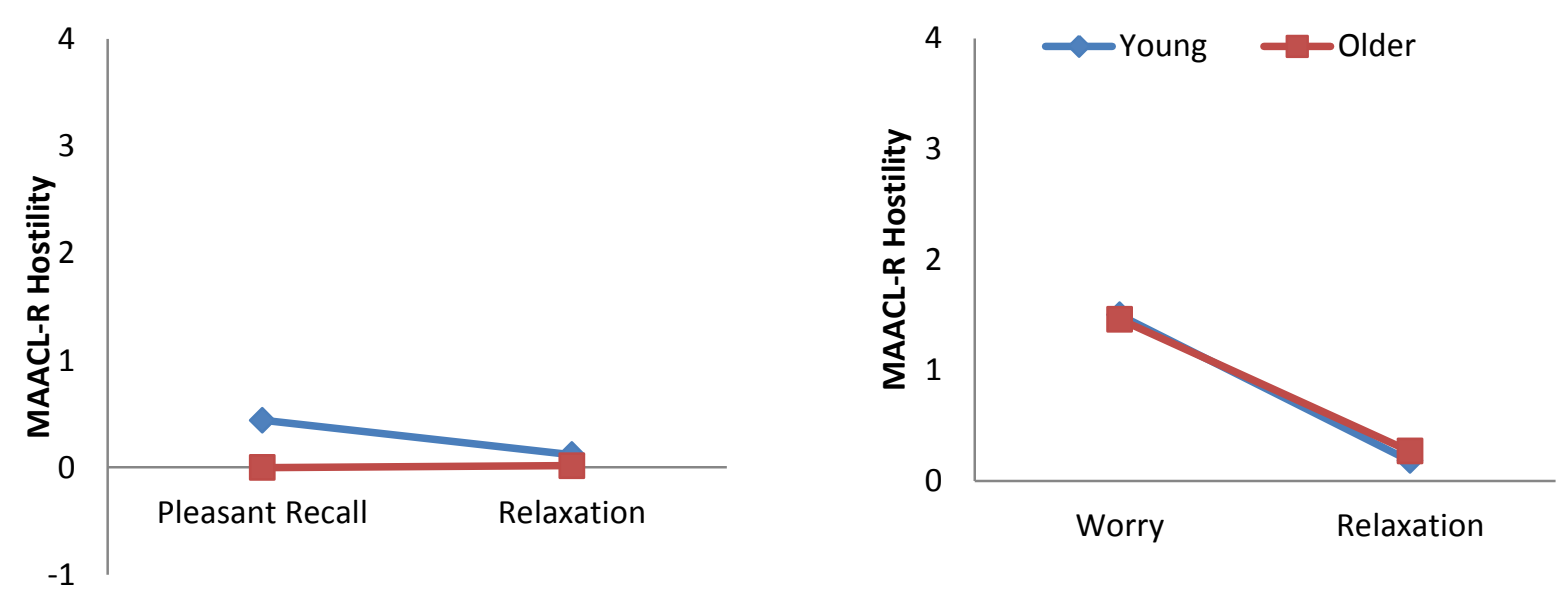

Figure 8. Interaction of induction condition and time on hostility.

The fourth analysis was a mixed model repeated measures 2 (Age: Younger and Older Adults) x 2 (Induction: Worry and Pleasant Recall) x 2 (Time: Post-Induction and PostRelaxation) ANCOVA conducted on the MAACL-R positive affect subscale. Sex and baseline positive affect were entered as covariates. A significant main effect for condition emerged, $F(1$, $102)=21.76, p<.001$, partial $\eta^{2}=.18$. This main effect is qualified by a significant condition by time interaction, $F(1,102)=24.44, p<.001$, partial $\eta^{2}=.19$. This interaction is displayed in 
Figure 9. Simple main effects analyses demonstrated that individuals in the worry condition experienced an increase in positive affect after the relaxation period. No differences across time were noted for the pleasant recall group. Also, greater positive affect was reported during the pleasant recall condition than during the worry condition. No effect of age was found.
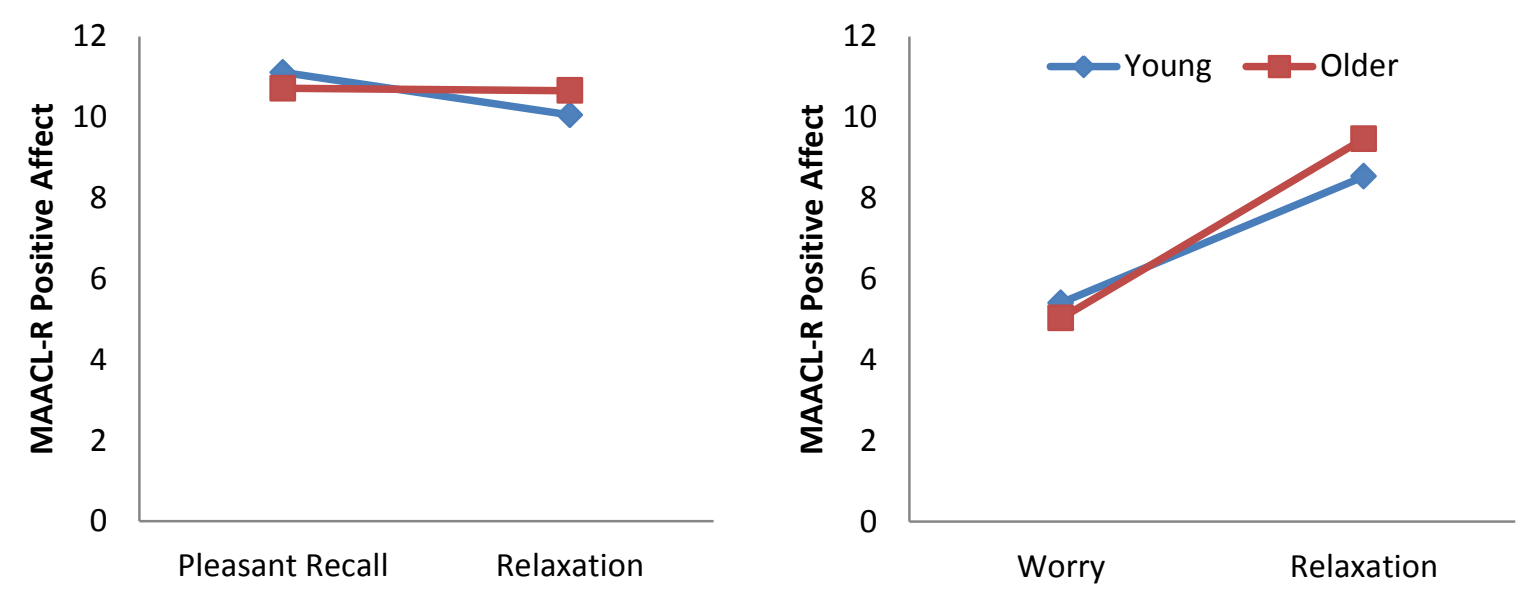

Figure 9. Interaction of induction condition and time on positive affect.

With regard to research question 13 , worry and pleasant recall inductions differentially affected emotions. Specifically, an increase in anxiety, depression, and hostility was observed for the worry induction. Research question 14 aimed to address the effects of relaxation after each induction. It appears that relaxation did not affect emotions experienced by the pleasant recall group, but a decrease in anxiety, depression, hostility, and increase in positive affect were found for the worry induction. Levels of positive affect decreased during the worry induction as well. With regard to research question 15, younger and older adults experienced similar degrees of depression, hostility, and positive affect during the inductions. However, younger adults appear to have experienced greater anxiety during the worry condition than older adults. With regard to research question 16 , no age differences in emotions following relaxation were found.

\section{Post-Experiment Questionnaire}


After the completion of the relaxation period, participants were asked to rate how similar the thinking (pleasant recall or worry) induction was compared to their everyday thinking or worrying. Ratings were made on a scale ranging from 1 (very untrue) to 7 (very true). A 2 (Age: Younger and Older Adults) x 2 (Induction: Worry and Pleasant Recall) ANOVA was conducted on responses to this item. A main effect of condition was found, $F(1,104)=6.55, p=.01$, partial $\eta^{2}=.06$, which suggests that the participants in the pleasant recall condition found the thinking to be more similar to their everyday thinking compared to individuals in the worry condition. This main effect was clarified by a significant age by condition interaction, $F(1,104)=4.94, p=$. 03 , partial $\eta^{2}=.05$. The response scale ranged from 1 (not at all similar) to 7 (very similar) to everyday thinking or worrying. Specifically, older adults found that the control condition was moderately similar to their everyday thinking $(M=5.44)$, but older adults reported that the worry condition $(M=3.96)$, was less similar to their everyday worrying. In contrast, younger adults found that both the pleasant recall $(M=4.46)$ and worry conditions $(M=4.36)$ were moderately similar to their everyday thinking or worrying.

At the end of the study, participants were presented with the following statement and asked to rate using a Likert-type scale how true (7) or untrue (1) the statement was for them: "I attempted to follow the induction instructions." A 2 (Age: Younger and Older Adults) x 2 (Induction: Worry and Pleasant Recall) ANOVA was conducted on responses to this item. There were no significant main effects or interactions found. Both experimental groups reported that it was true that they attempted to follow the instructions $\left(M_{\text {worry }}=6.62, M_{\text {pleasant }}=6.41\right)$.

\section{Exploratory Analyses}

Exploratory analyses were conducted to determine if age or induction had any effects on heart rate variability (HRV). HRV is measured using HF Power, which was ln-transformed to 
create a normal distribution. Four participants were excluded as their HRVs were univariate outliers greater than three SDs from the mean at baseline. A 2 (Age: Younger and Older Adults) x 2 (Induction: Worry and Pleasant Recall) x 2 (Time: Induction, Relaxation) mixed model ANCOVA was conducted on log-transformed HF Power. A significant main effect of age was found, $F(1,69)=4.71, p=.03$, partial $\eta^{2}=.06$. This main effect was qualified by a significant age by condition interaction, $F(1,69)=4.05, p=.05$, partial $\eta^{2}=.06$. Interaction is displayed in Figure 6. Simple effects analyses were conducted. An effect of condition on HF Power was evident for older adults, but not for younger adults. Specifically, older adults had significantly greater HF Power in the worry condition than the pleasant recall condition. Adjusted means are displayed in Table 4.
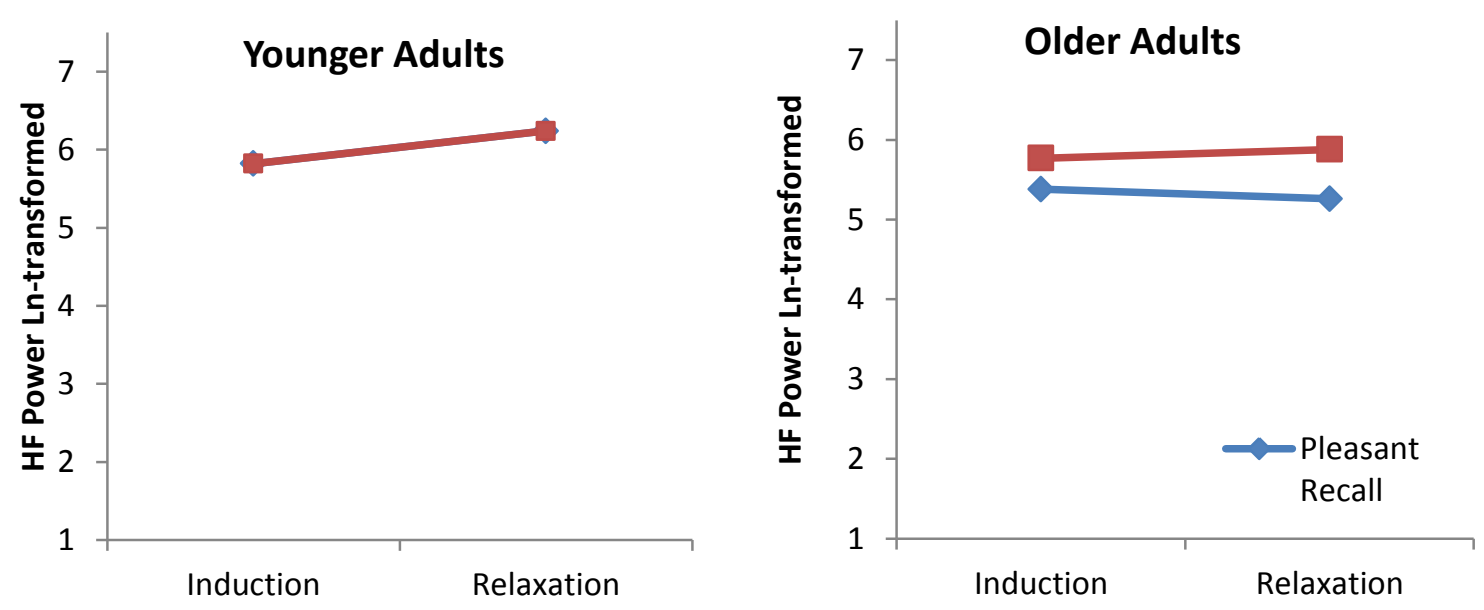

Figure 10. Interaction of Age and Condition on HF Power (Ln-transformed)

\section{Discussion}

Worry can be disabling for older adults, yet their experience of worry is not well understood. Most research on late life anxiety consists of treatment studies (e.g., Stanley et al., 2009) or non-experimental studies that rely solely on self-report measures. The present study 
appears to be the first to use an experimental manipulation of worry with an older adult sample. A strength of the present study is that the manipulation was idiographic, such that each individual identified his or her three main concerns for the worry manipulation or three pleasant (or neutral) activities in which one engaged during the past week. This design eliminates the need to provide stimuli that are content valid for both older and younger adults. Both age differences and group differences due to the experimental manipulation were found. A discussion of these results and their implications for lifespan developmental theories of emotion follows.

\section{Age Differences at Baseline}

Before reviewing the results of the primary analyses, it is important to consider age and sex differences present prior to the experiences. Younger adults reported greater stress, anxiety, depression, and worry than older adults reported on the baseline assessment measures. After a brief resting baseline, worry intensity, arousal, and emotions were measured again. In addition to greater trait levels of anxiety and depression, younger adults reported higher state levels of anxiety, depression, and hostility, and less positive affect than older adults. Meanwhile, older adults scored lower on a brief cognitive assessment. Thus, younger adults have higher rates of symptoms of anxiety, depression, and stress, yet their cognitive functioning may be sharper. These findings are consistent with those of previous studies (e.g., Gould \& Edelstein, 2010; Hunt et al., 2003), and with theoretical accounts of increased emotion regulation in late adulthood. The present study's finding of greater well-being among older adults support Socioemotional Selectivity Theory (SST). SST presents the notion that older adults are motivated by emotionfocused goals and engage in situations that enhance positive affect and minimize negative affect. Meanwhile, younger adults are more motivated by information-seeking goals. Another 
interesting age difference at baseline emerged. Younger adults reported greater self-reported arousal and greater worry intensity at baseline. To accompany higher subjective ratings of the various symptoms, younger adults had higher average HR and greater HRV. In a recent review of older adults' physiological reactivity, Uchino, Birmingham, and Berg (2010) indicated that older adults have lower maximal HRs. Due to the presence of an age difference at baseline, statistical analyses were used to account for any differences. Sex differences were evident at baseline. Women reported greater trait worry, hostility, anxiety, worry intensity, and greater selfreported arousal. The presence of greater hostility among women was unexpected, but is consistent with findings of previous research (Robinson, Brower, \& Gomberg, 2001). For example, Suarez (2008) examined sex differences in the relation between poor sleep and hostility and anger. Women who had difficulty falling asleep reported significantly more anger and hostility than men. This finding may suggest that when women have increased distress (as evidenced in the present study by increased anxiety, worry, and arousal), they experience greater hostility. As evidenced by the present study's findings, affective symptoms may vary significantly among men and women. In the present study, sex and baseline measures were included as covariates in each analysis to account for these differences.

\section{Primary Research Questions}

The purpose of the present study was to conduct a multi-method assessment of the experience of worry among older and younger adults. Experimental inductions of worry are effective in creating a worrisome state (e.g., Borkovec et al., 1983); however, worry has not been induced with an older adult sample to date. In creating a worrisome state for older and younger adults in a controlled environment, we were able to directly examine age differences in worry intensity, self-reported arousal, anxiety, depression, hostility, positive affect, and HR. Older 
adults' ability to recover from a worrisome state during relaxation was also tested in the present study. Furthermore, a greater understanding of the worry experience in late life will inform the identification and treatment of worry.

Effects on worry intensity. As expected, worry intensity was greater during the worry induction compared to the pleasant recall induction; however, no age differences were found across either condition. Thus, the present study extends earlier work to an older adult sample that demonstrated the effectiveness of a worry induction in younger adults and individuals with GAD (e.g., Ruscio \& Borkovec, 2004). There is ample evidence from previous research that older adults are amenable to participating in laboratory tasks as long as the tasks are meaningful (e.g., Gruhn et al., 2005). Laboratory experiments, such as the present study, provide evidence about the experience of emotions in late life, which is important for geropsychologists.

The absence of an age difference in worry intensity (after controlling for baseline levels) for the worry and pleasant recall inductions has important implications. Although younger adults may worry more on an everyday basis, younger and older adults experience worry at a similar intensity. In a clinical setting, one must consider that older adults may experience anxiety and worry symptoms at subsyndromal levels due to lower baseline rates of these symptoms

The relaxation condition significantly reduced worry intensity for the worry induction group across all three time points, as was hypothesized. Contrary to our hypothesis, a reduction in worry intensity during relaxation for the pleasant recall induction was found as well. Nevertheless, after the focused breathing exercise was completed, greater levels of worry intensity were found for the worry induction compared to the pleasant recall induction. One explanation for this finding is that the relaxation procedure is not entirely effective. Perhaps if one practiced relaxation for a longer period, the effects of relaxation would be more robust. A 
longer relaxation period may have been needed for individuals who were worrying compared to those in the pleasant recall induction. The present findings demonstrate that a simple focused breathing exercise can significantly reduce experimentally-induced worry in a short amount of time (about 2.5 minutes) for both older and younger adults. The rapid reduction of experimentally-induced worry with focused breathing has important implications for the future study of older adult worry in the laboratory. The present study established that it is feasible to induce worry among older adults without lasting negative effects. The present study's results are consistent with findings of Scogin and colleagues (1992), who found that progressive muscle relaxation (PMR) and imagined PMR (without actual muscle tensing) were effective for a sample of older adults. The effectiveness of a brief intervention in reducing worry is important for clinicians who seek to teach older adults how to rapidly decrease their worrying. Furthermore, the findings of the present study are consistent with findings of CBT with older adults (e.g., Stanley et al., 2009).

Effects on self-reported arousal. Worrying is conceptualized as a cognitive avoidance strategy, in which one attempts to avoid physiological arousal (Borkovec et al., 2004). Consequently, it is important to measure the effects of worrying on both self-reported arousal and objectively measured physiological arousal. In the present study, self-reported arousal, as measured by the SAM arousal item, was higher in the worry induction than the pleasant recall induction, as was expected. Consistent with the findings from tests of the Cognitive Avoidance Theory, worrying is associated with subjective arousal. Evidence of a suppression in physiological arousal was not found in the present study. Furthermore, the present study was not a direct test of the Cognitive Avoidance Theory. In a direct test of the Cognitive Avoidance Theory, one particular anxiety-evoking stimulus, such as imagining being victimized or giving a 
public speech, would be selected. Then, participants would be asked to worry about the stimulus or imagine it. Evidence of a reduction in HR or HRV during the induction period would provide evidence in support of Cognitive Avoidance Theory.

As one ages, the magnitude of physiological arousal associated with emotions may decrease, but the actual response pattern does not change (Levenson, 2000). The present study's finding of an age difference in arousal independent of experimental condition is consistent with Levenson's account of emotion in late life. Older adults reported lower rates of self-reported arousal throughout the worry and pleasant recall condition. In addition to greater subjective arousal, younger adults also had faster HR and greater HRV.

Relaxation significantly reduced self-reported arousal for the worry induction, as was hypothesized. An unexpected reduction in arousal occurred for the pleasant recall induction as well. However, arousal decreased at a faster rate for the worry induction than the pleasant recall induction. Thus, the present study demonstrates that focused breathing is an effective intervention for rapidly decreasing both worry intensity and self-reported arousal. The findings of the present study are consistent with a large body of evidence supporting relaxation (e.g., progressive muscle relaxation) as a treatment for worry (e.g., Carter, Johnson, \& Borkovec, 1986), and as a means of reducing subjective anxiety to an anxiety-arousing stimulus (e.g., public speaking; Hazlett-Stevens \& Borkovec, 2001).

Age differences in recovery were examined by determining whether older and younger adults differed in their self-reported arousal after relaxation. During the worry and pleasant recall inductions, younger adults reported greater arousal compared to older adults. After relaxation, older and younger adults' self-reported arousal did not differ. Therefore, the age differences present during the inductions lessened following the focused breathing task, as no age effect was 
found. One possible explanation for this finding is that younger adults experienced greater reductions in subjective arousal, which eliminated the main effect found during the inductions. Alternatively, relaxation may have been less effective for older adults, which could have eliminated the age difference. Regardless of the explanation, there is an age difference in recovery, such that younger adults experienced a greater decline in subjective arousal compared to older adults.

HR and HRV. At baseline, age differences in HR and HRV were evident. Younger adults had higher average HRs and greater HRV, consistent with previous findings (for a review of age differences in psychophysiology see Uchino et al., 2010; Lau, Edelstein, \& Larkin, 2001). Older adults have lower resting HR and lower HRV due to age-related changes in physiology and in cardiovascular system structures (Uchino et al., 2010). In an attempt to obtain healthy older adults for the present study, stringent exclusion criteria were applied to the present sample to exclude participants taking medications that could affect HRs and participants with past or current heart conditions. Despite the exclusion criteria, older adults in the present study had greater BMIs, which are independent predictors of cardiovascular disease (e.g., Eckel, 1997). Additionally, the older adults were more likely to have parental history of coronary heart disease or myocardial infarction. Younger adults' parents are likely to be younger and consequently, the parents probably have not yet developed coronary heart disease, which could account for this age difference in parental history of certain medical conditions. Younger adults had higher average HRs than older adults regardless of stage of the experiment. The age difference in objectively measured HR parallels an age difference found for subjective arousal in the present study. In the present study, older adults had lower magnitudes of subjective and objective arousal, which is 
consistent with Levenson's (2000) premise that older adults are less physiologically reactive than younger adults, but the pattern of reactivity is the same.

Contrary to our hypotheses that the worry induction would result in greater HR compared to a pleasant recall induction and relaxation, HR did not differ across the worry or pleasant recall inductions, or during the relaxation condition. Previous studies with younger adult samples found that HR was greater during a worry induction compared to a neutral induction, baseline, or relaxation (e.g., Hazlett-Stevens \& Borkovec, 2001; Peasley-Miklus \& Vrana, 2000). One explanation for the absence of an effect on HR in the present study is that the induction differed from that of previous studies, which presented participants with a specific task (e.g., a speech; Hazlett-Stevens \& Borkovec, 2001) or an image (e.g., victimization, Peasley-Miklus \& Vrana, 2000) to worry about. For example, Peasley-Miklus and Vrana (2000) found that worrying about victimization resulted in lower HR when compared to imagining victimization. The authors also found that participants had greater HR during relaxation compared to the worry induction. Peasley-Miklus and Vrana's findings support the Cognitive Avoidance Theory of worry in that worrying resulted in a brief reduction in physiological arousal. Worrying uses verbal descriptions rather than images, which are associated with greater HR and arousal. Thus, comparing worrying to a condition in which fear was induced through imagery may be important in establishing a relation between worrying and a reduction in HR (e.g., Thayer et al., 1996; York et al., 1986).

One other explanation for the absence of an effect of induction on HR is that a pleasant recall condition was employed in the present study. The pleasant recall condition might not have been an adequate control condition for HR. Another difference between the present study and previous studies is that baseline HR was statistically covaried in the present study, but was not included as a covariate in most other studies. By controlling for baseline HR, we eliminated a 
significant amount of variance, which resulted in a smaller range of HR within which differences could be detected.

An examination of age and condition differences in HRV yielded interesting findings. Baseline age differences emerged such that younger adults had greater HF Power than older adults. HF Power has been found to decrease with age in other studies as well (Stein, Kleiger, \& Rottman, 1997). Older age is associated with a decrease in parasympathetic-mediated indices of HRV, such as HF power. Furthermore, low levels of HRV are a risk factor for cardiovascular disease (see Thayer, Yamamoto, \& Brosschot, 2010 for a review). In addition to baseline differences in HF Power, a significant effect of condition was found for older adults, but not for younger adults. That is, older adults who participated in the worry condition had greater HF Power compared to those who participated in the pleasant recall condition. This finding of greater HF Power during worry does not support the hypotheses set forth. Worrying was expected to be associated with low levels of HF Power, which has been demonstrated in multiple experimental studies (e.g., Davis et al., 2002; Thayer et al., 1996; Verkuil, Brosschot, Borkovec \& Thayer, 2009).

In contrast to the expected results, the present study's findings provide evidence of older adults experiencing increased parasympathetic activity during worrying. In a subset of their sample, Verkuil et al. found that women with depression also experienced an increase in HF Power during worrying compared to relaxation. The authors suggest that the increase in HF Power may reflect an underlying regulation strategy that may be aimed to minimize or eliminate the experience of negative thoughts and mood. For example, greater controlled respiration increases HF Power (Malliani, Lombardi, \& Pagani, 1994). Greater HRV is associated with increased emotion regulation as well (Thayer \& Lane, 2000). Thus, it is possible that older adults 
may be more engaged in emotion regulation strategies during the worry condition than during pleasant recall. Their sustained efforts in managing their worrisome thoughts may result in greater HRV and thus lower levels of subjective arousal, as was demonstrated by the SAM. In sum, the finding of older adults experiencing greater HF Power during worry was unexpected, but it may fit with life-span developmental accounts of emotions.

\section{Self-reported emotions: anxiety, depression, hostility, and positive affect. As} hypothesized, worry generated greater self-reported anxiety and depression and lower positive affect. Participants also reported greater hostility during worry compared to pleasant recall. These results suggest that worry is experienced as a mix of anxiety, depression, hostility, and low positive affect. The present study is the first study to demonstrate a causal relation between worry and anxiety, depression, and hostility with older adults. These findings replicate and extend results from studies of younger adults (e.g., Andrews \& Borkovec, 1988; Behar et al., 2005; McLaughlin et al., 2007a) in which worry inductions generated depressed affect and anxiety. Similar to the findings of the present study, Andrews and Borkovec found that hostility was greater and positive affect was lower during worrying compared to baseline levels. Thus, worrying generates various negative emotions, which are characterized as negative affect. Previous studies found an association between high negative affect and low HRV (Bliel, Gianaros, Jennings, Flory \& Manuck, 2008). However, there is more to the picture than only negative affect. Worrying was associated with a decrease in positive affect, which is consistent with a tripartite model of emotion (e.g., Clark \& Watson, 1991). In the tripartite model of emotion, there are three factors that contribute to anxiety and depression: negative affect, physiological arousal, and low positive affect. The findings from the present study support the presence of these three factors in the experience of worry for both older and younger adults. 
Previous studies have generated support for the tripartite model in an examination of anxiety and depression symptoms among older and younger adults (Teachman, Siedlecki, \& Magee, 2007). However, the extent to which older and younger adults have physiological arousal in response to worry differs.

Interestingly, there were age variations in the experience of anxiety. Specifically, younger adults reported more anxiety than older adults during the worry induction. No age differences in the experience of depression, positive affect, or hostility during the worry or pleasant recall inductions were found. Three possible explanations are put forth to account for the finding of lower anxiety during worry among older adults. First, it is possible that older adults report less anxiety because they are experiencing lower arousal and have lower HRs compare to younger adults. On the other hand, older adults may experience lower HRs, and thus report less cognitive anxiety. Regardless of the direction of the relation between HR and anxiety, the tripartite theory (Clark \& Watson, 1991) and much research supports the notion that arousal is more closely related to anxiety than depression. Thus, the lower rates of arousal may account for lower rates of anxiety among older adults, but no differences in depression. This explanation is consistent with Levenson's (2000) conclusion that older adults have similar emotional experiences to younger adults, but have a lower magnitude of physiological arousal associated with emotional experience. A third possibility is that the older adults found the task to be less similar to their everyday worrying, as demonstrated by responses to the manipulation check questions. Since the task seemed to be less ecologically valid for the older adults, they may not have been as engaged in the worry induction as younger adults. A fourth possible explanation of the lower anxiety reported by older adults in the worry condition is that older adults identified worry topics that are less anxiety-provoking than worry topics identified by younger adults. Older adults may monitor 
their anxiety and arousal and keep their anxiety levels within a certain range of tolerability. This monitoring could be a form of antecedent-focused emotion regulation such as situation modification (Urry \& Gross, 2010).

Lifespan developmental theories (e.g., SST) suggest that older adults are motivated to reduce negative emotions and increase positive emotions. The present findings could be interpreted in light of SST. In this case, it may be that older adults select less anxiety provoking worry topics as a way of optimizing positive emotions and minimizing negative emotions in older adults' motivation toward emotion-focused goals. In contrast, younger adults may worry about topics that are aligned with their motivations to seek information-focused goals. One limitation to interpreting these data as support for SST, is that there is no explanation for possible age differences in arousal and/or tolerance of arousal. Schultz and Heckhausen (1997) might speculate that the secondary control processes may be playing a role in older adults' decreased experience of anxiety. Through secondary control processes, older adults could have opted to avoid more anxiety-provoking worries during the experiment.

A third possible explanation for the results is that older adults overly rely on affect optimization strategies, which is consistent with DIT. When using optimization strategies to regulate emotions, one may not experience complex emotions and may avoid challenging situations that require cognitive or affective complexity. Labouvie-Vief and colleagues suggest that due to declining cognitive and affective complexity most older adults have a self-protective regulation style. These individuals continue to experience negative affect and medium rates of positive affects accompanied by mastery of their environment. However, these individuals with a self-protective regulation style may have less empathy, less relationship security, and lower ratings of their own health. If older adults are self-protective, they may choose to minimize their 
anxiety through the selection of less arousing topics and these individuals may even manage their environments in order to avoid problems to worry about. This account is consistent with Urry and Gross's emotional regulation model (2010).

The present study has important clinical implications for the health and treatment of worry in older adults. First, it is evident that worry generates negative affect and increased selfreported arousal for older adults. Second, worry has been found to be a cardiovascular risk factor in previous research (Kubzansky et al. 1997). Moreover, previous research has found that the generation is related to lower HRV, which is a predictor of cardiovascular disease as well (Bleil et al., 2008). Thus, the link between worry and negative outcomes is strengthened. Worrying impairs one's quality of life in the short-term with the generation of affect, and in the long-term with an increased risk of medical problems. In addition to cardiovascular risk factors, anxiety symptoms, which can be generated from worrying, are associated with poor cognitive performance (Beaudreau \& O'Hara, 2009) and decreased functional status of older adults (Brenes et al., 2005). In the present study, relaxation was effective in reducing negative affect for older and younger adults in the worry condition. Any prior age differences in anxiety disappeared following the relaxation period. The effect of relaxation on negative emotions is consistent with a large body of research. For example, Scogin et al. (1992) found that progressive muscle relaxation (PMR) or imaginal PMR is effective for older adults. Decreases in anxiety symptoms were found after older widows were taught and practiced relaxation training with anxiety symptoms (DeBerry, 1982; 1989). Mindfulness interventions for anxiety and depression have a growing body of research support with younger adults (e.g., Hofman, Sawyer, Witt \& Oh, 2010). The present results demonstrate that a brief focused breathing task is an effective intervention to help older adults reduce negative emotions induced in the laboratory. 


\section{Conclusion}

The findings from the present study illuminate both similarities and differences in the experience of worry for older and younger adults. The main focus of the present study was to characterize the experience of worry among older adults. Older adults reported increased arousal during worry, but this arousal was not accompanied by greater HRs. After worrying, older adults experienced anxiety, depression, low positive affect, and hostility. Thus, the tripartite model fits older adults' experience of worry as worrying resulted in negative affect, low positive affect, and anxious arousal.

In addition to characterizing the experience of worry for older adults, it was important to compare older adults' experience of worry to that of younger adults. Age differences were found with regards to the experience of anxiety, such that younger adults reported greater anxiety than older adults during the worry induction. Regardless of induction condition, older adults reported less arousal and experienced lower HRs compared to younger adults. Importantly, older and younger adults did not differ in the intensity of their worry after baseline differences were controlled. Thus, it seems that older adults experience worry as less arousing and less-anxiety provoking compared to younger adults. However the relation between physiological arousal and worry among older adults is not well understood. Older adults may report lower anxiety in response to worrying as a function of experiencing decreased levels of arousal.

There are various explanations for the present study's finding of lower anxiety following worry for older adults. Older adults may engage in emotion regulation strategies (e.g., avoiding arousing worry content) to regulate their arousal levels in order to minimize arousal. Alternatively, older adults may be less physiologically responsive to worrying compared to younger adults. 


\section{Limitations}

There are several possible limitations to the present study. To begin, the composition of the sample is not representative of the entire population of older adults in the U.S. Thus, the results may not be generalizable to all older Americans. The demographic characteristics of the older and younger adults differed. The older adults in the present study were mostly Caucasian and were highly educated with a mean education level of 16 years. Younger adults were more ethnically or racially diverse, but were also well educated with a mean education level of 14 years.

A second limitation of the present study is that individuals who met criteria for an anxiety disorder were not identified or excluded from the study. Although individuals who were taking medications that influence HR (e.g., anxiolytics) were excluded from the present study, individuals taking antidepressants were allowed to participate.

Third, there are limitations to the methods used to measure the dependent variables. As worrying is a covert behavior, self-report data were relied upon to characterize the experience of worry. There are numerous problems with self-report data that were discussed earlier (Schwartz, 1999). One specific problem that arose is that the internal consistency for the MAACL-R was poorer for older adults compared to younger adults at baseline for anxiety and hostility. Internal consistency for depression was poorer for younger adults compared to older adults. This problem in internal consistency may reflect older and younger adults' difficulties in actually differentiating these emotional states. Additionally, some technical problems with the HR monitor occurred during data collection. In addition to technical malfunctions, the transmission of the HR signal from the wireless HR monitor may have been affected by a participant's body composition or the strength of his or her signal from the heart (Polar, personal communication, 
2010). The loss of data resulted in a smaller sample size for HRV analyses (47 younger adults and 45 older adults). Perhaps with a larger sample size, an effect of worry on HRV may have been found for both age groups, as more participants would have been in each cell, yielding more power to detect an effect.

One additional methodological issue is the manner in which baseline values were controlled in the present study. Baseline measures may affect the magnitude of responses to inductions in the present study as specified by the Law of Initial Values (Wilder, 1976). In the present study, it is possible that younger adults had higher HRs at baseline, which could have made it more difficult to detect changes in HR during the worry or relaxation condition.

\section{Future Directions}

Although the present study provided information about how worry is experienced among older adults, several questions remain to be addressed. It is important to continue to examine older adults' arousal and physiological reactivity in response to worrying. Measures of cardiovascular responses (HR and HRV) in the present study may not have been sensitive to changes in arousal. It is possible that other measures of autonomic arousal such as skin conductance or blood pressure may be sensitive to changes in arousal in late life (Uchino et al., 2010). Additionally, research on stress and aging frequently includes biomarkers to quantify the effects of stress (for a review, see Piazza, Almeida, Dmitrieva \& Klein, 2010), but there is a need to extend this research to late life anxiety. The inclusion of biomarkers as a measurement of the effects of worrying or anxiety also is worthy of exploration, as it may permit researchers to examine how anxiety and worry influence markers or risk factors for physical illness, disease, and disability. 
Future experimental studies of worry and anxiety in late life can improve our understanding of older adults' experiences of arousal during worry. For example, in future research studies, the magnitude of arousal and perceived intensity of arousal can be examined using experimental methods. The relation between cognitive anxiety and anxious arousal among older adults is not well understood. Additionally, it is important to test the Cognitive Avoidance Theory of worry in older adult samples. In three studies with younger adult participants, the Cognitive Avoidance Theory was tested by examining whether worry or other conditions (e.g., relaxation) had different effects on cardiovascular responses to images of anxiety-evoking stimuli (Borkovec \& Hu, 1990; Lyonfields et al., 1993; Peasley-Miklus \& Vrana, 2000). Results from these three studies demonstrated that worrying suppressed cardiovascular responses, which was conceptualized as an avoidance of arousal. A direct test of this theory with an older adult sample would utilize a stimulus that is anxiety-provoking for older adults. The comparison of older adults' physiological responses during a worry induction compared to other inductions conducted prior to exposure to the anxiety-evoking stimulus would serve as a test of worry as a strategy used to avoid arousal. Sensitive measures of physiological arousal are needed to examine whether worry functions to lower physiological arousal for older adults.

Examination of the external validity of tasks employed in future studies is essential. For example, Teachman and Gordon (2009) suggest that older adults find threats to their physical well-being and/or homeostasis (e.g., candle blowing task) to be salient. Although older adults may experience greater arousal and threat in response to these tasks, it is not clear if the manipulations from Teachman and Gordon or the present study are externally valid for older adults. 


\section{References}

American Heart Association (1996). Heart rate variability standards of measurement, physiological interpretation, and clinical use. Circulation, 93, 1043-1065.

American Psychiatric Association. (2000). Diagnostic and Statistical Manual of Mental Disorders, DSM-IV-TR (Fourth ed.). Washington, DC: American Psychiatric Association (APA).

Andor, T., Gerlach, A. L., \& Rist, F. (2008). Superior perception of phasic physiological arousal and the detrimental consequences of the conviction to be aroused on worrying and metacognitions in GAD. Journal of Abnormal Psychology, 117, 193-205. doi: 10.1037/0021-843X.117.1.193

Andrews, V. H., \& Borkovec, T. D. (1988). The differential effects of inductions of worry, somatic anxiety, and depression on emotional experience. Journal of Behavior Therapy and Experimental Research, 19, 21-26. doi: 10.1016/0005-7916(88)90006-7

Arch, J. J., \& Craske, M. G. (2006). Mechanisms of mindfulness: Emotion regulation following a focused breathing induction. Behaviour Research and Therapy, 44, 1849-1858. doi: 10.1016/j.brat.2005.12.007

Ayres, C. R., Sorrell, J. T., Thorp, S. R., \& Wetherell, J. L. (2007). Evidence-based psychological treatments for late-life anxiety. Psychology and Aging, 22, 8-17. doi: $10.1037 / 0882-7974.22 .1 .8$

Babcock, R. L., Laguna, L. R., Laguna, K. D., \& Urusky, D. A. (2000). Age differences in the experience of worry. Journal of Mental Health and Aging, 6, 227-235.

Backs, R. W., da Silva, S. P., \& Han, K. (2005). A comparison of younger and older adults' selfassessment Manikin ratings of affective pictures. Experimental Aging Research, 31, 421- 
440. doi: $10.1080 / 03610730500206808$.

Barlow, D. H. (1991). Disorders of Emotion. Psychological Inquiry, 2, 58-71.

Barlow, D. H., \& Craske, M. G. (1994). Mastery of your anxiety and panic ( $2^{\text {nd }}$ ed.). Albany, NY: Graywind.

Barlow, D. H., Allen, L. B., \& Choate, M. L. (2004). Toward a unified treatment for emotional disorders. Behavior Therapy, 35, 205-230. doi: 10.1016/S0005-7894(04)80036-4

Basevitz, P., Pushkar, D., Chaikelson, J, Conway, M., \& Dalton, C. (2008). Age-related differences in worry and related processes. International Journal of Aging and Human Development, 66, 283-305. doi: 10/21/90/AG.66.4.b

Beaudreau, S. A., \& O'Hara, R. (2008). Late -life anxiety and cognitive impairment: a review. American Journal of Geriatric Psychiatry, 16, 790-803. doi: 10.1097/JGP.0b013e31817945c3

Beaudreau, S. A., \& O'Hara, R. (2009). The association of anxiety and depressive symptoms with cognitive performance in community-dwelling older adults. Psychology and Aging, 24, 507-512. doi: $10.1037 / \mathrm{a} 0016035$

Beck, J., Stanley, M., \& Zebb, B. (1995). Psychometric properties of the Penn State Worry Questionnaire in older adults. Journal of Clinical Geropsychology, 1, 33-42.

Beckingham, A. C., Coutu-Wakulczyk, G., \& Lubin, B. (1993). French-Language Validation of the DACL and MAACL-R. Journal of Clinical Psychology, 49, 685-695.

Beekman, A. T., Bremmer, M. A., Deeg, D. J., van Balkom, A. J., Smit, J.H., de Beurs, E., et al. (1998). Anxiety disorders in later life: a report from the Longitudinal Aging Study Amsterdam. International Journal of Geriatric Psychiatry, 13, 717-726.

Behar, E., Zuellig, A. R., \& Borkovec, T. D. (2005). Thought and imaginal activity during worry 
and trauma recall. Behavior Therapy, 36, 157-168. doi: 10.1016/S0005-7894(05)80064-4

Blanchard-Fields, F. (1997). The role of emotion in social cognition across the adult life span. In K. W. Schaie \& M. P. Lawton (Eds.) Annual Review of Gerontology and Geriatrics: Vol. 17 (pp. 238-265).

Blanchard-Fields, F., Jahnke, H. C., \& Camp, C. (1995). Age differences in problem-solving style: The role of emotional salience. Psychology and Aging, 10, 173-180.

Blanchard-Fields, F., Stein, R., \& Watson, T. L. (2004). Age differences in emotion-regulation strategies in handling everyday problems. The Journals of Gerontology Series B: Psychological Sciences and Social Sciences, 59, P261-P269.

Blazer, D. G. (1996). The psychiatric interview of the geriatric patient. In E. W. Busse \& D. G. Blazer (Eds.), Textbook of geriatric psychiatry (pp. 175-189). Washington DC: American Psychiatric Press.

Bleil, M. E., Gianaros, P. J., Jennings, J. R., Flory, J.D., \& Manuck, S. B. (2008). Trait negative affect: toward an integrated model of understanding psychological risk for impairment in cardiac autonomic function. Psychosomatic Medicine, 70, 328-337.

Borkovec, T. D., \& Hu, S. (1990). The effect of worry on cardiovascular response to phobic imagery. Behaviour Research and Therapy, 28, 69-73. doi: 10.1016/00057967(90)90056-O

Borkovec, T. D., \& Inz, J. (1990). The nature of worry in generalized anxiety disorder: a predominance of thought activity. Behaviour Research and Therapy, 28, 153-158. doi: $10.1016 / 0005-7967(90) 90027-G$

Borkovec, T. D., Alcaine, O. M., \& Behar, E. (2004). Avoidance theory of worry and generalized anxiety disorder. In R. G. Heimberg, C. L. Turk \& D. S. Mennin (Eds.) 
Generalized Anxiety Disorder: Advances in Research and Practice (pp. 77-108). New York: The Guilford Press.

Borkovec, T. D., Lyonfields, J. D., Wiser, S. L., \& Diehl, L. (1993). The role of worrisome thinking in the suppression of cardiovascular response to phobic imagery. Behaviour Research and Therapy, 31, 321-324. doi: 10.1016/0005-7967(93)90031-O

Borkovec, T. D., Robinson, E., Pruzinsky, T., \& DePree, J. A. (1983). Preliminary exploration of worry: some characteristics and processes. Behaviour Research and Therapy, 21, 9-16.

Bradley, M. M. \& Lang, P. J. (1994), Measuring emotion: The self-assessment manikin and the semantic differential. Journal of Behavioral Therapy and Experimental Psychiatry, 25, 49-59.

Bradley, M. M., \& Lang, P. J. (1999). International affective digitized sounds (IADS): Stimuli, instruction manual and affective ratings (Tech. Rep. No. B-2). Gainesville, FL: The Center for Research in Psychophysiology, University of Florida.

Brenes, G. A. (2006). Age differences in the presentation of anxiety. Aging \& Mental Health, 10, 298-302. doi: 10.1080/13607860500409898

Brenes, G. A., Guralnik, J. M., Williamson, J. D., Fried, L. P., Simpson, C., Simonsick, E. M., et al. (2005). The influence of anxiety on the progression of disability. Journal of the American Geriatrics Society, 53, 34-39. doi: 10.1111/j.1532-5415.2005.53007.x

Brosschot, J., Gerin, W., \& Thayer, J. (2006). The perseverative cognition hypothesis: A review of worry, prolonged stress-related physiological activation, and health. Journal of Psychosomatic Research, 60, 113-124. doi:10.1016/j.jpsychores.2005.06.074

Brosscot, J. F., Van Dijk, E., \& Thayer, J. F. (2007). Daily worry is related to low heart rate variability during waking and the subsequent nocturnal sleep period. International 
Journal of Psychophysiology, 63, 39-47. doi: 10.1016/j.ijpsycho.2006.07.016

Brown, T., Antony, M., \& Barlow, D. (1992). Psychometric properties of the Penn State Worry Questionnaire in a clinical anxiety disorders sample. Behaviour Research and Therapy, 30, 33-37. doi: 10.1016/0005-7967(92)90093-V

Brown, T.A., \& Barlow, D.H. (2009). A proposal for a dimensional classification system based on the shared features of the DSM-IV anxiety and mood disorders: Implications for assessment and treatment. Psychological Assessment, 21, 256-271. doi: $10.1037 / \mathrm{a} 0016608$

Brown, T. A., Chorpita, B. F., Worotitsch, W., \& Barlow, D. H. (1997). Psychometric properties of the Depression Anxiety Stress Scales (DASS) in clinical samples. Behaviour Research and Therapy, 35, 79-89.

Bryant, C., Jackson, H., \& Ames, D. (2008). The prevalence of anxiety in older adults:

Methodological issues and a review of the literature. Journal of Affective Disorders, 109, 233-250. doi: 10.1016/j.jad.2007.11.008

Carstensen, L. (2000). Carstensen Emotion Questionnaire. Unpublished manuscript, Stanford University, Stanford, CA.

Carstensen, L. L. (1995). Evidence for a life-span theory of socioemotional selectivity. Current Directions in Psychological Science, 4, 151-156.

Carstensen, L. L., \& Fredrickson, B. (1998). Influence of HIV status and age on cognitive representations of others. Health Psychology, 17, 494-503. doi: 10.1037/02786133.17 .6 .494 
Carstensen, L. L., Fung, H. H., \& Charles, S. T. (2003). Socioemotional selectivity theory and the regulation of emotion in the second half of life. Motivation and Emotion, 27, 103-123. doi: 0146-7239/03/0600-0103/0

Carter, W. R., Johnson, M. C., \& Borkovec, T. D. (1986). Worry: an electrocortical analysis. Advances in Behaviour Research and Therapy, 8, 193-204. doi:10.1016/01466402(86)90004-4

Chelminski, I. and Zimmerman, M. (2003). Pathological worry in depressed and anxious patients. Journal of Anxiety Disorders, 17, 533-546. doi: 10.1016/S0887-6185(02)00246-3

Cisler, J.M., \& Koster, E. H. (2010). Mechanisms of attentional biases toward threat in anxiety disorders: an integrative review. Clinical Psychology Review, 30, 203-216. doi:10.1016/j.cpr.2009.11.003

Clark, L. A., \& Watson, D. (1991). Tripartitie model of anxiety and depression: psychometric evidence and taxonomic implications. Journal of Abnormal Psychology, 100, 316-336.

Cortina, J. M. (1993). What is coefficient alpha? An examination of theory and applications. Journal of Applied Psychology, 78, 98-104.

Craske, M. G., Rapee, R. M., Jackel, L., \& Barlow, D. H. (1989). Qualitative dimensions of worry in DSM-III-R generalized anxiety disorder subjects and nonanxious controls. Behaviour Research and Therapy, 27, 397-402.

Crittenden, J., \& Hopko, D. R. (2006). Assessing worry in older and younger adults: Psychometric properties of an abbreviated Penn State Worry Questionnaire (PSWQ-A). Journal of Anxiety Disorders, 20, 1036-1054. doi: 10.1016/j.janxdis.2005.11.006 
Davey, G. C. L. (1994). Pathological worrying as exacerbated problem-solving. In G. Davey \& F. Tallis (Eds.), Worrying: Perspectives on Theory, Assessment and Treatment (pp. 3560). Chichester, England: John Wiley \& Sons.

Davis, M., Eshelman, E. R., \& McKay, M. (2000). The Relaxation \& Stress Reduction Workbook ( $5^{\text {th }}$ Ed.). Oakland, CA: New Harbinger Publication.

Davis, M., Montgomery, I., \& Wilson, G. (2002). Worry and heart rate variables: autonomic rigidity under challenge. Anxiety Disorders, 16, 639-659.

De Beurs, E., Beekman, A. T. F., van Balkom, A. J. L. M., Deeg, D. J. H., van Dyck, R. , \& van Tilburg, W. (1999). Consequences of anxiety in older persons: its effect on disability, well-being and use of health services. Psychological Medicine, 29, 583-593.

DeBerry, S. (1982). The effects of meditation-relaxation on anxiety and depression in a geriatric population. Psychotherapy: Theory, Research, and Practice, 19, 512-521.

DeBerry, S. (1989). A comparison of meditation-relaxation and cognitive/behavioral techniques for reducing anxiety and depression in a geriatric population. Journal of Geriatric Psychiatric, 22, 231-247.

Diefenbach, G. J., Stanley, M. A., \& Beck, J. G. (2001). Worry content reported by older adults with and without generalized anxiety disorder. Aging \& Mental Health, 5, 269-274. doi: $10.1080 / 13607860120065069$

Dugas, M. J., Letarte, H., Rhéaume, J., Freeston, M. H., \& Ladouceur, R. (1995). Worry and problem solving: Evidence of a specific relationship. Cognitive Therapy and Research, 19, 109-120. doi: 10.1007/BF02229679

Fox, L. S., \& Knight, B. G. (2005). The effects of anxiety on attentional processes in older adults. Aging \& Mental Health, 9, 585-593. doi: 10/1080/13607860500294282 
Fox, L. S., Knight, B. G., \& Zelinski, E. M. (1998). Mood induction with older adults: a tool for investigating effects of depressed mood. Psychology \& Aging, 13, 519-523.

Freeston, M. H., Dugas, M. J., \& Ladouceur, R. (1996). Thoughts, images, worry, and anxiety. Cognitive Therapy and Research, 20, 1573-2819. doi: 10.1007/BF02229237

Fresco, D. M., Frankel, A. N., Mennin, D. S., Turk, C. L., \& Heimberg, R. G. (2002) Distinct and overlapping features of rumination and worry: The relationship of cognitive production to negative affective states. Cognitive Therapy and Research, 26, 179-188.

Friedman, B. H., Thayer, J. F., \& Borkovec, T. D. (2000). Explicit memory bias for threat words in generalized anxiety disorder. Behavior Therapy, 31, 745-756. doi: 10.1016/S00057894(00)80042-8

Gill, D. J., Freshman, A., Blender, J. A., \& Ravina, B. (2008). The Montreal Cognitive Assessment as a screening tool for cognitive impairment in Parkinson's Disease. Movement Disorders, 23, 1043-1046. doi: 10.1002/mds.22017

Gloster, A. T., Rhoades H. M., Novy, D., Klotsche, J., Senior, A., Kunik, M, et al. (2008). Psychometric properties of the Depression Anxiety and Stress Scale-21 in older primary care patients. Journal of Affective Disorders, 110, 248-259. doi:10.1016/j.jad.2008.01.023

Gould, C. E., \& Edelstein, B. A. (2010). Worry, emotion control, and anxiety control in older and young adults. Journal of Anxiety Disorders, 24, 759-766. doi:10.1016/j.janxdis.2010.05.009

Gross, J. J., Carstensen, L. L., Pasupathi, M., Tsai, J., Skorpen, C. G., \& Hsu, A. Y. C. (1997). Emotion and aging: Experience, expression, and control. Psychology and Aging, 12, 590599. 
Gross, J. J., \& John, O. P. (2003). Individual differences in two emotion regulation processes: Implications for affect, relationships, and well-being. Journal of Personality and Social Psychology, 85, 348-362. doi: 10.1037/0022-3514.85.2.348

Gross, J. J., \& Thompson, R. A. (2007). Emotion Regulation Conceptual Foundations. In J. J. Gross (Ed.), Handbook of Emotion Regulation (pp. 3-24). New York: The Guilford Press.Gum, A. M., King-Kallimanis, B., \& Kohn, R. (2009). Prevalence of mood, anxiety, and substance-abuse disorders for older Americans in the National Comorbidity Survey-Replication. American Journal of Geriatric Psychiatry, 17, 769-781. doi: 10.1097/JGP.0b013e3181ad4f5a

Hazlett-Stevens, H., \& Borkovec, T. D. (2001). Effects of worry and progressive relaxation on the reduction of fear in speech phobia: An investigation of situational exposure. Behavior Therapy, 32, 503-517. doi: 10.1016/S0005-7894(01)80033-2

Helson, H. (1964). Adaptation level theory. New York: Harper \& Row.

Hoehn-Saric, R., McLeod, D. R., \& Zimmerli, W. D. (1989). Somatic manifestations in women with generalized anxiety disorder. Archives of General Psychiatry, 46, 1113-1119.

Hofman, S. G., Sawyer, A. T., Witt, A. A., \& Oh, D. (2010). The effect of mindfulness-based therapy of depression: a meta-analytic review. Journal of Consulting and Clinical Psychology, 78, 169-183. doi:10.1037/a0018555.

Howell, D. C. (2001). Statistical methods for psychology $\left(5^{\text {th }}\right.$ ed.) New York: Duxbury Press. Hunt, S., Wisocki, P. A., \& Roger, P. R. (2009). "What, me worry?” An examination of the literature on worry and the older adult. The Behavior Therapist, 32, 9-16. 
Hunt, S., Wisocki, P., \& Yanko, J. (2003). Worry and use of coping strategies among older and younger adults. Journal of Anxiety Disorders, 17, 547-560. doi: 10.1016/S08876185(02)00229-3

John, O. P., \& Gross, J. J. (2004). Healthy and unhealthy emotion regulation personality processes, individual differences, and life span development. Journal of Personality, 72, 1301-1334.

Knight, B. G., Maines, M. L., \& Robinson, G. S. (2002). The effects of sad mood on memory in older adults: A test of the mood congruence effect. Psychology and Aging, 17, 653-661. doi: $10.1037 / / 0882-7974.17 .4 .653$

Kogan, J. N., \& Edelstein, B. A. (2004). Modification and psychometric examination of a selfreport measure of fear in older adults. Journal of Anxiety Disorders, 18, 397-409. doi: $10.1016 / \mathrm{S} 0887-6185(02) 00260-8$

Kubzansky, L. D., Kawachi, I., Spiro, A., Weiss, S. T., Voknas, P. S., \& Sparrow, D. (1997). Is worrying bad for your heart? A prospective study of worry and coronary heart disease in the Normative Aging Study. Circulation, 95, 818-824.

Kunzmann, U., \& Grühn, D. (2005). Age differences in emotional reactivity: The sample case of sadness. Psychology and Aging, 20, 47-59. doi: 10.1037/0882-7974.20.1.47

Kunzmann, U., Kupperbusch, C. S., \& Levenson, R. W. (2005). Behavioral inhibition and amplification during emotional arousal: A comparison of two age groups. Psychology and Aging, 20, 144-158. doi: 10.1037/0882-7974.20.1.144

Labouvie-Vief, G. (2008). Dynamic integration theory: Emotion, cognition, and equilibrium in later life. In V. L. Bengtson, D. Gans, N. M. Putney, and M. Silberstein (Eds) Handbook 
of Theories of Aging, $2^{\text {nd }}$ edition (pp. 227-293). New York: Springer Publishing Company, LLC.

Labouvie-Vief, G., Diehl, M., Jain, E., \& Zhang, F. (2007). Six-year change in affect optimization and affect complexity across the adult life span: A further examination. Psychology and Aging, 22, 738-751. doi: 10.1037/0882-7974.22.4.738.

Labouvie-Vief, G., \& Márquez, M. (2004). Dynamic integration: affect optimization and differentiation in development. In D. Y. Dai \& R. J. Sternberg (Eds.), Motivation, emotion, and cognition (pp. 237-272). Mahwah, NJ: Erlbaum.

Lang, P. J. (1977). Psychophysiological assessment of anxiety and fear. In J. D. Cone \& R. P. Hawkins (Eds.), Behavioral assessment: New directions in clinical psychology. New York: Brunner-Mazel.

Lang, P. J., Bradley, M. M., \& Cuthbert, B. N. (2005). International affective picture system (IAPS): Instruction manual and affective ratings. Technical Report A-6, The Center for Research in Psychophysiology, University of Florida, Retrieved from: http://www.ssas.de/wiki/images/4/42/TechManual2004.pdf on October 11, 2009.

Lau, A. W. (2000). Psychophysiological responses of older adults to an anxiety-evoking stimulus (Doctoral dissertation). Retrieved from West Virginia University Electronic Theses and Dissertations. (000002378).

Lau, A. W., Edelstein, B. A., \& Larkin, K. T. (2001). Psychophysiological arousal in older adults: a critical review. Clinical Psychology Review, 21, 609-630. doi: 10.1016/S02727358(00)00052-0 
Lawton, M. P., \& Nahemow, L. (1973). Ecology and the aging process. In C. Eisdorfer \& M. P. Lawton (Eds.), The Psychology of Adult Development and Aging (pp. 619-674). Washington, DC: American Psychological Association.

Lawton, M. P., Kleban, M. H., Rajagopal, D., \& Dean, J. (1992). Dimensions of affective experience in three age groups. Psychology and Aging, 7, 171-184. doi: 10.1037/08827974.7.2.171

Le Roux, H, Gatz, M., \& Wetherell, J. L. (2005). Age at onset of generalized anxiety disorder in older adults. American Journal of Geriatric Psychiatry, 13, 23-30.

Lee, L. O., \& Knight, B. G. (2009). Attentional bias for threat in older adults: Moderation of the positivity bias by trait anxiety and stimulus modality. Psychology and Aging, 24, 741747. doi: $10.1037 / \mathrm{a} 00164049$

Lenze, E. J., Mulsaint, B. H., Shear, M. K., Alexopoulos, G. S., Frank, E., \& Reynolds, C. F. (2001). Comorbidity of depression and anxiety disorders in later life. Depression and Anxiety, 14, 86-93. doi: 10.1002/da.1050

Lenze, E. J., Mulsant, B. H, Molhman, J. Shear, M. K, Dew, M. A., Shultz, R., et al. (2005). Generalized Anxiety Disorder in Late Life: Lifetime course and comorbidity with major depressive disorder. American Journal of Geriatric Psychiatry, 13, 77-80.

Levenson, R. W. (2000). Expressive, physiological, and subjective changes in emotion across adulthood. In S. H. Quails \& N. Abeles (Eds.), Psychology and the aging revolution. Washington, DC: American Psychological Association.

Levenson, R. W., Carstensen, L. L., Friesen, W. V., \& Ekman, P. (1991). Emotion, physiology, and expression in old age. Psychology and Aging, 6, 28-35. 
Livermore, N., Sharpe, L., \& McKenzie, D. (2007). Selective attention to threatening information in anxious patients with chronic obstructive pulmonary disease. Cognitive Therapy and Research, 31, 885-895. doi: 10.1007/s10608-007-9168-4

Lovibond, S. H., \& Lovibond, P. F. (1995). Manual for the Depression Anxiety Stress Scales. Psychology Foundation, Sydney.

Lubin, B., \& Zuckerman, M. (1999). The Multiple Affect Adjective Check List-Revised (3 ${ }^{\text {rd }}$ ed.). San Diego, CA: Educational and Industrial Testing Service.

Lubin, B., Zuckerman, M., Hanson, P. G., Armstrong, T., Rinck, C. M., \& Seever, M. (1986). Reliability and validity of the multiple affect adjective check list - revised. Journal of Psychopathology and Behavioral Assessment, 8, 103-117.

Luis, C. A., Keegan, A. P., \& Mullan, M. (2009). Cross validation of the Montreal Cognitive Assessment in community dwelling older adults residing in the southeastern US. International Journal of Geriatric Psychiatry, 24, 197-201. doi: 10.1002/gps.2101

MacLeod, C., \& Rutherford, E. (2004). Information-processing approaches: assessing the selective functioning of attention, interpretation, and retrieval. In R. G. Heimberg, C. L. Turk, and D. S. Mennin (Eds.), Generalized Anxiety: Advances in Research and Practice. New York, NY: The Guilford Press (pp. 109-142).

MacLeod, C., \& McLaughlin, K. (1995). Implicit and explicit memory bias in anxiety: A conceptual replication. Behaviour Research and Therapy, 33, 1-14.

MacLeod, C., Mathews, A., \& Tata, P. (1986). Attentional bias in emotional disorders. Journal of Abnormal Psychology, 95, 15-20. 
Malliani, A., Lombardo, R., \& Pagani, M. (1994). Power spectrum analysis of heart rate variability: a tool to explore neural regulatory mechanisms. British Heart Journal, 71, 12.

Mather, M., \& Carstensen, L. L. (2005). Aging and motivated cognition: the positivity effect in attention and memory. Trends in Cognitive Sciences, 9, 496-502. doi: 10.1016/j.tics.2005.08.005.

Mathews, A., Mogg, K., May, J., \& Eysenck, M. W. (1989). Implicit and explicit memory bias in anxiety. Journal of Abnormal Psychology, 98, 236-240.

Matthews, G., \& Funke, G. J. (2006). Worry and information-processing. In G. C. L. Davey and A. Wells (Eds.), Worry and its psychological disorders: theory, assessment, and treatment (pp. 21-40). Hoboken, NJ: Wiley.

McLaughlin, K. A., Borkovec, T. D., \& Sibrava, N. J. (2007a). The effects of worry and rumination on affect states and cognitive activity. Behavior Therapy, 38, 23-38. doi: 10.1016/j.beth.2006.03.003

McLaughlin, K. A., Mennin, D. S., \& Farach, F. J. (2007b). The contributory role of worry in emotion generation and dysregulation in generalized anxiety disorder. Behaviour Research and Therapy, 45, 1735-1752. doi: 10.1016/j.brat.2006.12.004

Mennin, D. S., Heimberg, R. G., Turk, C. L., \& Fresco, D. M. (2005). Preliminary evidence for an emotion dysregulation model of generalized anxiety disorder. Behaviour Research and Therapy, 43, 1281-310. doi: 10.1016/j.brat.2004.08.008

Mennin, D. S., Heimberg, R. G., Turk, C. L., \& Fresco, D. M. (2002). Applying an emotion regulation framework to integrative approaches to generalized anxiety disorder. Clinical Psychology: Science and Practice, 9, 85-90. doi: 10.1093/clipsy.9.1.85 
Metzger, R. L., Miller, M. L., Cohen, M., Sofka, M., \& Borkovec, T. D. (1990). Worry changes decision making: The effect of negative thoughts on cognitive processing. Journal of Clinical Psychology, 46, 78-88. doi: 10.1002/1097-4679(199001)46:1<78::AIDJCLP2270460113>3.0.CO;2-R

Meyer, T. J., Miller, M. L, Metzger, R. L., \& Borkovec, T. D. (1990). Development and validation of the Penn State Worry Questionnaire. Behavior Research and Therapy, 28, 487-495. doi: 10.1016/0005-7967(90)90135-6

Mitte, K. (2008). Memory bias for threatening information in anxiety and anxiety disorders: A meta-analytic review, Psychological Bulletin, 134, 886-911. doi: 10.1037/a0013343

Molina, S. \& Borkovec, T. D. (1994). The Penn State Worry Questionnaire: Psychometric properties and associated characteristics. In Davey, G., \& Tallis, F. (Eds), Worrying: Perspectives on Theory, Assessment and Treatment (pp. 265-284). Chister, England: John Wiley \& Sons.

Nasreddine, Z. A., Phillips, N. A., Bédirian, V., Charbonneau, S., Whitehead, V., Collin, I., et al. (2005). The Montreal Cognitive Assessment, MoCA: A brief screening tool for mild cognitive impairment. Journal of the American Geriatrics Society, 53, 695-699. doi: 10.1111/j.1532-5415.2005.53221.x

Neikrug, S. M. (2003). Worrying about a frightening old age. Aging Mental Health, 7(5), 326333. doi: $10.1080 / 1360786031000150702$

Nolen-Hoeksema, S., Wisco, B.E., \& Lyubomirsky, S. (2008). Rethinking rumination. Persepectives on Psychological Science, 7, 400-424. doi:10.1111/j.17456924.2008.00088.x 
Novick-Kline, P., Turk, C. L., Mennin, D. S., Hoyt, E. A., \& Gallagher, C. L. (2005). Level of emotional awareness as a differentiating variable between individuals with and without generalized anxiety disorder. Journal of Anxiety Disorders, 19, 557-572. doi:

10.1016/j.janxdis.2004.06.001

Peasley-Miklus, C., \& Vrana, S. R. (2000). Effect of worrisome and relaxing thinking on fearful emotional processing. Behaviour Research and Therapy, 38, 129-144.

Person, D. C., \& Borkovec, T. D. (1995, August). Anxiety disorders among the elderly: Patterns and issues. Paper presented at the $103^{\text {rd }}$ annual meeting of the American Psychological Association, New York, NY.

Pieper, S., Brosschot, J. F., Van Der Leeden, R., \& Thayer, J. F. (2007). Cardiac effects of momentary assessed worry episodes and stressful events. Psychosomatic Medicine, 69, 901-909. doi: 10.1097/PSY.0b13e31815a9230

Piazza, J. R., Almeida, D. M., Dmitrieva, N. O., \& Klein, L. C. (2010). Frontiers in the use of biomarkers of health in research on stress and aging. Journals of Gerontology: Psychological Sciences, 66B, 513-525. doi: 10.1093/geronb/gbq049

Powers, C. B., Wisocki, P. A., \& Whitbourne, S. K. (1992). Age differences and correlates of worrying in young and elderly adults. Gerontologist, 32, 82-88.

Purdon, C., \& Harrington, J. (2006). Worry in psychopathology. In G. C. L. Davey \& A. Wells (Eds.). Worry and its Psychological Disorders (pp. 41-67). West Sussex, England: John Wiley \& Sons, Ltd.

Robinson, A. R., Brower, K. J., \& Gomberg, E. S. L. (2001). Explaining unexpected gender differences in hostility among persons seeking treatment for substance use disorders. Journal of Studies on Alcohol, 62, 667-674. 
Roemer, L., Molina, S., \& Borkovec, T. D. (1997). An investigation of worry content among generally anxious individuals. Journal of Nervous \& Mental Disease, 185, 314-319.

Ruscio, A. M., \& Borkovec, T. D. (2004). Experience and appraisal of worry among high worriers with and without generalized anxiety disorder. Behaviour Research and Therapy, 42, 1469-1482. doi: 10.1016/j.brat.2003.10.007

Ruscio, A.M. (2002). Delimiting the boundaries of generalized anxiety disorder: differentiating high worriers with and without GAD. Journal of Anxiety Disorders, 16, 377-400.

Salters-Pedneault, K., Roemer, L., Tull, M. T., Rucker, L., \& Mennin, D. S. (2006). Evidence of broad deficits in emotion regulation associated with chronic worry and generalized anxiety disorder. Cognitive Therapy Research, 30, 469-480. doi: 10.1007/s10608-006$9055-4$

Schulz, R., \& Heckhausen, J. (1997). Emotion and control: A life-span perspective. In K. W. Schaie \& M. P. Lawton (Eds.) Annual Review of Gerontology and Geriatrics: Vol. 17 (pp. 185-205).

Schwartz, N. (1999). How the questions shape the answers. American Psychologist, 54, 93.

Scogin, F., Rickard, H. C., Keith, S., Wilson, J., \& McElreath, L. (1992). Progressive and imaginal relaxation training for elderly persons with subjective anxiety. Psychology and Aging, 7, 419-424.

Segerstrom, S.C., Glover, D. A., Craske, M.G., \& Fahey, J. L. (1999). Worry affects the immune response to phobic fear. Brain, Behavior, and Immunity, 13, 80-92.

Smith, T., Gildeh, N., \& Holmes, C. (2007). The Montreal Cognitive Assessment: Validity and Utility in a Memory Clinic Setting. The Canadian Journal of Psychiatry, 52, 329-332.

Stanley, M., Beck, J., \& Zebb, B. (1996). Psychometric properties of four anxiety measures in older adults. Behaviour Research and Therapy, 34, 827-838. 
Stanley, M., Novy, D., Bourland, S., Beck, J., \& Averill, P. (2001). Assessing older adults with generalized anxiety: A replication and extension. Behaviour Research and Therapy, 39, 221-235.

Stanley, M. A., Wilson, N. L., Novy, D. M., Rhoades, H.M, Wagener, P.D., Greisinger, A. J., et al. (2009). Cognitive behavior therapy for generalized anxiety disorder among older adults in primary care. Journal of the American Medical Association, 301, 1460-1467. doi: $10.1001 /$ jama.2009.458

Stein, P. K., Kleiger, R. E., \& Rottman, J. N. (1997). Differening effects of age on heart rate variability in men and women. The American Journal of Cardiology, 80, 302-305.

Stöber, J. (1998). Worry, problem elaboration and suppression of imagery: The role of concreteness. Behaviour Research and Therapy, 36, 751-756. doi: 10.1016/S08876185(99)00048-1

Suarez, E. C. (2008). Self-reported symptoms of sleep disturbance and inflammation, coagulation, insulin resistance and psychosocial distress: evidence for gender disparity. Brain, Behavior, and Immunity, 22, 960-968. doi:10.1016/j.bbi.2008.01.011

Tabachnick, B. G., \& Fidell, L. S. (2007). Using Multivariate Statistics, $5^{\text {th }}$ edition. Boston: Pearson Education, Inc.

Taylor, R. L., \& O’Brien, W. H. (1999). The role of worry and verbal-linguistic mentation in cardiovascular reactivity to a mental arithmetic stressor. Anxiety, Stress, \& Coping, 12(1), 23-39.

Taylor, S., \& Rachman, S. (1994). Klein's suffocation theory of panic. Archives of General Psychiatry, 51, 505-506. 
Teachman, B. A., \& Gordon, T. (2009). Age differences in anxious responding: Older and calmer, unless the trigger is physical. Psychology and Aging, 24, 703-714. doi: $10.1037 / \mathrm{a} 0016813$

Teachman, B. A., Siedlecki, K. L., \& Magee, J. C. (2007). Aging and symptoms of anxiety and depression: structural invariance of the tripartite model. Psychology and Aging, 22, 260170. doi: $10.1037 / 0882-7974.22 .1 .160$

Thayer, J. F., Friedman, B. H., \& Borkovec, T. D. (1996). Autonomic characteristics of Generalized Anxiety Disorder and worry. Biological Psychiatry, 39, 255-266. doi: 10.1016/0006-3223(95)00136-0

Thayer, J. F., Yamamoto, S. S., \& Brosschot, J. F. (2010). The relationship of automatic imbalance, heart rate variability and cardiovascular disease risk factors. International Journal of Cardiology, 141, 122-131.

Tsai, J. L., Levenson, R. W., \& Carstensen, L. L. (2000). Autonomic, expressive, and subjective responses to emotional films in older and younger Chinese American and European American adults. Psychology and Aging, 15, 684-69.

Uchino, B. N., Birmingham, W., \& Berg, C. A. (2010). Are older adults less or more physiologically reactive? A meta-analysis of age-related differences in cardiovascular reactivity to laboratory tasks. Journals of Gerontology: Psychological Sciences, 65B, 154-162.

Urry, H. L., \& Gross, J. J. (2010). Emotion regulation in older age. Current Directions in Psychological Science, 19, 352-357. doi: 10.1177/096372140388395

Velten, E. (1968). A laboratory task for induction of mood states. Behaviour Research and Therapy, 6, 473-482. doi: 10.1016/0005-7967(68)90028-4 
Verkuil, B., Brosschot, J. F., Borkovec, T. D., \& Thayer, J. F. (2009). Acute autonomic effects of experimental worry and cognitive problem solving: why worry about worry? International Journal of Clinical and Health Psychology, 9, 439-453.

Vrana, S. R., Cuthbert, B. N., Lang, P. L. (1986). Fear imagery and text processing. Psychophysiology, 23, 247-253. doi: 10.1111/j.1469-8986.1986.tb00626.x

Watson, D., Clark, L. A., \& Tellegen, A. (1988). Development and validation of brief measures of positive and negative affect: The PANAS scales. Journal of Personality and Social Psychology, 54, 1063-1070. doi: 10.1037/0022-3514.54.6.1063

Wetherell, J. L., Le Roux, H., \& Gatz, M. (2003). DSM-IV criteria for generalized anxiety disorder in older adults: distinguishing the worried from the well. Psychology and Aging, 18, 622-627.

Wetherell, J. L., Sorrell, J. T., Thorpe, S. R., \& Patterson, T. L. (2005). Psychological interventions for late-life anxiety: A review and early lessons from the CALM Study. Journal of Geriatric Psychiatry and Neurology, 18, 72-82. doi: 10.1177/0891988705276058

Wetherell, J. L., Thorp, S. R., Patterson, T. L., Golshan, S., Jeste, D. V., \& Gatz, M. (2004). Quality of life in geriatric generalized anxiety disorder: a preliminary investigation. Journal of Psychiatric Research, 38, 305-312. doi: 10.1016/j.jpsychires.2003.09.003

Wilson, M., Smith, N. C., \& Holmes, P. S. (2007). The role of effort in influencing the effect of anxiety on performance: testing the conflicting predictions of processing efficiency theory and the conscious processing hypothesis. British Journal of Psychology, 98, 411428. doi: 10.1348/000712606X133047 
Wisocki, P. A. (1994). The experience of worry among the elderly. In G. Davey \& F. Tallis (Eds.), Worrying: Perspectives on Theory, Assessment and Treatment (pp. 247-261). Chichester, England: John Wiley \& Sons.

Wong, G., \& Baden, A. L. (2001). Multiculturally sensitive assessment with older adults: Recommendations and areas for additional study. In L. A. Suzuki, J. G. Ponterotto, \& P. J. Meller (Eds.), Handbook of multicultural assessment: Clinical, psychological, and educational applications (pp. 497-522). San Francisco: Jossey-Bass, Inc.

Wrosch, C., Schulz, R., \& Heckhausen, J. (2004). Health stresses and depressive symptomatology in the elderly: A control-process approach. Current Directions in Psychological Science, 31, 17-20. doi: 10.1111/j.0963-7214.2004.01301005.x

York, D., Borkovec, T. D., Vasey, M., \& Stern, R. (1987). Effects of worry and somatic anxiety induction on thoughts, emotion and physiological activity. Behaviour Research and Therapy, 25, $523-526$.

Zuckerman, M., \& Lubin, B. (1985). Manual for the Multiple Affect Adjective Check List (2 ${ }^{\text {nd }}$ ed.). San Diego, CA: Educational and Industrial Testing Service. 


\section{Appendix A}

\section{Screening Questionnaire (SONA/Telephone)}

In order to determine if you are eligible for the research study, I am going to ask you some questions. Participation in this screening is voluntary. You are free to stop participating in the screening at any time. If you are not eligible for the study, all information gathered will be shredded to protect your confidentiality.

What is your age?

[exclude if not 18-30 y.o. or 60 y.o. or older]

What is your gender? $\square$ Male $\square$ Female

1. On average, how often do you smoke cigarettes? [exclude if smoker at present time]

$\square$ Never

$\square$ I am not currently smoking

$\square$ less than one pack per day

$\square$ 1-2 packs per day

$\square$ 2-3 packs per day

$\square$ greater than 3 packs per day

1. Please describe any cardiovascular related illness that you may have, including high blood pressure:

2. Please list any other medical or psychiatric problems that you have:

3. Please list any drugs (legal or otherwise) that you are currently taking including; birth control (contraceptives), heart medications, cold or allergy medications, over the counter medications, asthma medications, Beta-Blockers (i.e. Inderal, Tenormin), psychoactive drugs (i.e. Adderall, Xanax, Haldol, Lithium, Prozac), or diet pills.

If participant is not excluded on basis of age or smoking status, inform participant about possible lab appointment times. Ask participant to refrain from using smokeless tobacco, drinking caffeinated beverages, drinking alcohol, or engaging in aerobic physical activity for 2 hours before study appointment. 
Appendix B

Demographic and Medical Questionnaire

Please answer the following questions.

Years of Education: (high school $=12$ years $)$

Marital Status: Please check one.

Single $\quad \square$ Married $\square$ Separated $\square$ Divorced $\square$ Widowed

Ethnicity: (race) Please check all that apply.

$\square$ African American (Black)

$\square$ Asian

$\square$ Caucasian (White)
Hispanic

Biracial

Other:

What is your current job or occupation status? Please check one.

$\square$ Working full time

$\square$ Homemaker

$\square$ Retired

$\square$ Student $\square$ Working part time

$\square$ Looking for work, unemployed

$\square$ Disabled - unable to work

Please answer the following questions about your health as best as you can.

1. On average, how often do you use smokeless tobacco?

$\square$ never

$\square$ I am not currently using smokeless tobacco

$\square$ 1-4 times per day

$\square$ 5-8 times per day

$\square$ 9-13 times per day

$\square$ greater than thirteen times per day 
2. How often do you drink alcohol?

$\square$ never

$\square$ infrequently (a few drinks per year)

$\square$ occasionally (1-2 drinks per month)

$\square$ weekly (1-3 drinks per week)

$\square$ weekly (3-6 drinks per week)

$\square$ daily (7-14 drinks per week)

$\square$ daily (more than 14 drinks per week)

3. How many cups of caffeinated coffee, tea, or soda do you have per day?

$\square$ 1-2 cups per day

$\square$ 3-4 cups per day

$\square$ 5-6 cups per day

$\square$ 7-8 cups per day

$\square$ greater than eight cups per day

4. How many times per week do you engage in aerobic physical activity?

$\square$ never

$\square 1-2$ times

$\square$ 3-6 times

$\square 7$ or more times

5. Please list any major surgeries and medical, or psychiatric illnesses you have had in the past. 


\section{Family Information:}

6. What is your best estimate of your family's net income (before expenses are accounted for)?

$\square$ Less than 25,000

$\square 25,000$ to 50,000

50,000 to 74,999

$\square 75,000$ or Greater

7. Below is a list of health problems. Please check off the box next to the condition if your mother or father has or had any of the following health problems.

$\square \quad$ High blood pressure (hypertension)

Angina (chest pains)

Heart attack

Coronary heart disease
Diabetes

Kidney Disease

Cancer

8. What is your height?

9. How much do you weigh? 


\section{Appendix C}

Please rate how worried you are right now using the below scale.

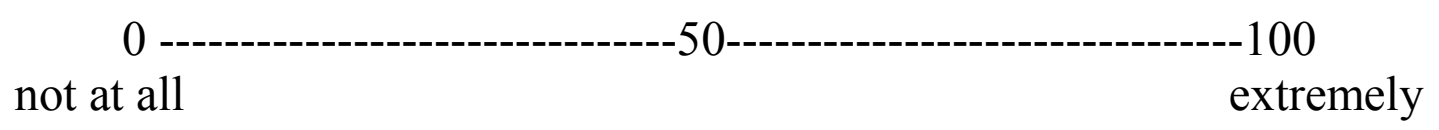

Instructions to be read aloud the first time: "If you'll look at the sheet, you will see 5 figures, arranged along a continuum. We call this set of figures SAM, and you will be using these figures to rate how you feel at several points during the experiment."2

"The excited vs. calm dimension is the type of feeling displayed here. At one end of the scale you felt stimulated, excited, frenzied, jittery, wide-awake, aroused. If you felt completely aroused, place an " $\mathrm{X}$ " over the figure at the left of the row like this (demonstrated with SAM). You can indicate you felt completely calm by placing an " $\mathrm{X}$ " over the figure at the right of the row like this (demonstrate with SAM). You can represent intermediate levels by placing an " $\mathrm{X}$ " over any of the other figures. If you are not at all excited nor at all calm, place an " $X$ " over the figure in the middle of the row. If you wish to make a more finely tuned rating of how excited or calm you feel, place an "X" between the pictures, like this. ${ }^{1}$

\footnotetext{
${ }^{2}$ These instructions were altered from those presented in the manual because Lang and colleagues (2005) presented these instructions to be used for all three scales to be used to rate pictures from the International Affective Picture System (Lang, Bradley, \& Cuthbert, 2005). The SAM figures are not presented here, but can be found in Lang et al. (2005).
} 


\section{Appendix D \\ Post-Experiment Measures}

Please read each item carefully. Answer the items by circling the number on the scale below each question.

1. How similar is this worrying to your everyday worrying?

$\begin{array}{lc}\text { Not at all } & \text { Extremely } \\ \text { Similar } & \text { Similar }\end{array}$

2. I attempted to follow the induction instructions.

\begin{tabular}{|c|}
\hline Very \\
\hline Untrue \\
\hline
\end{tabular}




\section{Appendix E}

Content Generated for Inductions

\section{Pleasant Recall Content}

\begin{tabular}{|c|c|}
\hline Younger Adult $(\mathrm{N}$, if $>1)$ & $\operatorname{Older} \operatorname{Adult}(N$, if $>1)$ \\
\hline $\begin{array}{l}\text { 5k marathon } \\
\text { also catching up with two of my best friends } \\
\text { about our freshman year of college } \\
\text { bars } \\
\text { baseball practice } \\
\text { best friend came to visit } \\
\text { bonfire at a friend's } \\
\text { boyfriend } \\
\text { cheerleading nationals } \\
\text { cleaned my house } \\
\text { coopers rock } \\
\text { dancing around at night like we were kids } \\
\text { with no worries and nothing else to do } \\
\text { dinner with parents } \\
\text { drake concert } \\
\text { dropped leaves off a roof onto gibbies } \\
\text { bouncers [hung out with friends at night] } \\
\text { easter baskets/egg hunt } \\
\text { easter lunch with my family } \\
\text { easter with family } \\
\text { experienced the first WVU football game of } \\
\text { the season } \\
\text { family dinner } \\
\text { family picnic } \\
\text { field trip } \\
\text { friend's } 21 \text { st bday } \\
\text { future } \\
\text { gambled with my brother } \\
\text { gave sister a great gift } \\
\text { got an A on a test } \\
\text { got free coffee } \\
\text { had "family" dinner with the boys } \\
\text { hanging out with four of my good girlfriends } \\
\text { homework } \\
\text { hung out with friends } \\
\text { hung out with friends (cards and beer) } \\
\text { hung out with my sister } \\
\text { I got to sleep in } \\
\text { money }\end{array}$ & $\begin{array}{l}3 \text { mile walk } \\
\text { attending classes at OLLI } \\
\text { babysit my grandchildren - watching him } \\
\text { play with puppies } \\
\text { bike riding on Decker's Creek } \\
\text { bingo } \\
\text { boat ride } \\
\text { church } \\
\text { church AM with lunch } \\
\text { church PM } \\
\text { cut my son's hair and trimmed his moustache } \\
\text { - gave him skin care to thick keratinous feet } \\
\text { and hands } \\
\text { dance teacher [teaching dance] } \\
\text { dinner with a friend } \\
\text { discharge teaching to } 18 \text { yr old alcoholic } \\
\text { MVA victim - encouraged him to seek help } \\
\text { - suggested going to AA } \\
\text { family } \\
\text { gardened } \\
\text { going to ideal protein launches (job related) } \\
\text { going to Ohio next month } \\
\text { had homemade soup } \\
\text { had subway lunch with people who live in } \\
\text { unity } \\
\text { helped wife get yard ready for garden tour } \\
\text { housework } \\
\text { hung } 4 \text { of my paintings at VCC } \\
\text { joined son and grandsons to get ice cream } \\
\text { knit with friends } \\
\text { movie } \\
\text { nephew picked up income tax papers } \\
\text { nice experience Saturday [participating in } \\
\text { study] } \\
\text { planted flowers } \\
\text { played with my grandchildren } \\
\text { prepared a talk } \\
\text { read a very interesting mystery } \\
\text { relaxed }\end{array}$ \\
\hline
\end{tabular}




\begin{tabular}{|c|c|}
\hline Younger Adult $(\mathrm{N}$, if $>1)$ & $\underline{\operatorname{Older} \operatorname{Adult}(\mathrm{N}, \text { if }>1)}$ \\
\hline $\begin{array}{l}\text { movies with my sister } \\
\text { played cornhole outside } \\
\text { played with dog } \\
\text { playing Wii with roommates } \\
\text { playing with the kiddies } \\
\text { Psi Chi Induction Ceremony } \\
\text { quality time with my siblings } \\
\text { relay for life } \\
\text { running with my dog } \\
\text { saw my best friend } \\
\text { school } \\
\text { shopping } \\
\text { shopping with mom } \\
\text { shopping with my mom } \\
\text { sleep/get rest } \\
\text { slept } \\
\text { Sonic } \\
\text { spa \& movie night in the dorm } \\
\text { spent quality time relaxing with my friends } \\
\text { spent time with close friends } \\
\text { spent time with my family and friends } \\
\text { spent time with my brother } \\
\text { spent time with my son } \\
\text { studied } \\
\text { summer shopping } \\
\text { talked about good time with sister and } \\
\text { brother-in law } \\
\text { tested car battery } \\
\text { took [my dog] to dog park } \\
\text { visit from boyfriend } \\
\text { visited with friends } \\
\text { watch the hockey game } \\
\text { watched a movie with family } \\
\text { watched a movie (2) } \\
\text { watched basketball games } \\
\text { watched tv } \\
\text { watched world cup } \\
\text { wedding dress fitting } \\
\text { went bowling } \\
\text { went home and saw family } \\
\text { went out to eat with friends } \\
\text { went out with friends } \\
\text { went the movies (2) } \\
\text { wing }\end{array}$ & $\begin{array}{l}\text { relaxed at home } \\
\text { relaxing dinner with wife } \\
\text { saw good movie } \\
\text { shopping } \\
\text { shopping } \\
\text { son visited for a day } \\
\text { spoke to daughter on Father's Day } \\
\text { spoke to my brother by phone } \\
\text { started weight training } \\
\text { stayed home and did nothing } \\
\text { talked to all three sons and everyone was free } \\
\text { thanksgiving dinner } \\
\text { toured } 2 \text { forts in Charleston } \\
\text { toured a mansion in Charleston, SC } \\
\text { vacation } \\
\text { visit friends } \\
\text { visit grandchildren } \\
\text { visit relatives } \\
\text { walk with dog } \\
\text { walk with friend on rail trail at little falls } \\
\text { walked } \\
\text { walked beach } \\
\text { walked my } 2 \text { miles } \\
\text { walmart } \\
\text { watch good movie } \\
\text { watch granddaughter } \\
\text { watch tv } \\
\text { watched ballgame on tv } \\
\text { watched video "letter in a bottle" } \\
\text { went camp[ing] } \\
\text { went for pizza on Father's Day } \\
\text { went out to eat } \\
\text { went to a banquet } \\
\text { went to brunch with my sister } \\
\text { went to church } \\
\text { went to church on Sunday night } \\
\text { went to lunch with different friends } \\
\text { went to lunch with friends } \\
\text { went to sons for birthday and basketball } \\
\text { work in garden } \\
\text { work outside/lawn } \\
\text { worked on books for Family Grief Center }\end{array}$ \\
\hline
\end{tabular}


$\underline{\text { Worry Induction Content }}$

\begin{tabular}{|l|l|}
\hline \multicolumn{1}{|c|}{ Younger Adult $(\mathrm{N}$, if $>1)$} & \multicolumn{1}{c|}{ Older Adult $(\mathrm{N}$, if $>1)$} \\
\hline acceptance & activities \\
acceptance/reciprocated feelings & aging \\
baseball team & change in domestic situation due to \\
being unwanted & retirement \\
career & children \\
classes & crime \\
college grades & direction this country is going \\
death & don't want to worry my daughter about my \\
family and friends & care \\
family/relationships/health & ecological calamities \\
family (6) & family \\
finals & family integrity \\
financial issues (2) & family safety \\
friends & farm animals in winter \\
friend's drug use & feeling physically weak \\
friend's family & finances \\
future & financial \\
germs & financial - retirement \\
getting good grade on finals & flat tire \\
girl troubles & future \\
grades & future health \\
graduating & future plans \\
grandparent's health & getting along with others \\
having my own money & grandchildren \\
health (2) & health (2) \\
independence & health checkups \\
job & health/welfare of children \\
job (finding one) & home \\
job placement after graduation & household chores \\
lil brother & how to spend retirement meaningfully \\
living completely on my own & income \\
money and paying for things & marriage of my daughter \\
money (6) & money \\
mother & my blind spots \\
moving away & my building roof - how it would be fixed, \\
my family & who will I get to fix it and how i will pay \\
my financial & for the work \\
my future job & my electrical work in my building - what is \\
my health & still wrong with it, how to ensure that it is \\
my relationship with the boyfriend & safe and won't start a fire \\
not being good enough & my gas heater - what's wrong with it and how \\
\hline
\end{tabular}




\begin{tabular}{|c|c|}
\hline Younger Adult $(\mathrm{N}$, if $>1)$ & $\underline{\operatorname{Older} \operatorname{Adult}(\mathrm{N}, \text { if }>1)}$ \\
\hline $\begin{array}{l}\text { parents } \\
\text { regaining weight } \\
\text { relationships } \\
\text { school (grades) } \\
\text { school work } \\
\text { school (5) } \\
\text { soccer } \\
\text { success } \\
\text { summer classes } \\
\text { summer job } \\
\text { switching majors } \\
\text { tests for class } \\
\text { the future } \\
\text { throwing up } \\
\text { upcoming interview and program acceptance } \\
\text { upcoming tests } \\
\text { work } \\
\text { work (\$) }\end{array}$ & $\begin{array}{l}\text { can i manage to get it working again before } \\
\text { winter } \\
\text { my health (3) } \\
\text { my husband's health } \\
\text { my kids } \\
\text { my mother's living situation } \\
\text { my pets } \\
\text { my son's future employment } \\
\text { my weight } \\
\text { newsletter } \\
\text { not knowing how long I'll live } \\
\text { obesity } \\
\text { others unable to make a decent living } \\
\text { our health as we get older - esp. our brains } \\
\text { our politicians and their ability to govern } \\
\text { parents } \\
\text { pharmacology course } \\
\text { purpose in life } \\
\text { reading } \\
\text { salvation } \\
\text { son and his girls } \\
\text { son's future } \\
\text { surgery } \\
\text { that i might have something physically } \\
\text { wrong that doctors don't know about } \\
\text { the swim club's future } \\
\text { unable to take care of myself if I should get } \\
\text { ill } \\
\text { unfinished work } \\
\text { USA } \\
\text { Where should I live? } \\
\text { wife's health } \\
\text { Work ( } 2 \text { ) }\end{array}$ \\
\hline
\end{tabular}

John $\mathrm{H}$ ogain - Virginia University Libraries,
ou=Acquisitions Department, 